\title{
When all eyes are on you : studies into threat processing and pharmacological treatment of social anxiety disorder
}

Citation for published version (APA):

Schutters, S. (2011). When all eyes are on you : studies into threat processing and pharmacological treatment of social anxiety disorder. [Doctoral Thesis, Maastricht University]. Maastricht University. https://doi.org/10.26481/dis.20110908ss

Document status and date:

Published: 01/01/2011

DOI:

10.26481/dis.20110908ss

Document Version:

Publisher's PDF, also known as Version of record

Please check the document version of this publication:

- A submitted manuscript is the version of the article upon submission and before peer-review. There can be important differences between the submitted version and the official published version of record.

People interested in the research are advised to contact the author for the final version of the publication, or visit the DOI to the publisher's website.

- The final author version and the galley proof are versions of the publication after peer review.

- The final published version features the final layout of the paper including the volume, issue and page numbers.

Link to publication

\footnotetext{
General rights rights.

- You may freely distribute the URL identifying the publication in the public portal. please follow below link for the End User Agreement:

www.umlib.nl/taverne-license

Take down policy

If you believe that this document breaches copyright please contact us at:

repository@maastrichtuniversity.nl

providing details and we will investigate your claim.
}

Copyright and moral rights for the publications made accessible in the public portal are retained by the authors and/or other copyright owners and it is a condition of accessing publications that users recognise and abide by the legal requirements associated with these

- Users may download and print one copy of any publication from the public portal for the purpose of private study or research.

- You may not further distribute the material or use it for any profit-making activity or commercial gain

If the publication is distributed under the terms of Article 25fa of the Dutch Copyright Act, indicated by the "Taverne" license above, 



\section{When \\ All Eyes \\ are on \\ You}

Studies into Threat Processing

$$
\text { and }
$$

Pharmacological Treatment

of

Social Anxiety Disorder 
Cover design: Pieter Schutters

Printing: Wöhrmann Print Service

Lay out: Adri Romijn

\section{ISBN 9789085708421}

(C) copyright Sara Schutters, Maastricht 2011

All rights reserved. No part of this publication may be reproduced, stored in a retrieval system, or transmitted in any form or by any means, electronic, mechanical, photocopying, recording, or otherwise, without the prior permission in writing from the proprietor. 


\title{
When all eyes are on you
}

\author{
Studies into Threat Processing
}

and

Pharmacological Treatment

of

Social Anxiety Disorder

PROEFSCHRIFT

Ter verkrijging van de graad doctor aan de Universiteit Maastricht, op gezag van de Rector Magnificus, Prof. mr. G.P.M.F. Mols,

volgens het besluit van het College van Decanen,

in het openbaar te verdedigen op donderdag 8 september 2011 om 12:00 uur

door

Sara Schutters

Geboren op 3 augustus 1974 te Lommel, België 


\section{PROMOTORES}

Prof. J.J. van Os

Prof. H.G.M. Westenberg † (UMC Utrecht)

\section{COPROMOTOR}

Dr. K.R.J. Schruers

\section{BEOORDELINGSCOMMISSIE}

Prof. Dr. E.J.L. Griez (voorzitter)

Prof. Dr. I. Myin-Germeys

Prof. Dr. A.J.L.M. van Balkom (VUmc en GGZ inGeest, Amsterdam)

Dr. M.J. Voncken

The research presented in this thesis was conducted at the Department of Psychiatry of University Medical Centre Utrecht and at the School for Mental Health and Neuroscience, Department of Psychiatry and Psychology of Maastricht University, The Netherlands. 


\section{CONTENTS}

\section{INTRODUCTION}

$\begin{array}{lll}\text { Chapter } 1 & \text { Social Anxiety Disorder } & 11\end{array}$

Chapter 2 General overview of the studies 29

PART I. Threat processing in Social Anxiety Disorder

Chapter $3 \quad 35 \% \mathrm{CO}_{2}$ sensitivity in Social Anxiety Disorder 37

Chapter $4 \quad$ Reduced Recognition of Anger and Disgust in Social Anxiety 57 Disorder

Chapter 5 The association between Social Phobia, Social Anxiety 75 Cognitions and Paranoid Symptoms

PART II. Pharmacological Treatment of Social Anxiety Disorder

Chapter 6 Mirtazapine in Generalized Social Anxiety Disorder:

A randomised, double-blind, placebo-controlled study

Chapter 7 Paroxetine augmentation in patients with Generalized Social Anxiety Disorder, non-responsive to mirtazapine or placebo

Chapter 8 Efficacy of Quetiapine in Generalized Social Anxiety Disorder: Results from an open-label study

Summary and Discussion

Samenvatting en Discussie

Dankwoord

Curriculum Vitae

Publicaties 

Introduction 



\section{Chapter 1}

Social Anxiety Disorder 



\title{
Clinical picture and classification
}

Social anxiety is a universal phenomenon; many people experience discomfort or fear in social situations from time to time. However, individuals with social anxiety disorder (or social phobia) experience excessive and/or chronic social anxiety, disrupting functioning and impairing their everyday life. These patients often think that other people are judging them and they feel and behave as if 'all eyes are on them'.

\begin{abstract}
A 30-year old woman with social anxiety disorder tells about her time in primary school:

"I always kept silent in the classroom, hoping the teacher would not point to me to answer a question. At a certain moment, I had to stay home because of a flu. When I returned to school and entered the classroom, everybody looked at me. I nearly panicked. I must have looked like an idiot. I did not want to have this dreadful experience again and tried to invent several solutions. Most often I just went to school and sat in the stair hall for all day. The teacher did not notice that I was not in the classroom anyway."
\end{abstract}

The first mention of the term social phobia ("phobie sociale") was already made in the early 1900s (Janet, 1903). Nevertheless, social phobia originally received little medical and scientific attention and was not included in the first two versions of the American Diagnostic and Statistical Manual of Mental Disorders (DSM) (American Psychiatric Association, 1952, 1968). In the eighties and nineties, social phobia gained more professional and public interest and was increasingly recognized as a real anxiety disorder for which treatment can offer an improvement of patients' quality of life (Kasper, 1998). Social phobia was conceptualized as an official diagnostic entity in the third edition of the DSM (American Psychiatric Association, 1980). Social phobia was given the alternative name social anxiety disorder in the fourth edition of the DSM (American Psychiatric Association, 1994, 2000).

In DSM-IV, social anxiety disorder (SAD) is defined as a marked and persistent fear of one or more social or performance situations in which the person is exposed to unfamiliar people or to possible scrutiny by others. While the individual recognizes that his or her fears are excessive or unreasonable, overcoming it can be quite difficult. Going through the feared situations, or anticipating them, the person suffers from distressing cognitions (worry about their performance and the assumed opinion from 
others) and physical symptoms such as blushing, sweating, and trembling. The instances of intense fear and discomfort may even resemble panic attacks. Social situations are endured with extreme distress, or are avoided. Avoidance behaviour can lead to social isolation and additional problems may develop, such as depression. Some sufferers may use alcohol or other drugs to reduce fears and inhibitions at social events.

Two subtypes of SAD are described. The first is generalized SAD, in which patients are anxious in most situations concerning performance and interactional situations. In specific (or non- generalized) SAD, patients fear some particular social situations, which are mostly performance related, such as public speaking and writing or eating in front of others. Chronic stage fright, which significantly impairs or disrupts an artist's performance is another example of specific SAD.

\section{Epidemiology}

A series of epidemiological studies have indicated that SAD is a frequent condition in the community with a lifetime prevalence of at least $7 \%$ and 12 -month prevalence of about 3-4\% (Wittchen \& Fehm, 2003). SAD is considered the third most common psychiatric disorder, exceeded in lifetime prevalence only by major depression and alcohol dependence (Kessler, et al., 1994). More women than men seem to be affected (Fehm, Pelissolo, Furmark, \& Wittchen, 2005). The disorder has an early onset during childhood or adolescence and is enduring with a course of up to 20 years or more (Wittchen \& Fehm, 2001). In course of time, SAD is increasingly complicated by comorbid disorders (50-80\% of comorbidity), such as other anxiety disorders, depressive disorders, or alcohol and substance use disorders (Wittchen \& Fehm, 2003). In addition, there is an increased risk of psychosocial impairment and disability; impairment in individual and social roles, impact on quality of life, increased health services utilization and increased suicidal ideations have been quantified by several epidemiological surveys (Wittchen \& Fehm, 2001). Both types of SAD tend to be underdiagnosed and undertreated (Stein \& Chavira, 1998). The generalized subtype is usually more invalidating, has less chance of spontaneous recovery and carries a higher risk of comorbidity.

\section{Etiology and Pathogenesis}

Genetic as well as environmental factors have been implicated in the etiology of SAD and several neurobiological as well as psychological processes are described in the pathogenesis of SAD. 
Three main topics will be discussed: 1 . Neurobiology including genetics, neurochemistry and neuroanatomy; 2 . Psychological models and related empirical research; 3. Environmental influences.

\section{Neurobiology}

\section{Genetics}

The heritability of SAD has been investigated in family and in twin studies. Family studies in clinical populations have found a two- to threefold increased risk in relatives of SAD subjects in comparison to relatives of normal subjects (Tillfors, 2004). General population studies showed a strong association between parental SAD and SAD among off-spring (Lieb, Wittchen, et al., 2000) and an increased rate of a positive parental history of excessive social anxiety in subjects with SAD (Tillfors, Furmark, Ekselius, \& Fredrikson, 2001).

Whereas twin studies of related constructs such as shyness (Plomin \& Daniels, 1986) and social fears (Skre, et al., 2000) suggest these have heritable components, only two twin studies have specifically examined the heritability of SAD itself (Kendler, Myers, Prescott, \& Neale, 2001; Kendler, Neale, Kessler, Heath, \& Eaves, 1992). Monozygotic twins showed a higher concordance rate for SAD than dizygotic twins ( $24 \%$ versus $15 \%$ ), which further supports a genetic contribution to SAD. The heritability of SAD has been estimated at about $30-50 \%$. The authors reported that the familial transmission of SAD seems to be determined by a combination of genetic and individual-specific environmental factors in both men and women, whereas evidence for influential shared environmental factors was only found in men (Kendler, et al., 2001; Kendler, et al., 1992).

A genetically influenced trait that may be a precursor of SAD is behavioral inhibition (Hirshfeld-Becker, 2010). This temperamental construct refers to a style of reacting that some infants and young children exhibit when confronted with novel situations or unfamiliar adults or peers, characterized by wariness, withdrawal, as well as heightened physiological arousal (Hirshfeld-Becker, et al., 2008). Twin studies indicate that there is a strong genetic contribution to behavioral inhibition, with higher heritability for children extreme in inhibition (Tillfors, 2004). Cloninger has described a similar temperamental construct, harm avoidance, defined as a heritable tendency to respond intensely to aversive stimuli and to learn to avoid punishment, novelty, and non-reward passively (Cloninger, 1986). Harm avoidance, which is associated with SAD as well (Pelissolo, et al., 2002), has been linked to a locus on chromosome 8p21 (Cloninger, et al., 1998; Zohar, et al., 2003). 


\section{Neurochemistry}

Research on neurotransmitter abnormalities in SAD initially focused on the role of noradrenaline, because of the clear involvement of adrenergic activity in symptoms often experienced by SAD patients (blushing, sweating, tremor, palpitations). Some research has provided support for adrenergic dysfunction in SAD, such as an increased noradrenergic reactivity to orthostatic and yohimbine (an $\alpha 2$-antagonist) challenges, and an increased heart rate reactivity (only in the specific subtype of SAD), but there are many inconsistencies among those studies (Li, Chokka, \& Tibbo, 2001). Furthermore, although $\beta$-adrenergic blockers may relieve performance anxiety symptoms such as tremor, they failed to show clinical significant effects in generalized SAD (Liebowitz, et al., 1992; Turner, Beidel, \& Jacob, 1994). Therefore, noradrenaline may not play a primary role in the pathogenesis of SAD.

A role for serotonin (5-hydroxytryptamine, 5-HT) in SAD is suggested by the clinical efficacy of monoamine oxidase inhibitors (MAOIs) and selective serotonin reuptake inhibitors (SSRIs), which all have significant effects on 5-HT. SAD patients challenged with fenfluramine, a 5-HT-releasing agent (Tancer, et al., 1994), or with mchlorophenylpiperazine, a partial 5- $\mathrm{HT}_{2}$ receptor agonist (Hollander, et al., 1998), showed an increased cortisol response compared to controls, though prolactin responses were normal. These results suggest that the post-synaptic $5-\mathrm{HT}_{2}$ receptors are hypersensitive in $\mathrm{SAD}$, whereas $5-\mathrm{HT}_{1}$ receptors, responsible for prolactin response, are functioning normally ( $\mathrm{Li}$, et al., 2001). On the other hand, a positron emission tomography (PET) study in SAD patients showed reduced levels of $5-\mathrm{HT}_{1}$ receptor binding in the amygdala and mesiofrontal areas (Lanzenberger, et al., 2007). Another neuroimaging study, using single photon emission computed tomography (SPECT), found increased binding at serotonergic transporter sites in the thalamus in SAD patients (van der Wee, et al., 2008). Further evidence for deficient central serotonergic signalling in SAD is provided by tryptophan depletion experiments. Tryptophan depletion causes a marked reduction in plasma tryptophan and consequently brain 5-HT synthesis and release (Bell, Abrams, \& Nutt, 2001). Tryptophan depletion in SAD patients reverses therapeutic effect of SSRI's (Argyropoulos, et al., 2004) and increases responsivity of the autonomic nervous system (van Veen, et al., 2009) when exposed to a behavioral challenge, suggesting that enhanced $5-\mathrm{HT}$ function is important in maintaining response in SAD.

A role of dopaminergic dysregulation in SAD was first suggested by Liebowitz and colleagues (1987), who based their hypothesis on several clinical observations of effective treatments e.g. MAOls, and an experiment showing a correlation between low dopamine levels in cerebrospinal fluid and introversion (King, et al., 1986). An increased prevalence of SAD has been demonstrated in patients who went on to develop Parkin- 
son's disease, an illness characterized by loss of striatal dopamine (Stein, Heuser, Juncos, \& Uhde, 1990). However, a neuroendocrine study, using levodopa, was unable to demonstrate the existence of any abnormality in dopaminergic function (Tancer, et al., 1994). The most comprehensive evidence for dopaminergic dysfunction in SAD is provided by neuroimaging studies (Freitas-Ferrari, et al., 2010). Two SPECT studies have found evidence of altered striatal density of dopamine reuptake sites in SAD patients (Tiihonen, et al., 1997; van der Wee, et al., 2008). A lower $D_{2}$ receptor availability was observed in SAD patients in one SPECT study (Schneier, et al., 2000), but findings were not replicated in a later study of the same group, which aimed at clarifying the discrepancies related to the dopaminergic system in SAD (Schneier, et al., 2009). In conclusion, evidence concerning the neurochemical substrates involved in generalized SAD largely point toward serotonergic and dopaminergic dysfunction (Westenberg, 2009).

Chemical challenges involve the use of exogenous compounds, such as lactate, $\mathrm{CO}_{2}$, caffeine, pentagastrin or cholecystokinin to produce and mimic the patient's naturally occurring fear/anxiety. These challenges have been used predominantly in panic disorder, examining the provocation of panic attacks in particular. It is suggested that SAD patients generally are less sensitive than panic disorder patients and slightly more than healthy controls (Coupland, 2001). However, results of challenge studies in SAD are not univocal. For example, lactate sensitivity appears to be normal in SAD (Liebowitz, et al., 1985), and $\mathrm{CO}_{2}$ challenge studies have not always found exaggerated responses in SAD patients (Caldirola, Perna, Arancio, Bertani, \& Bellodi, 1997; Papp, et al., 1993).

\section{Neuroanatomy}

Neuroimaging techniques have found changes in neural activity in limbic and paralimbic regions in SAD (Freitas-Ferrari, et al., 2010). The amygdala appears to play a crucial role in the pathophysiology of SAD. Furthermore, alterations in pre-frontal regions and a reduced activity in striatal and parietal areas have been observed and the hippocampus appears to be involved as well. Interestingly, follow-up studies observed a decrease in perfusion in these same areas after either pharmacological or psychological treatment.

\section{Conclusion}

Empirical research has advanced the knowledge concerning the neuro-chemical and neuro-anatomic substrates involved in SAD, and has provided preliminary evidence for a genetic diathesis in this condition. In spite of these advances, there is no comprehensive neurobiological model for SAD yet. 


\section{Psychological models and empirical research}

Cognitive theories of SAD propose that cognitive biases in the processing of socially threatening information can, at least partially, explain etiology and maintenance of this disorder (Musa \& Lepine, 2000).

In the cognitive model of Beck, Emery and Greenberg (1985), it is suggested that SAD is due to the existence of dysfunctional beliefs, such as high standard for social performance, conditional beliefs concerning social evaluation and unconditional beliefs about the self. When the person enters a social situation, he or she will experience a set of physiological and behavioral symptoms of anxiety. He/she will start to monitor these internal changes, which will interfere with his ability to process and respond to social cues. In addition, attentional biases towards threat cues (criticism) from others, and negative interpretative biases, aggravate the person's belief that he or she is really socially incompetent.

The cognitive model of Clark and Wells (1995) postulates that a heightened selffocus is critical in SAD. Patients will shift their attention from the environment to detailed monitoring of themselves when they believe they are in danger of negative evaluation by others. They use this interoceptive information to construct a negative impression of themselves. Furthermore, they engage in 'safety' behaviours that are intended to reduce the risk of negative evaluation, such as avoiding eye contact and rehearsing questions during a conversation. This may prevent them from experiencing disconfirmation of their unrealistic beliefs and/or make them come across as odd or uninterested.

The cognitive-behavioral model of Rapee and Heimberg (1997) similarly proposes that a social situation will trigger a series of processes that generate and maintain social anxiety. When a patient encounters a social situation or simply anticipates it, he/she will form a mental representation of his/her external appearance and behaviour as seen by others. This mental representation is based on information retrieved from long-term memory (prior experience in the situation), internal and external cues, whereby attention is directed towards potential threats or signs of negative evaluation (awareness of one's own voice, blushing/ signs of boredom from others). In addition, SAD patients will formulate a prediction of the performance standard the audience is supposed to be using in the given situation. A comparison is then made between the mental representation of self as (supposedly) seen by others and the others' expected standards. The discrepancy between the two determines the prediction of negative evaluation, which gives rise to anxiety with its physiological, cognitive and behavioral aspects. 
To conclude, all cognitive models emphasize the role of biases in information processing in SAD. The model of Beck and colleagues (1985) and the model of Clark and Wells (1995) highlight the importance of heightened self-focus, whereas Rapee and Heimberg (1997) in addition suggest a role of attention towards external threat.

These psychological models have been supported by empirical research, showing biases in information processing in SAD (Hirsch \& Clark, 2004). Individuals with SAD appear to have a specific interpretational/judgmental bias towards self-relevant social information (Heinrichs \& Hofmann, 2001). With regard to attentional processes in SAD, a bimodal pattern has been suggested, in which an enhanced attention to threat in the first stage is followed by active avoidance of this information (hypervigilanceavoidance) (Amir, Foa, \& Coles, 1998; Garner, Mogg, \& Bradley, 2006).

\section{Environmental influences}

Research suggests that family environment and the parent-child relationship play a role in the development of SAD. A number of studies support associations between children's excessive social anxiety and parental behaviours, such as overprotection, exaggerated control, rejection, modelling social avoidance, encouraging avoidance, not giving optimal guidance in pro-social behaviour, limiting social contact and forming insecure attachments (Hirshfeld-Becker, Fredman, Robin, \& Rosenbaum, 1999).

The influence of peer groups is only investigated marginally. The studies suggest that inhibited or withdrawn behaviour in children becomes associated with rejection or neglect by peers as the child grows older, and that this rejection or neglect may be associated with internalizing symptoms, social evaluative anxiety or anxiety disorders. However, it is still unknown whether there is a causal role for peer neglect or rejection in the initial onset of SAD (Hirshfeld-Becker, et al., 1999).

Socially constructed gender roles have been implicated in SAD. In clinical studies, $S A D$ is about equally represented in men and women, whereas SAD is more prevalent in women in epidemiological studies. It has been suggested that this difference in gender distribution found in clinical versus epidemiological studies, indicates that more men than women seek treatment for SAD. A possible explanation is the lower social acceptance of social anxiety, inhibited temperament and shyness amongst men and boys (Kagan, 1994). Furthermore, behavioral inhibition appears to be more stable and is more often associated with later generalized social fears in girls than in boys (Hirshfeld, et al., 1992; Schwartz, Snidman, \& Kagan, 1999).

Cultural issues, such as social norms may play a role as well. A recent review suggests that the prevalence and expression of social anxiety/SAD depends on the particular culture (Hofmann, Anu Asnaani, \& Hinton, 2010). Asian cultures typically show the 
lowest rates, whereas Russian and US samples show the highest rates of SAD. A syndrome related to SAD, named "Taijin Kyofusho" (meaning fear of facing other people) has been extensively described in Japan and other Asian countries (Ono, et al., 2001). Sufferers of this condition experience intense shame and have irrational fears of causing offence to others. It is most frequently encountered, at least in treatment settings, among young adult males, which contrasts with SAD where the prevalence of females is somewhat greater than that of males (Chapman, Mannuzza, \& Fyer, 1995). The syndrome shares manifestations with SAD including fear of gaze and blushing, but it may not share other diagnostic criteria, because the perceived consequences of their social performance is different, i.e. causing offence or embarrassment to others instead of to the self. Therefore, taijin kyofusho is often not recognized as SAD by the Western clinical interviews (Chapman, et al., 1995) and this may account for the lower prevalence of SAD found in Asian countries.

\section{Conclusion}

Although a number of neurobiological, psychological and environmental factors have been implicated in SAD, the etiology and pathogenesis of this disorder is not clear yet. It is conceivable that SAD may develop from a number of possible pathways and that factors may work together to put a person at risk (Hirshfeld-Becker, et al., 1999). Research into the processing of threat may offer an integrated approach to understand neurobiological as well as socio-psychological mechanisms involved in SAD (Stein \& Nesse, 2011). Based on an evolutionary perspective, it has been recently suggested that particular psychopathologies seem to occur as a result of a dysregulation of a potential threat system, which is devoted to detecting subtle signs of potential danger and eliciting precautionary responses that may help to forestall or ameliorate the eventuality of such threats (Woody \& Boyer, 2011). With regard to SAD, potential threat from dominant conspecifics may be particularly important. Elucidating the processing of these and other threats by SAD patients could lead to a better understanding of this disorder.

\section{Treatment}

Several psychological treatments for SAD have been developed in the past decades, including exposure, cognitive therapy, social skills training, applied relaxation, and several combinations of these (Rodebaugh, Holaway, \& Heimberg, 2004). The most wellresearched psychosocial treatment for SAD is cognitive-behavioral therapy, which is currently considered first-line psychological treatment (Hofmann, 2010). 
Furthermore, substantial advances have been made in the pharmacological treatment of SAD. Double-blind controlled studies have demonstrated efficacy of monoamine oxidase inhibitors (MAOIs), selective serotonin reuptake inhibitors (SSRIs), benzodiazepines and the serotonin noradrenalin reuptake inhibitor (SNRI) venlafaxine in the treatment of SAD (Van Ameringen, Mancini, Patterson, \& Simpson, 2009). In addition, there is circumstantial evidence for efficacy of olanzapine (Barnett, Kramer, Casat, Connor, \& Davidson, 2002), mirtazapine (Muehlbacher, et al., 2005), and the anticonvulsants, gabapentin (Pande, et al., 1999) and pregabalin (Pande, et al., 2004) in SAD. Currently, SSRIs and venlafaxine are recognized as the first line pharmacological agents in the treatment of SAD based on their efficacy, safety, tolerability and effectiveness in treating conditions commonly comorbid with SAD, such as depression (Van Ameringen, et al., 2009). However, resistance to first-line treatment is a substantial problem. Approximately $50 \%$ of the patients with SAD do not respond or still have significant residual symptoms after treatment with a SSRI (Van Ameringen, Mancini, Pipe, \& Bennett, 2004). 


\section{References}

American Psychiatric Association (1952). Diagnostic and Statistical Manual of Mental Disorders, First Edition: Washington, DC: American Psychiatric Association.

American Psychiatric Association (1968). Diagnostic and Statistical Manual of Mental Disorders, Second Edition: Washington, DC: American Psychiatric Association.

American Psychiatric Association (1980). Diagnostic and Statistical Manual of Mental Disorders, Third Edition: DSM-III: Washington, DC: American Psychiatric Association.

American Psychiatric Association (1994). Diagnostic and Statistical Manual of Mental Disorders. Fourth edition: Washington, DC: American Psychiatric Association.

American Psychiatric Association (2000). Diagnostic and Statistical Manual of Mental Disorders. Fourth edition, text revised: Washington, DC: American Psychiatric Association.

Amir, N., Foa, E. B., \& Coles, M. E. (1998). Automatic activation and strategic avoidance of threat-relevant information in social phobia. J Abnorm Psychol, 107(2), 285290.

Argyropoulos, S. V., Hood, S. D., Adrover, M., Bell, C. J., Rich, A. S., Nash, J. R., et al. (2004). Tryptophan depletion reverses the therapeutic effect of selective serotonin reuptake inhibitors in social anxiety disorder. Biol Psychiatry, 56(7), 503509.

Barnett, S. D., Kramer, M. L., Casat, C. D., Connor, K. M., \& Davidson, J. R. (2002). Efficacy of olanzapine in social anxiety disorder: a pilot study. J Psychopharmacol, 16(4), 365-368.

Beck, A. T., Emery, G., \& Greenberg, R. L. (1985). Anxiety disorders and phobias: New York: Basic Books.

Bell, C., Abrams, J., \& Nutt, D. (2001). Tryptophan depletion and its implications for psychiatry. Br J Psychiatry, 178, 399-405.

Caldirola, D., Perna, G., Arancio, C., Bertani, A., \& Bellodi, L. (1997). The $35 \% \mathrm{CO}_{2}$ challenge test in patients with social phobia. Psychiatry Res, 71(1), 41-48.

Chapman, T. F., Mannuzza, S., \& Fyer, A. J. (1995). Epidemiology and family studies of social phobia. In R. G. Heimberg, M. R. Liebowitz, D. A. Hope \& F. R. Schneier (Eds.), Social phobia: Diagnosis, assessment and treatment. New York: Guilford Press.

Clark, D. M., \& Wells, A. (1995). A cognitive model of social phobia. In R. G. Heimberg, M. R. Liebowitz, D. A. Hope \& F. R. Schneier (Eds.), Social phobia: Diagnosis, assessment, and treatment (pp. 41-68). New York: Guilford Press. 
Cloninger, C. R. (1986). A unified biosocial theory of personality and its role in the development of anxiety states. Psychiatr Dev, 4(3), 167-226.

Cloninger, C. R., Van Eerdewegh, P., Goate, A., Edenberg, H. J., Blangero, J., Hesselbrock, V., et al. (1998). Anxiety proneness linked to epistatic loci in genome scan of human personality traits. Am J Med Genet, 81(4), 313-317.

Coupland, N. J. (2001). Social phobia: etiology, neurobiology, and treatment. J Clin Psychiatry, 62 Suppl 1, 25-35.

Fehm, L., Pelissolo, A., Furmark, T., \& Wittchen, H. U. (2005). Size and burden of social phobia in Europe. Eur Neuropsychopharmacol, 15(4), 453-462.

Freitas-Ferrari, M. C., Hallak, J. E., Trzesniak, C., Filho, A. S., Machado-de-Sousa, J. P., Chagas, M. H., et al. (2010). Neuroimaging in social anxiety disorder: A systematic review of the literature. Prog Neuropsychopharmacol Biol Psychiatry.

Garner, M., Mogg, K., \& Bradley, B. P. (2006). Orienting and maintenance of gaze to facial expressions in social anxiety. J Abnorm Psychol, 115(4), 760-770.

Heinrichs, N., \& Hofmann, S. G. (2001). Information processing in social phobia: a critical review. Clin Psychol Rev, 21(5), 751-770.

Hirsch, C. R., \& Clark, D. M. (2004). Information-processing bias in social phobia. Clin Psychol Rev, 24(7), 799-825.

Hirshfeld-Becker, D. R. (2010). Familial and temperamental risk factors for social anxiety disorder. New Dir Child Adolesc Dev, 127, 51-65.

Hirshfeld-Becker, D. R., Fredman, S. J., Robin, J. A., \& Rosenbaum, J. F. (1999). The aetiology of social anxiety disorder. In H. G. M. Westenberg \& J. A. den Boer (Eds.), Social Anxiety Disorder.

Hirshfeld-Becker, D. R., Micco, J., Henin, A., Bloomfield, A., Biederman, J., \& Rosenbaum, J. (2008). Behavioral inhibition. Depress Anxiety, 25(4), 357-367.

Hirshfeld, D. R., Rosenbaum, J. F., Biederman, J., Bolduc, E. A., Faraone, S. V., Snidman, N., et al. (1992). Stable Behavioral-Inhibition and Its Association with Anxiety Disorder. Journal of the American Academy of Child and Adolescent Psychiatry, 31(1), 103-111.

Hofmann, S. G. (2010). Recent advances in the psychosocial treatment of social anxiety disorder. Depress Anxiety, 27(12), 1073-1076.

Hofmann, S. G., Anu Asnaani, M. A., \& Hinton, D. E. (2010). Cultural aspects in social anxiety and social anxiety disorder. Depress Anxiety, 27(12), 1117-1127.

Hollander, E., Kwon, J., Weiller, F., Cohen, L., Stein, D. J., DeCaria, C., et al. (1998). Serotonergic function in social phobia: comparison to normal control and obsessivecompulsive disorder subjects. Psychiatry Res, 79(3), 213-217.

Janet, P. (1903). Les obsessions et la psychasthénie: Paris: F. Alcan.

Kagan, J. (1994). Galen's prophecy: New York: Basic Books. 
Kasper, S. (1998). Social phobia: the nature of the disorder. J Affect Disord, 50 Suppl 1, S3-9.

Kendler, K. S., Myers, J., Prescott, C. A., \& Neale, M. C. (2001). The genetic epidemiology of irrational fears and phobias in men. Arch Gen Psychiatry, 58(3), 257-265.

Kendler, K. S., Neale, M. C., Kessler, R. C., Heath, A. C., \& Eaves, L. J. (1992). The genetic epidemiology of phobias in women. The interrelationship of agoraphobia, social phobia, situational phobia, and simple phobia. Arch Gen Psychiatry, 49(4), 273281.

Kessler, R. C., McGonagle, K. A., Zhao, S., Nelson, C. B., Hughes, M., Eshleman, S., et al. (1994). Lifetime and 12-month prevalence of DSM-III-R psychiatric disorders in the United States. Results from the National Comorbidity Survey. Arch Gen Psychiatry, 51(1), 8-19.

King, R. J., Mefford, I. N., Wang, C., Murchison, A., Caligari, E. J., \& Berger, P. A. (1986). CSF dopamine levels correlate with extraversion in depressed patients. Psychiatry Res, 19(4), 305-310.

Lanzenberger, R. R., Mitterhauser, M., Spindelegger, C., Wadsak, W., Klein, N., Mien, L. K., et al. (2007). Reduced serotonin-1A receptor binding in social anxiety disorder. Biol Psychiatry, 61(9), 1081-1089.

Li, D., Chokka, P., \& Tibbo, P. (2001). Toward an integrative understanding of social phobia. Revue de psychiatry \& de neuroscience, 26(3), 13.

Lieb, R., Wittchen, H. U., Hofler, M., Fuetsch, M., Stein, M. B., \& Merikangas, K. R. (2000). Parental psychopathology, parenting styles, and the risk of social phobia in offspring: a prospective-longitudinal community study. Arch Gen Psychiatry, 57(9), 859-866.

Liebowitz, M. R., Campeas, R., \& Hollander, E. (1987). MAOls: impact on social behavior. Psychiatry Res, 22(1), 89-90.

Liebowitz, M. R., Fyer, A. J., Gorman, J. M., Dillon, D., Davies, S., Stein, J. M., et al. (1985). Specificity of lactate infusions in social phobia versus panic disorders. Am J Psychiatry, 142(8), 947-950.

Liebowitz, M. R., Schneier, F., Campeas, R., Hollander, E., Hatterer, J., Fyer, A., et al. (1992). Phenelzine vs atenolol in social phobia. A placebo-controlled comparison. Arch Gen Psychiatry, 49(4), 290-300.

Muehlbacher, M., Nickel, M. K., Nickel, C., Kettler, C., Lahmann, C., Pedrosa Gil, F., et al. (2005). Mirtazapine treatment of social phobia in women: a randomized, double-blind, placebo-controlled study. J Clin Psychopharmacol, 25(6), 580-583.

Musa, C. Z., \& Lepine, J. P. (2000). Cognitive aspects of social phobia: a review of theories and experimental research. Eur Psychiatry, 15(1), 59-66. 
Ono, Y., Yoshimura, K., Yamauchi, K., Asai, M., Young, J., Fijuhara, S., et al. (2001). Taijin Kyofusho in a Japanese Community Population. Transcultural Psychiatry, 38(4), 9.

Pande, A. C., Davidson, J. R., Jefferson, J. W., Janney, C. A., Katzelnick, D. J., Weisler, R. H., et al. (1999). Treatment of social phobia with gabapentin: a placebocontrolled study. J Clin Psychopharmacol, 19(4), 341-348.

Pande, A. C., Feltner, D. E., Jefferson, J. W., Davidson, J. R., Pollack, M., Stein, M. B., et al. (2004). Efficacy of the novel anxiolytic pregabalin in social anxiety disorder: a placebo-controlled, multicenter study. J Clin Psychopharmacol, 24(2), 141-149.

Papp, L. A., Klein, D. F., Martinez, J., Schneier, F., Cole, R., Liebowitz, M. R., et al. (1993). Diagnostic and substance specificity of carbon-dioxide-induced panic. Am J Psychiatry, 150(2), 250-257.

Pelissolo, A., Andre, C., Pujol, H., Yao, S. N., Servant, D., Braconnier, A., et al. (2002). Personality dimensions in social phobics with or without depression. Acta Psychiatr Scand, 105(2), 94-103.

Plomin, R., \& Daniels, D. (1986). Genetics and shyness. In W. Jones, J. Cheek, \& S. Briggs (Eds.) Shyness: perspectives on research and treatment. New York, NY: Plenum. .

Rapee, R. M., Brown, T. A., Antony, M. M., \& Barlow, D. H. (1992). Response to hyperventilation and inhalation of $5.5 \%$ carbon dioxide-enriched air across the DSMIII-R anxiety disorders. J Abnorm Psychol, 101(3), 538-552.

Rapee, R. M., \& Heimberg, R. G. (1997). A cognitive-behavioral model of anxiety in social phobia. Behav Res Ther, 35(8), 741-756.

Rodebaugh, T. L., Holaway, R. M., \& Heimberg, R. G. (2004). The treatment of social anxiety disorder. Clin Psychol Rev, 24(7), 883-908.

Schneier, F. R., Abi-Dargham, A., Martinez, D., Slifstein, M., Hwang, D. R., Liebowitz, M. R., et al. (2009). Dopamine transporters, D2 receptors, and dopamine release in generalized social anxiety disorder. Depress Anxiety, 26(5), 411-418.

Schneier, F. R., Liebowitz, M. R., Abi-Dargham, A., Zea-Ponce, Y., Lin, S. H., \& Laruelle, M. (2000). Low dopamine $D(2)$ receptor binding potential in social phobia. Am J Psychiatry, 157(3), 457-459.

Schwartz, C. E., Snidman, N., \& Kagan, J. (1999). Adolescent social anxiety as an outcome of inhibited temperament in childhood. J Am Acad Child Adolesc Psychiatry, 38(8), 1008-1015.

Skre, I., Onstad, S., Torgersen, S., Philos, D. R., Lygren, S., \& Kringlen, E. (2000). The heritability of common phobic fear: a twin study of a clinical sample. J Anxiety Disord, 14(6), 549-562. 
Stein, D. J., Baldwin, D. S., Bandelow, B., Blanco, C., Fontenelle, L. F., Lee, S., et al. (2010). A 2010 evidence-based algorithm for the pharmacotherapy of social anxiety disorder. Curr Psychiatry Rep, 12(5), 471-477.

Stein, D. J., \& Nesse, R. M. (2011). Threat detection, precautionary responses, and anxiety disorders. Neurosci Biobehav Rev, 35(4), 1075-1079.

Stein, M. B., \& Chavira, D. A. (1998). Subtypes of social phobia and comorbidity with depression and other anxiety disorders. J Affect Disord, 50 Suppl 1, S11-16.

Stein, M. B., Heuser, I. J., Juncos, J. L., \& Uhde, T. W. (1990). Anxiety disorders in patients with Parkinson's disease. Am J Psychiatry, 147(2), 217-220.

Tancer, M. E., Mailman, R. B., Stein, M. B., Mason, G. A., Carson, S. W., \& Golden, R. N. (1994). Neuroendocrine responsivity to monoaminergic system probes in generalized social phobia. Anxiety, 1(5), 216-223.

Tiihonen, J., Kuikka, J., Bergstrom, K., Lepola, U., Koponen, H., \& Leinonen, E. (1997). Dopamine reuptake site densities in patients with social phobia. Am J Psychiatry, 154(2), 239-242.

Tillfors, M. (2004). Why do some individuals develop social phobia? A review with emphasis on the neurobiological influences. Nord J Psychiatry, 58(4), 267-276.

Tillfors, M., Furmark, T., Ekselius, L., \& Fredrikson, M. (2001). Social phobia and avoidant personality disorder as related to parental history of social anxiety: a general population study. Behav Res Ther, 39(3), 289-298.

Turner, S. M., Beidel, D. C., \& Jacob, R. G. (1994). Social phobia: a comparison of behavior therapy and atenolol. J Consult Clin Psychol, 62(2), 350-358.

Van Ameringen, M., Mancini, C., Patterson, B., \& Simpson, W. (2009). Pharmacotherapy for social anxiety disorder: an update. Isr J Psychiatry Relat Sci, 46(1), 53-61.

Van Ameringen, M., Mancini, C., Pipe, B., \& Bennett, M. (2004). Optimizing treatment in social phobia: a review of treatment resistance. CNS Spectr, 9(10), 753-762.

van der Wee, N. J., van Veen, J. F., Stevens, H., van Vliet, I. M., van Rijk, P. P., \& Westenberg, H. G. (2008). Increased serotonin and dopamine transporter binding in psychotropic medication-naive patients with generalized social anxiety disorder shown by 123I-beta-(4-iodophenyl)-tropane SPECT. J Nucl Med, 49(5), 757-763.

van Veen, J. F., van Vliet, I. M., de Rijk, R. H., van Pelt, J., Mertens, B., Fekkes, D., et al. (2009). Tryptophan depletion affects the autonomic stress response in generalized social anxiety disorder. Psychoneuroendocrinology, 34(10), 1590-1594.

Westenberg, H. G. (2009). Recent advances in understanding and treating social anxiety disorder. CNS Spectr, 14(2 Suppl 3), 24-33.

Wittchen, H. U., \& Fehm, L. (2001). Epidemiology, patterns of comorbidity, and associated disabilities of social phobia. Psychiatr Clin North Am, 24(4), 617-641. 
Wittchen, H. U., \& Fehm, L. (2003). Epidemiology and natural course of social fears and social phobia. Acta Psychiatr Scand Supp/(417), 4-18.

Woody, E., \& Boyer, P. (2011). Threat-detection and precaution: introduction to the special issue. Neurosci Biobehav Rev, 35(4), 989-990.

Zohar, A. H., Dina, C., Rosolio, N., Osher, Y., Gritsenko, I., Bachner-Melman, R., et al. (2003). Tridimensional personality questionnaire trait of harm avoidance (anxiety proneness) is linked to a locus on chromosome 8p21. Am J Med Genet B Neuropsychiatr Genet, 117B(1), 66-69. 


\section{Chapter 2}

General overview of the studies 

This thesis addresses processing of threat and pharmacotherapy in SAD, aiming at enhancing our understanding and improving treatment of this debilitating disorder.

Part I intended to investigate threat processing in SAD by means of different methodological tools, which may help in elucidating the underpinnings of this disorder. Threatening stimuli may be of physiological or psychological origin. Inhalation of high concentrations of $\mathrm{CO}_{2}$ can be regarded as a threatening physiological stimulus as it may be a signal of possible suffocation. It is suggested that increasing concentrations of $\mathrm{CO}_{2}$ triggers an inborn alarm system, probably indirectly by inducing acidosis across the blood-brain barrier which stimulates $\mathrm{pH}$-sensitive channels in the amygdala and brain stem (Maren, 2009; Richerson, 2004; Ziemann, et al., 2009). 35\% $\mathrm{CO}_{2}$ challenges have repeatedly shown to induce panic attacks in patients with panic disorder (Esquivel, Schruers, Maddock, Colasanti, \& Griez, 2010). SAD patients often experience panic-like symptoms, such as sweating and palpitations, and therefore they also may show an enhanced response to interoceptive threatening cues. The purpose of chapter three is to investigate the $35 \% \mathrm{CO}_{2}$ sensitivity in patients with SAD in comparison with patients with panic disorder and healthy controls.

In the psychological field, processing of threatening stimuli has been studied extensively, using semantic and facial stimuli. Threatening faces may be more ecologically valid stimuli than words in SAD because facial expressions are more directly related to social signals than semantic stimuli. Furthermore, research suggests that humans are biologically prepared to fear angry, threatening and rejecting faces (Ohman, 2009). Chapter four explores the recognition of threatening facial expressions in SAD compared to healthy controls.

Moreover, the processing of threat can be viewed in a social or environmental perspective. In current society in which performance and individual growth is increasingly important, social threat may be the most common every-day danger people have to 'survive' or succeed. It has been postulated that originally adaptive fear circuits have become more inappropriately activated in SAD, resulting in distorted cognitions, such as worry about negative evaluation by others (Cisler \& Koster, 2010; Ouimet, Gawronski, \& Dozois, 2009). Another well-known clinical condition characterized by distorted cognitions about threat by others, is paranoia. Persons with social anxiety or SAD and those with paranoid symptoms both experience fear for others, although with different motives, respectively fear for negative evaluation versus fear for harm by others. Epidemiological research may help in elucidating differential and common factors which play a role in the development of symptoms, associated with social threat in a natural environment. In chapter five, data from a general population sample are used to inves- 
tigate the natural association between SAD and paranoid symptoms, and their association with temperamental and environmental factors.

Part II of this thesis includes studies into the pharmacological treatment of SAD. Currently, SSRIs and the SNRI venlafaxine are the first-line treatment of choice in SAD (Stein, et al., 2010). However, treatment resistance is high (Van Ameringen, et al., 2004), and long-term use of SSRIs and venlafaxine can be complicated by side effects such as sexual dysfunction (Baldwin, 2004). Mirtazapine is an antidepressant with a different mode of action (blockade of noradrenergic and specific serotonergic receptors) and a different side-effect profile. The objective of chapter six was to assess the efficacy and the tolerability of mirtazapine in comparison with placebo in patients with generalized SAD, with a focus on sexual function.

The aim of chapter seven was to investigate if combination of mirtazapine with a SSRI, such as paroxetine causes a greater therapeutic effect and less sexual side effects than paroxetine monotherapy in SAD.

Quetiapine is an atypical antipsychotic, which antagonizes several receptors, such as specific receptors for serotonin and dopamine, which are both involved in the neurobiology of SAD (Westenberg, 2009). Moreover, animal models have shown that atypical antipsychotics also possess anxiolytic properties (Moore, Rees, Sanger, \& Tye, 1994), which has been confirmed by clinical reports (Vulink, Figee, \& Denys, 2011). Chapter eight describes an open-label pilot study in which the efficacy and tolerability of quetiapine in the treatment of generalized SAD is examined. 


\section{References}

Baldwin, D. S. (2004). Sexual dysfunction associated with antidepressant drugs. Expert Opin Drug Saf, 3(5), 457-470.

Cisler, J. M., \& Koster, E. H. (2010). Mechanisms of attentional biases towards threat in anxiety disorders: An integrative review. Clin Psychol Rev, 30(2), 203-216.

Esquivel, G., Schruers, K. R., Maddock, R. J., Colasanti, A., \& Griez, E. J. (2010). Acids in the brain: a factor in panic? J Psychopharmacol, 24(5), 639-647.

Maren, S. (2009). An acid-sensing channel sows fear and panic. Cell, 139(5), 867-869.

Moore, N. A., Rees, G., Sanger, G., \& Tye, N. C. (1994). Effects of olanzapine and other antipsychotic agents on responding maintained by a conflict schedule. Behav Pharmacol, 5(2), 196-202.

Ohman, A. (2009). Of snakes and faces: an evolutionary perspective on the psychology of fear. Scand J Psychol, 50(6), 543-552.

Ouimet, A. J., Gawronski, B., \& Dozois, D. J. (2009). Cognitive vulnerability to anxiety: A review and an integrative model. Clin Psychol Rev, 29(6), 459-470.

Richerson, G. B. (2004). Serotonergic neurons as carbon dioxide sensors that maintain pH homeostasis. Nat Rev Neurosci, 5(6), 449-461.

Stein, D. J., Baldwin, D. S., Bandelow, B., Blanco, C., Fontenelle, L. F., Lee, S., et al. (2010). A 2010 evidence-based algorithm for the pharmacotherapy of social anxiety disorder. Curr Psychiatry Rep, 12(5), 471-477.

Van Ameringen, M., Mancini, C., Pipe, B., \& Bennett, M. (2004). Optimizing treatment in social phobia: a review of treatment resistance. CNS Spectr, 9(10), 753-762.

Vulink, N. C., Figee, M., \& Denys, D. (2011). Review of atypical antipsychotics in anxiety. Eur Neuropsychopharmacol, 21(6), 429-449.

Westenberg, H. G. (2009). Recent advances in understanding and treating social anxiety disorder. CNS Spectr, 14(2 Suppl 3), 24-33.

Ziemann, A. E., Allen, J. E., Dahdaleh, N. S., Drebot, II, Coryell, M. W., Wunsch, A. M., et al. (2009). The amygdala is a chemosensor that detects carbon dioxide and acidosis to elicit fear behavior. Cell, 139(5), 1012-1021. 


\section{Part I}

Threat processing in Social Anxiety Disorder 



\section{Chapter 3}

\section{$35 \% \mathrm{CO}_{2}$ sensitivity in Social Anxiety Disorder}

Sara I.J. Schutters, Wolfgang Viechtbauer, Inge J. Knuts, Eric J.L. Griez, Koen R.J. Schruers 



\begin{abstract}
Objective

The $35 \%$ carbon dioxide $\left(\mathrm{CO}_{2}\right)$ challenge is a well-established model of panic. This study aimed at investigating $35 \% \mathrm{CO}_{2}$-sensitivity in patients with social anxiety disorder (SAD) compared to patients with panic disorder (PD) and normal controls.
\end{abstract}

\title{
Methods
}

First, a $35 \% \mathrm{CO}_{2}$ challenge was conducted including sixteen patients with generalized SAD, 16 with PD and 16 normal subjects. Outcome was assessed by a Visual Analogue Scale for Fear (VAS-F) and the Panic Symptom List (PSL). Second, meta-analyses of fear and panic scores were performed, including data of the present experiment and of previous $35 \% \mathrm{CO}_{2}$ challenge studies in SAD patients.

Results

The present $35 \% \mathrm{CO}_{2}$ challenge found equal increases in VAS-F and PSL in SAD patients compared to normal controls, whereas the $\mathrm{CO}_{2}$ response in PD patients was significantly stronger than in controls. The meta-analyses confirmed the experimental data from this study, and in addition showed an intermediate panic rate in SAD patients, in between normal controls and PD patients.

\section{Conclusion}

Neither our experiment, nor the meta-analyses found evidence for a similarly exaggerated $35 \% \mathrm{CO}_{2}$-sensitivity in SAD and PD, suggesting that the pathogenesis of SAD is different from PD, although SAD patients may be slightly more sensitive than nonanxious controls. 


\section{Introduction}

According to the DSM-IV (American Psychiatric Association, 2000), panic attacks can occur in the context of several mental disorders (Reed \& Wittchen, 1998). They are the main feature in Panic Disorder (PD): individuals with PD experience recurrent, unexpected and unpredictable panic attacks, which consequently are the cause of a persistent concern. Symptomatically similar episodes however also occur in the context of Social Anxiety Disorder (SAD) (Reed \& Wittchen, 1998). The core feature of SAD is fear of acting in an embarrassing or humiliating way, but patients with this condition may also experience panic attacks in certain circumstances. Whereas at least some panic attacks in PD are "out of the blue" and originally not anticipated or connected to certain situations, panic attacks in SAD are specifically linked to social situations (Gelernter, Stein, Tancer, \& Uhde, 1992). Although the situationally bound panic attacks in SAD phenomenologically resemble the unexpected panic attacks experienced by patients with $P D$, it is not known if they originate from a common biological mechanism.

The $35 \%$ carbon dioxide $\left(\mathrm{CO}_{2}\right)$ challenge is a well-established experimental model of panic (Griez \& Schruers, 1998, 2003; Rassovsky \& Kushner, 2003). In the past, 35\% $\mathrm{CO}_{2}$ hypersensitivity was conceptualized as a specific marker for PD. However, experimental research showed that $\mathrm{CO}_{2}$ inhalation does not only elicit panic in PD, but also in other nosological entities, such as situational phobias (Verburg, Griez, \& Meijer, 1994). Even healthy subjects have been shown to be sensitive to $\mathrm{CO}_{2}$ inhalation, in a dose dependent fashion (Griez, Colasanti, van Diest, Salamon, \& Schruers, 2007). These findings suggest that the $\mathrm{CO}_{2}$ response may be based on an inborn human survival mechanism and that $\mathrm{CO}_{2}$-hypersensitivity is not a simple marker of a single nosological entity. Rather, a continuum of $\mathrm{CO}_{2}$ sensitivity may exist, in which an increasing degree of sensitivity is related to an increased vulnerability to panic. The notion of an inborn mechanism is supported by recent neurobiological experiments showing the existence of $\mathrm{CO}_{2} / \mathrm{pH}$-sensitive chemosensors in the brain stem (Hodges \& Richerson, 2010; Richerson, 2004) and even in the amygdala (Ziemann, et al., 2009), which are known to coordinate fear responses to a variety of threats (Graeff \& Del-Ben, 2008; LeDoux, 2000). In this perspective, panic attacks may be viewed as a defensive response to acute and potentially threatening acid-base scenarios (Esquivel, Schruers, Maddock, Colasanti, \& Griez, 2010) and aberrant chemosensation may underlie anxiety disorders associated with panic attacks (Maren, 2009). $35 \% \mathrm{CO}_{2}$ challenges have been mainly conducted in patients with PD, who have consistently shown to have an exaggerated sensitivity (Fyer, et al., 1987; Griez, de Loof, Pols, Zandbergen, \& Lousberg, 1990; Griez, Lousberg, van den Hout, \& van der Molen, 1987). Three studies have addressed the 
issue of the sensitivity of SAD patients to a $35 \% \mathrm{CO}_{2}$ challenge (Caldirola, Perna, Arancio, Bertani, \& Bellodi, 1997; Gorman, et al., 1990; Papp, et al., 1993). The first study by Gorman and colleagues aimed at differentiating PD patients from controls and from another group of patients with anxiety disorder (22 patients with SAD) (Gorman, et al., 1990). With reference to this stated purpose, the study was negative, as in this particular experiment, no clear cut difference was found between the different diagnostic groups. A subsequent study from the same group found intermediate panic rates in SAD patients (30\%), suggesting they are less sensitive than PD patients (panic rate: 72\%), but more than normal controls (panic rate: 4\%) (Papp, et al., 1993). The most recent $35 \% \mathrm{CO}_{2}$ study found comparable panicogenic reactions in $\mathrm{SAD}$ and $\mathrm{PD}$ (Caldirola, et al., 1997). This $\mathrm{CO}_{2}$-challenge induced panic attacks in eleven out of $16 \mathrm{PD}$ patients (69\%), nine out of 16 SAD patients (56\%), seven out of 13 patients with comorbid PD and SAD (54\%), three out of 7 SAD patients with sporadic unexpected panic attacks (43\%) and one out of 16 normal controls (6\%). Interestingly, this latest study reported that SAD patients experienced the $\mathrm{CO}_{2}$-induced panic attacks as different from anxiety induced by social situations. In conclusion, the current $\mathrm{CO}_{2}$-challenges apparently do not yield consistent responses in SAD patients. It remains unclear if $\mathrm{CO}_{2}$ hypersensitivity plays a role in the pathogenesis of SAD.

The aim of the present study was to investigate $\mathrm{CO}_{2}$ sensitivity in SAD patients by two means. First, a $35 \% \mathrm{CO}_{2}$ experiment was performed to compare sensitivity in SAD patients who had never experienced a spontaneous panic attack, with healthy controls and with PD patients. Second, meta-analyses including data from the previous $\mathrm{CO}_{2}$ challenges were conducted to specify the magnitude of differences in $\mathrm{CO}_{2}$ sensitivity between SAD, PD and normal. Based on the assumption that the pathogenesis of spontaneous panic attacks, which are characteristic for PD differs from the pathogenesis of situational panic attacks, which also occur in SAD, we hypothesized that SAD patients would be less hypersensitive to $\mathrm{CO}_{2}$ than PD patients.

\section{Methods}

\section{$35 \% \mathrm{CO}_{2}$ challenge}

\section{Subjects}

Sixteen patients with social anxiety disorder (SAD), generalized type and 16 with panic disorder (PD) were recruited from the outpatient population of the Academic Anxiety Centre in Maastricht, The Netherlands. Patients were diagnosed according to the DSM- 
IV criteria and confirmed with the Mini International Neuropsychiatric Interview (Schruers, et al., 2000; Sheehan, et al., 1998). The patients with SAD had no co-morbid PD and vice versa. Furthermore, included SAD patients did not have a history of spontaneous, 'out of the blue' panic attacks. Patients with another primary (i.e. most severe) Axis I or Axis II disorder were excluded. Sixteen healthy controls (NC) were recruited from the general population via advertisement. All subjects gave their informed consent for the procedure after full explanation by the investigators. At the time of testing, all subjects had been free of any use of psychotropic medication, including benzodiazepines, for at least 2 weeks.

\section{Procedure and assessments}

The SAD and PD patients completed the Spielberger State and Trait Anxiety inventory (STAI) (Spielberger, 1983) and the Fear Questionnaire (FQ) (Marks \& Mathews, 1979) at screening (approximately 1 month before the challenge). The STAI is a 40-item instrument which includes state (STAI-1) and trait (STAI-2) scales, measuring respectively transient and enduring levels of anxiety. The $\mathrm{FQ}$ is a 15 -item inventory assessing severity of avoidance related to agoraphobic, social and blood-injury fears (Marks \& Mathews, 1979).

All participants inhaled a mixture of $35 \% \mathrm{CO}_{2}$ and $65 \% \mathrm{O}_{2}$. Before and after inhalation, subjects filled out a Visual Analogue Scale for Fear (VAS-F) (Schruers, et al., 2011) and the Panic Symptom List (PSL) (Schruers, et al., 2000). The VAS-F was used to measure subjective fear; the range of scores was $0-100$, with $0=$ no fear and $100=$ worst fear imaginable. This instrument has been validated previously for use during $35 \% \mathrm{CO}_{2}$ challenges (van Duinen, Rickelt, \& Griez, 2008). The PSL (PSL-IV) was used to evaluate panic symptomatology. It consists of a questionnaire listing thirteen items, each item representing a DSM-IV panic symptom, to be rated on a five point scale, from 0 (absent) to 4 (very intense). The PSL and VAS-F were administered $1 \mathrm{~min}$ before and after each inhalation. $\triangle$ VAS-F and $\triangle$ PSL (post-test scores minus pre-test scores) were calculated for each assessment. Criteria for a panic attack were a rise of at least 25 points on the VAS$F$ plus an increase in panic symptomatology (Pols, Verburg, Hauzer, Meijer, \& Griez, 1996; Schruers, et al., 2000).

Data-analysis

The present challenge results were analysed as follows. Independent-samples t-test were conducted to compare baseline STAI and FQ scores in SAD and PD. Baseline VAS-F and PSL and the $\triangle$ VAS-F and $\triangle$ PSL scores were analysed by using analyses of variance 
(ANOVA's) with one between-group factor (SAD versus PD versus NC). Post-hoc comparisons using the Tukey procedure were performed to find out which groups are significantly different from one another. Whenever assumptions for parametric tests (i.e., normal distribution, homogeneity of variance) were not met, non-parametric alternatives were used (Kruskal-Wallis Test, Mann-Whitney $U$ Test). The number of panic attacks following the $\mathrm{CO}_{2}$ challenge was calculated for each group and compared with chisquare tests.

\section{Meta-analyses}

Meta-analyses were conducted to quantitatively specify the magnitude of group differences in $35 \% \mathrm{CO}_{2}$ sensitivity between SAD patients, PD patients and normal controls. To the best of the authors' knowledge, all English-written published $35 \% \mathrm{CO}_{2}$ challenges up to January 1, 2011 that included SAD patients were reviewed. Whenever anxiety and panic responses to $\mathrm{CO}_{2}$ of SAD patients were obtainable directly from the articles, effect sizes of these measures were calculated and included for meta-analyses. In particular, within each study, the standardized mean change (Gibbons, Hedeker, \& Davis, 1993) for each group was computed (i.e., $d=\left(\bar{x}_{\text {post }}-\bar{x}_{\text {pre }}\right) / S D_{D}$ where $\bar{x}_{\text {pre }}$ and $\bar{x}_{\text {post }}$ are the means on the anxiety or panic outcome measure before and after the $\mathrm{CO}_{2}$ challenge and $\mathrm{SD}_{\mathrm{D}}$ denotes the standard deviation of the change scores). Standardization was necessary, since the instruments to assess anxiety and panic responses differed across studies. Based on the information provided in the articles, the proportion of cases in the three groups that experienced a panic attack (i.e., the panic rate) was also determined. Then, three separate meta-analyses were conducted using random-effects models to aggregate the anxiety and panic effect sizes and the panic rates across studies and to compare them across groups (for details on the model used, see Salanti, Higgins, Ades, \& loannidis, 2008). A constant heterogeneity across the three group contrasts (i.e., SAD vs. NC, PD vs. NC, and SAD vs. PD) was assumed. The models were fitted using restricted maximum likelihood (REML) estimation. Results are presented in terms of the estimated mean $d$ values $(\bar{d})$ or mean panic rates $(\bar{p})$ of the three groups (with corresponding 95\% confidence intervals) based on the random-effects models. If the omnibus test of equal effects (or rates) across the three groups was rejected, the pairwise contrasts (e.g., $\bar{d}_{P D}-\bar{d}_{N C}$ ) were also examined. In addition, forest plots are presented, showing the individual and aggregated $d$ values and panic rates. Likelihood ratio tests were used to test whether the amount of heterogeneity in the data was significantly larger than 0. 


\section{Results}

\section{$35 \% \mathrm{CO}_{2}$ challenge}

There were 6 men (37.5\%) and 10 women (62.5\%) in each of the three groups. There were no significant differences between the groups in mean age (SAD: $32.8 \pm 10.0$ years; PD: $32.8 \pm 9.5$ years; NC: $30.2 \pm 10.2$ years; $F(2,45)=0.4, p=.7)$. Mean scores on STAI 1, STAI 2 and FQ-SP (see table 1 ) were significantly higher in the SAD group compared to the PD group $(t(29)=-3.5, p=.001, t(28)=-6.0, p<.001$ and $t(29)=-6.4, p<.001$, respectively). The groups differed in baseline score on the VAS-F (Kruskal-Wallis $\chi^{2}=$ $12.3, \mathrm{df}=2, \mathrm{p}<.01$ ), with significantly higher scores in the SAD group and PD group compared to the NC group ( $z=-2.6, p<.01$ and $z=-3.4, p<.001$, respectively). Similar differences were found in baseline PSL scores (Kruskal-Wallis $\chi^{2}=15.3, d f=2, p<.001$ ): the anxiety groups showed significant higher scores than the NC group $(z=-2.4, p<.02$ for SAD and $z=-3.8, p<.001$ for PD). Mean scores are presented in table 1.

Table 1. Mean ( \pm SD) scores for 16 patients with Social Anxiety Disorder (SAD), 16 patients with Panic Disor$\operatorname{der}(\mathrm{PD})$ and 16 Normal Controls (NC).

$\begin{array}{lccc} & \text { SAD } & \text { PD } & \text { NC } \\ \text { STAI 1 } & 49.4( \pm 10.1)^{*} & 36.6( \pm 10.0) & - \\ \text { STAI 2 } & 58.5( \pm 11.5)^{* *} & 37.7( \pm 7.4) & - \\ \text { FQ-A } & 13.1( \pm 13.8)^{*} & 14.6( \pm 12.3) & - \\ \text { FQ-SP } & 26.1( \pm 9.6)^{*} & 7.6( \pm 6.1) & - \\ \text { FQ-BI } & 12( \pm 10.4)^{*} & 10( \pm 6.7) & - \\ \text { VAS-F } & & & 2.1( \pm 2.8) \\ \text { Before inhalation } & 21.4( \pm 24.6) & 18.8( \pm 17.0) & 15.8( \pm 22.7) \\ \text { After inhalation } & 44.0( \pm 34.4) & 67.1( \pm 21.3) & 13.7( \pm 22.4) \\ \text { Increase } & 22.6( \pm 36.1) & 48.4( \pm 27.4) & \\ \text { PSL } & & & 0.5( \pm 0.8) \\ \text { Before inhalation } & 3.0( \pm 5.0) & 4.0( \pm 3.2) & 6.4( \pm 4.3) \\ \text { After inhalation } & 13.5( \pm 9.2) & 17.2( \pm 9.1) & 5.9( \pm 3.9) \\ \text { Increase } & 10.5( \pm 9.4) & 13.4( \pm 7.6) & \end{array}$

STAI= State(1)-Trait(2) Anxiety Inventory

$F Q=$ Fear Questionnaire, $-A=$ Agoraphobia, $-S P=$ Social Phobia, $-B \mathrm{~B}=$ Blood Injury

VAS-F= Visual Analogue Scale for Fear

PSL= Panic Symptom List

$* \mathrm{n}=15 ; * * \mathrm{n}=14$ 
$\triangle$ VAS-F.

A one-way ANOVA revealed a significant difference in $\triangle \mathrm{VAS}-\mathrm{F}$ across the three groups $(F(2,45)=6.1, p<.005)$. Post-hoc comparisons using the Tukey procedure showed significant differences with higher scores in the PD group when compared to the $N C(p<.005)$ and when compared to the SAD $(p<.05)$ group. The SAD group did not differ significantly from the NC group $(p=.66)$. A graphical reproduction is shown in figure 1 .

$\triangle P S L$.

There was a significant difference in $\triangle$ PSL for the three groups $(F(2,45)=4.2, p=.02)$. Post-hoc comparisons showed a significant difference between PD and NC $(p<.02)$, with a higher mean score for the PD group (table 1 ). The SAD group did not differ significantly from the NC group, nor from the PD group ( $p=.20$ and $p=.50$ respectively). See figure 1 for a graphical reproduction.

Figure 1. Mean (standard error) $\triangle$ VAS-F and $\triangle$ PSL scores for 16 patients with Panic Disorder (PD), 16 patients with Social Anxiety Disorder (SAD) and 16 Normal Controls (NC).

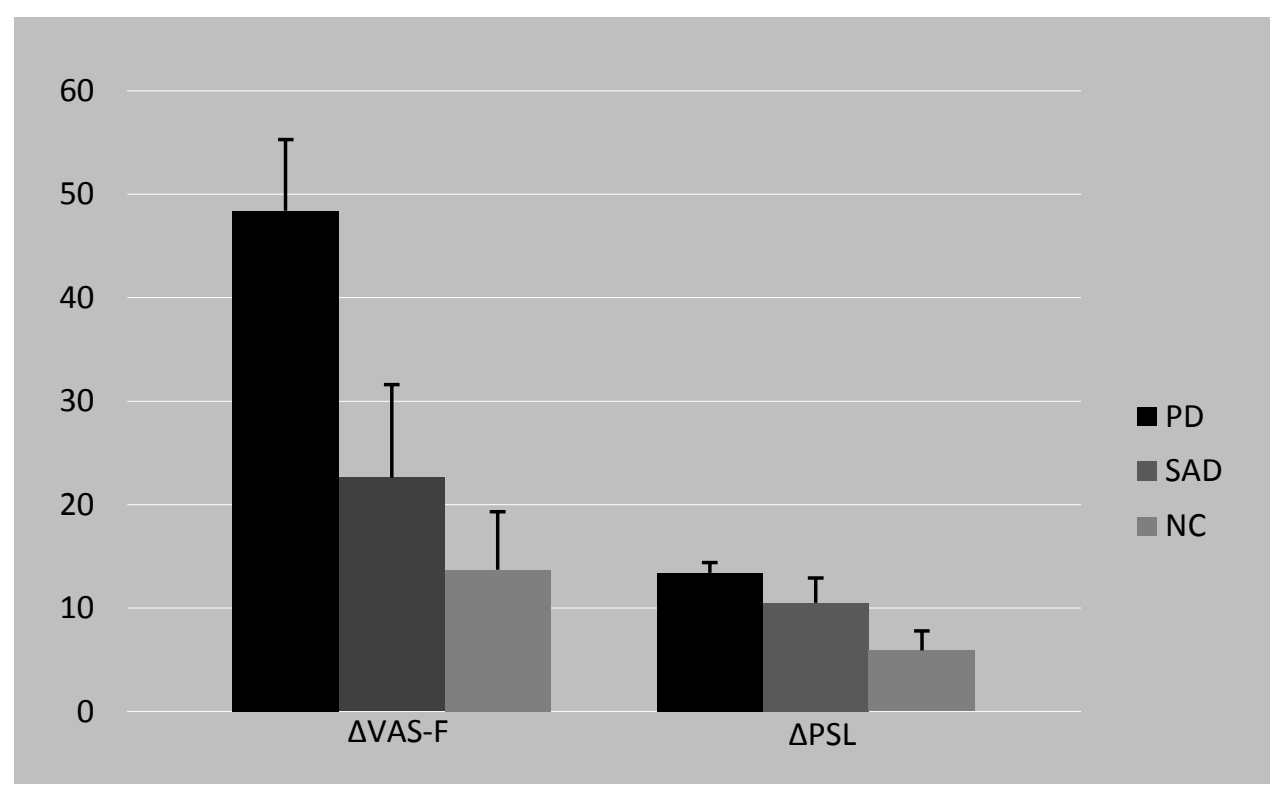




\section{Panic Rate.}

There were 12 panic attacks in the PD group, 8 in the SAD group and 3 in the NC group. A $2 \times 3$ chi-square analysis revealed a significant difference in the number of panic attacks among the three groups $\left(\chi^{2}=10.2, p=.006\right)$. Post-hoc comparisons showed that the panic rate in the PD group was significantly higher than in the NC group $\left(\chi^{2}=10.2\right.$, $p<.002)$. SAD patients did not differ significantly from PD patients $\left(\chi^{2}=2.1, p=.14\right)$ neither from the NC group $\left(\chi^{2}=3.5, p=.06\right)$.

\section{Meta-analysis}

\section{Included studies}

In addition to our $\mathrm{CO}_{2}$ study presented in this article, three previous $35 \% \mathrm{CO}_{2}$ challenges were identified as eligible for inclusion in the current meta-analyses (Caldirola, et al., 1997; Gorman, et al., 1990; Papp, et al., 1993).

Except from the study of Gorman et al. (Gorman, et al., 1990), which used doublebreathe, all studies employed the single breathe inhalation method. All studies assessed $\mathrm{CO}_{2}$ response by means of a fear scale, a panic symptom scale and all defined criteria for a panic attack. The American studies used a 10-point scale for assessing fear and the 28-item Acute Panic Inventory (API) (Dillon, Gorman, Liebowitz, Fyer, \& Klein, 1987) (Gorman, et al., 1990; Papp, et al., 1993), whereas the Italian group (Caldirola, et al., 1997) used the same scales as we did in the present $\mathrm{CO}_{2}$ study (i.e., VAS and PSL). Unfortunately, the latter study did not provide data on absolute mean changes in VAS and PSL and therefore could not be included in meta-analyses of changes in fear and panic symptomatology. Panic attacks were defined differently in the four studies, but the definitions all included a combination of increase in fear and in panic symptomatology. All studies used self-ratings for defining a panic attack, with the exception of Gorman et al. (Gorman, et al., 1990), which asked an attending psychiatrist to judge whether an actual panic attack occurred.

The characteristics of the subject groups of the included studies are shown in Table 2. The subjects in the Italian study were slightly younger, and there was a preponderance of men in the SAD groups of the American studies. 
Table 2. Characteristics of the Subject Groups in included studies

\begin{tabular}{|c|c|c|c|c|}
\hline Groups & Study & $\mathbf{N}$ & $\begin{array}{c}\text { Age } \\
(\text { Mean } \pm S D, y)\end{array}$ & $\begin{array}{c}\text { Sex } \\
\text { (\% Male) }\end{array}$ \\
\hline \multicolumn{5}{|c|}{ Control groups } \\
\hline & Gorman et al. 1990 & 14 & $27.1 \pm 5.6$ & 50 \\
\hline & Papp et al. 1993 & 23 & $31.2 \pm 8.6$ & 61 \\
\hline & Caldirola et al. 1997 & 16 & $25.8 \pm 2.8$ & 69 \\
\hline & Schutters et al. 2011 & 16 & $30.2 \pm 10.2$ & 37 \\
\hline \multicolumn{5}{|c|}{ Social anxiety disorder groups } \\
\hline & Gorman et al. 1990 & 22 & $34.9 \pm 8.5$ & 64 \\
\hline & Papp et al. 1993 & 20 & $34.3 \pm 9.2$ & 80 \\
\hline & Caldirola et al. 1997 & 16 & $30.7 \pm 9.6$ & 37 \\
\hline & Schutters et al. 2011 & 16 & $32.8 \pm 10.0$ & 37 \\
\hline \multicolumn{5}{|c|}{ Panic disorder groups } \\
\hline & Gorman et al. 1990 & 26 & $34.7 \pm 8.2$ & 38 \\
\hline & Papp et al. 1993 & 18 & $35.3 \pm 9.6$ & 33 \\
\hline & Caldirola et al. 1997 & 16 & $31.7 \pm 6.4$ & 50 \\
\hline & Schutters et al. 2011 & 16 & $32.8 \pm 9.5$ & 37 \\
\hline
\end{tabular}

\section{Effect sizes}

Figure $2 \mathrm{a}$ depicts the forest plot of the standardized mean changes in fear response to $\mathrm{CO}_{2}$ inhalation in control, SAD and PD groups. The random-effects model indicated that the largest increases in fear occurred in the PD group $(\bar{d}=1.10,95 \% \mathrm{Cl}: 0.77$ to 1.43$)$, followed by the SAD ( $\bar{d}=0.79,95 \% \mathrm{Cl}$ : 0.50 to 1.09$)$ and control groups ( $\bar{d}=0.59,95 \%$ $\mathrm{Cl}: 0.30$ to 0.88 ), the latter showing the lowest increases. The differences in the standardized mean changes between the three groups were significant $\left(\chi^{2}=6.1\right.$, df $=2$, $\mathrm{p}=.047)$. The PD group had a significantly higher increase than the control group $\left(\bar{d}_{P D}-\right.$ $\left.\bar{d}_{N C}=0.57, \mathrm{p}=.01\right)$. SAD patients neither differed significantly from controls $\left(\bar{d}_{S A D}-\bar{d}_{N C}=\right.$ $0.23, \mathrm{p}=.29)$, nor from PD patients $\left(\bar{d}_{P D}-\bar{d}_{S A D}=.34, \mathrm{p}=.13\right)$. All of the heterogeneity in the data could be accounted for based on sampling variability.

Figure $2 \mathrm{~b}$ displays the forest plot of the standardized mean changes in panic symptomatology in response to $\mathrm{CO}_{2}$ inhalation in control, SAD and PD groups. The randomeffects model indicated the highest increases in the PD patients $(\bar{d}=1.24,95 \% \mathrm{Cl}: 0.90$ to 1.58$)$, followed by controls ( $\bar{d}=1.01,95 \% \mathrm{Cl}: 0.68$ to 1.35$)$ and SAD patients $(\bar{d}=$ $0.96,95 \% \mathrm{Cl}: 0.65$ to 1.27$)$ groups. However, the differences between the three groups was not significant $\left(\chi^{2}=1.9, d f=2, p=.39\right)$. No heterogeneity was again found in the data.

The forest plot for the panic rates is shown in Figure $2 c$. The differences in the rates between the control, SAD and PD groups were significant $\left(\chi^{2}=69.9\right.$, $\left.d f=2, p<.0001\right)$. 
The risk of SAD patients experiencing a panic attack during the $\mathrm{CO}_{2}$-challenge was $\bar{p}=.41$ (95\% Cl: .30 to .53$)$, falling in between the panic rate of controls $(\bar{p}=.09,95 \% \mathrm{Cl}$ : .01 to .17) and PD groups ( $\bar{p}=.66,95 \% \mathrm{Cl}$ : .54 to .77$)$. All pairwise contrasts between the three groups were significant (all $p<.001)$. Some slight heterogeneity was present in the data, but it was not significant $(p=.44)$.

Figure 2a. Forest plot of the Standardized Mean Change in Fear

\begin{tabular}{|c|c|c|c|c|c|}
\hline Group/Study & Mean & SD & $\mathbf{N}$ & & SMC $[95 \% \mathrm{Cl}]$ \\
\hline \multicolumn{6}{|l|}{ Control Groups } \\
\hline Gorman, 1990 & 1.43 & 2.56 & 14 & $\longmapsto$ & $0.56[0.00,1.12]$ \\
\hline Papp, 1993 & 1.36 & 2.28 & 23 & $\longmapsto$ & $0.60[0.15,1.04]$ \\
\hline Caldirola, 1997 & NA & NA & 16 & & NA [ NA, NA ] \\
\hline Schutters, 2011 & 13.70 & 22.40 & 16 & $\longmapsto$ & $0.61[0.08,1.15]$ \\
\hline Random-Effects Model & & & & & $0.59[0.30,0.88]$ \\
\hline \multicolumn{6}{|c|}{ Social Anxiety Disorder Groups } \\
\hline Gorman, 1990 & 2.05 & 2.58 & 22 & $\longmapsto$ & $0.79[0.32,1.27]$ \\
\hline Papp, 1993 & 2.47 & 2.61 & 20 & $\longmapsto$ & $0.95[0.42,1.47]$ \\
\hline Caldirola, 1997 & NA & NA & 16 & & $\mathrm{NA}[\mathrm{NA}, \mathrm{NA}]$ \\
\hline Schutters, 2011 & 22.60 & 36.10 & 16 & $\longmapsto$ & $0.63[0.09,1.16]$ \\
\hline Random-Effects Model & & & & & $0.79[0.50,1.09]$ \\
\hline \multicolumn{6}{|l|}{ Panic Disorder Groups } \\
\hline Gorman, 1990 & 1.80 & 2.23 & 26 & $\longmapsto$ & $0.81[0.36,1.25]$ \\
\hline Papp, 1993 & 3.33 & 2.66 & 18 & $\longmapsto-\longrightarrow$ & $1.25[0.63,1.87]$ \\
\hline Caldirola, 1997 & NA & NA & 16 & & $\mathrm{NA}[\mathrm{NA}, \mathrm{NA}]$ \\
\hline Schutters, 2011 & 48.40 & 27.40 & 16 & $\longmapsto$ & $1.77[0.98,2.55]$ \\
\hline \multirow[t]{4}{*}{ Random-Effects Model } & & & & $<$ & $1.10[0.77,1.43]$ \\
\hline & & & & $\Gamma$ & \\
\hline & & & & $\begin{array}{llll}0 & 0.75 & 1.5 & 2.25\end{array}$ & \\
\hline & \multicolumn{5}{|c|}{ Standardized Mean Change } \\
\hline
\end{tabular}


Figure 2b. Forest plot of the Standardized Mean Change in Panic Symptomatology

\begin{tabular}{|c|c|c|c|c|c|}
\hline Group/Study & Mean & SD & $\mathbf{N}$ & & $\mathrm{SMC}[95 \% \mathrm{Cl}]$ \\
\hline \multicolumn{6}{|l|}{ Control Groups } \\
\hline Gorman, 1990 & 8.79 & 9.08 & 14 & $\longmapsto$ & $0.97[0.33,1.60]$ \\
\hline Papp, 1993 & 5.91 & 7.20 & 23 & $\longmapsto \square$ & $0.82[0.35,1.29]$ \\
\hline Caldirola, 1997 & NA & NA & 16 & & NA [ NA, NA ] \\
\hline Schutters, 2011 & 5.90 & 3.90 & 16 & $\longmapsto$ & $1.51[0.80,2.23]$ \\
\hline Random-Effects Model & & & & & $1.01[0.68,1.35]$ \\
\hline \multicolumn{6}{|c|}{ Social Anxiety Disorder Groups } \\
\hline Gorman, 1990 & 12.50 & 12.90 & 22 & $\longmapsto$ & $0.97[0.46,1.48]$ \\
\hline Papp, 1993 & 13.53 & 16.12 & 20 & $\longmapsto$ & $0.84[0.33,1.35]$ \\
\hline Caldirola, 1997 & NA & NA & 16 & & NA [ NA, NA ] \\
\hline Schutters, 2011 & 10.50 & 9.40 & 16 & $\longmapsto$ & $1.12[0.49,1.74]$ \\
\hline Random-Effects Model & & & & & $0.96[0.65,1.27]$ \\
\hline \multicolumn{6}{|l|}{ Panic Disorder Groups } \\
\hline Gorman, 1990 & 14.65 & 15.40 & 26 & $\longmapsto-1$ & $0.95[0.49,1.41]$ \\
\hline Papp, 1993 & 18.72 & 12.90 & 18 & $\longmapsto$ & $1.45[0.79,2.11]$ \\
\hline Caldirola, 1997 & NA & NA & 16 & & NA [ NA, NA ] \\
\hline Schutters, 2011 & 13.40 & 7.60 & 16 & $-\quad \longrightarrow$ & $1.76[0.98,2.55]$ \\
\hline \multirow[t]{4}{*}{ Random-Effects Model } & & & & & $1.24[0.90,1.58]$ \\
\hline & & & & $T$ & \\
\hline & & & & $\begin{array}{llll}0 & 0.75 & 1.5 & 2.25\end{array}$ & 3 \\
\hline & \multicolumn{5}{|c|}{ Standardized Mean Change } \\
\hline
\end{tabular}

Figure 2c. Forest plot of the Panic Rate

\begin{tabular}{|c|c|c|c|c|}
\hline Group/Study & Cases & $\mathbf{N}$ & & Panic Rate $[95 \% \mathrm{Cl}]$ \\
\hline \multicolumn{5}{|l|}{ Control Groups } \\
\hline Gorman, 1990 & 3 & 14 & $\longmapsto$ & $0.21[0.05,0.51]$ \\
\hline Papp, 1993 & 1 & 23 & $\square$ & $0.04[0.00,0.22]$ \\
\hline Caldirola, 1997 & 1 & 16 & 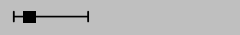 & $0.06[0.00,0.30]$ \\
\hline Schutters, 2011 & 3 & 16 & $\longmapsto$ & $0.19[0.04,0.46]$ \\
\hline Random-Effects Model & & & $<$ & $0.09[0.01,0.17]$ \\
\hline \multicolumn{5}{|c|}{ Social Anxiety Disorder Groups } \\
\hline Gorman, 1990 & 8 & 22 & $\longmapsto$ & $0.36[0.17,0.59]$ \\
\hline Papp, 1993 & 6 & 20 & $\longmapsto$ & $0.30[0.12,0.54]$ \\
\hline Caldirola, 1997 & 9 & 16 & $\longmapsto$ & $0.56[0.30,0.80]$ \\
\hline Schutters, 2011 & 8 & 16 & $\longmapsto$ & $0.50[0.25,0.75]$ \\
\hline Random-Effects Model & & & & $0.41[0.30,0.53]$ \\
\hline \multicolumn{5}{|l|}{ Panic Disorder Groups } \\
\hline Gorman, 1990 & 13 & 26 & $\longmapsto-$ & $0.50[0.30,0.70]$ \\
\hline Papp, 1993 & 13 & 18 & $\rightarrow-1$ & $0.72[0.47,0.90]$ \\
\hline Caldirola, 1997 & 11 & 16 & $\square$ & $0.69[0.41,0.89]$ \\
\hline Schutters, 2011 & 12 & 16 & $\longmapsto$ & $0.75[0.48,0.93]$ \\
\hline \multirow[t]{4}{*}{ Random-Effects Model } & & & & $0.66[0.54,0.77]$ \\
\hline & & & $1 \quad 1$ & 7 \\
\hline & & & $\begin{array}{llll}0 & 0.25 & 0.5 & 0.75\end{array}$ & 1 \\
\hline & & & Panic Rate & \\
\hline
\end{tabular}




\section{Discussion}

Both the present $35 \% \mathrm{CO}_{2}$ experiment and the meta-analyses of $35 \% \mathrm{CO}_{2}$ responses showed that SAD patients do not report more $\mathrm{CO}_{2}$-induced fear or panic symptomatology than normal controls, but the meta-analysis found intermediate $\mathrm{CO}_{2}$-elicited panic rates in SAD, midway between normal and PD. This strongly suggests that SAD patients may react more than controls, but certainly not as strong as patients with PD.

Therefore, the results are in line with the idea of an intermediate $\mathrm{CO}_{2}$ reactivity in SAD, as suggested by some earlier studies (Blechert, Wilhelm, Meuret, Wilhelm, \& Roth, 2010; Holt \& Andrews, 1989b; Papp, et al., 1993). $\mathrm{CO}_{2}$ studies in patients with other anxiety disorders and in healthy subjects support a continuum model for $\mathrm{CO}_{2}$ vulnerability. For instance, patients with obsessive-compulsive disorder and animal phobia react in a similar way to healthy controls (E. Griez, et al., 1990; Perna, Bertani, Arancio, Ronchi, \& Bellodi, 1995; Verburg, et al., 1994). On the other hand, patients with situational phobia and healthy subjects with infrequent panic attacks display a $\mathrm{CO}_{2}$-sensitivity close to PD patients (Perna, Gabriele, Caldirola, \& Bellodi, 1995; Verburg, et al., 1994). Further supporting the continuum model is the finding that negative affect in healthy subjects depends on the concentration of $\mathrm{CO}_{2}$ used (Griez, et al., 2007; Schruers, et al., 2011).

Since the $\mathrm{CO}_{2}$ challenge strongly disturbs the "internal milieu", it is possible that the degree of $\mathrm{CO}_{2}$ susceptibility may be a function of vulnerability to (threatening) interoceptive cues. Conceivably, there is a spectrum of interoceptive vulnerability within anxiety disorders. PD patients appear to be most sensitive for internally generated cues (Craske, 1991). On the other extreme, animal phobia is characterized by a fear of a purely external stimulus, suggesting a high sensitivity for exteroceptive cues (Craske \& Sipsas, 1992). The same may apply to obsessive-compulsive disorder, in which for example contamination by germs is feared. With regard to SAD, sensitivity to both exteroceptive and interoceptive cues seems to play a role. SAD patients are typically afraid of negative evaluation by others. Therefore, they may be most vulnerable for external social cues. Yet, SAD patients may also be hypersensitive for interoceptive cues, as cognitive models have suggested an important role of heightened self-focus in SAD (Clark \& Wells, 1995). Empirical research has in addition found an increased awareness of autonomic anxiety symptoms in SAD patients, certainly when these symptoms may be obvious for the external world (e.g., sweating, blushing) (Anderson \& Hope, 2009; Spector, Pecknold, \& Libman, 2003). Several studies found an exaggerated physiological arousal in the non-generalized subtype of SAD (Heimberg, Hope, Dodge, \& Becker, 1990; Hofmann, Newman, Ehlers, \& Roth, 1995; McTeague, et al., 2009), suggesting this subtype may resemble PD. Our sample specifically included patients with the gen- 
eralized SAD, but the subtype was not specified in the previous $35 \% \mathrm{CO}_{2}$ challenges (Caldirola, et al., 1997; Gorman, et al., 1990; Papp, et al., 1993). It is conceivable that the SAD patients with an exaggerated response to $\mathrm{CO}_{2}$ are those who predominantly experience autonomic symptoms, such as the non-generalized subtype. The highest $\mathrm{CO}_{2}$ sensitivity may be found in patients with respiratory symptoms, such as in the respiratory subtype of PD (Freire, et al., 2008; Freire, Perna, \& Nardi, 2010), because these symptoms specifically have been shown to be the best predictors for panic in a $\mathrm{CO}_{2}$ experiment (Colasanti, et al., 2008). Further $\mathrm{CO}_{2}$-studies addressing the type of symptoms (blushing, sweating, palpitations, dyspnea) induced by the $35 \%$ challenge are needed to elucidate if $\mathrm{CO}_{2}$ vulnerability is related to autonomic hyperactivity and respiratory symptoms in SAD.

The present results should be viewed in light of several limitations. First, the sample size of the present $\mathrm{CO}_{2}$-experiment was rather small, therefore the possibility of a Type 2 error cannot be excluded. However, this was the reason for the meta-analyses, which support our experimental results. Second, assessment instruments were those from previous $\mathrm{CO}_{2}$ studies (VAS and PSL) and these do not include specific social anxiety symptoms. Nevertheless, VAS and PSL have been shown to be reliable tools for investigating biological $\mathrm{CO}_{2}$ sensitivity (Rassovsky \& Kushner, 2003). Finally, it should be acknowledged that the present meta-analyses only addressed the $35 \% \mathrm{CO}_{2}$-challenge. The reason for this were the methodological differences with other challenges (Blechert, et al., 2010; Holt \& Andrews, 1989a, 1989b; Rapee, Brown, Antony, \& Barlow, 1992). Moreover, one of the $35 \% \mathrm{CO}_{2}$ studies lacked data on $\mathrm{CO}_{2}$-induced changes in fear and panic symptomatology (Caldirola, et al., 1997) and therefore could not be included in the respective meta-analyses.

In conclusion, neither our experiment, nor the meta-analyses found evidence for an exaggerated $35 \% \mathrm{CO}_{2}$-sensitivity in $\mathrm{SAD}$ as is known in PD. The $\mathrm{CO}_{2}$-elicited panic rate of SAD patients appears intermediate, in between PD patients and non-anxious individuals. The results generally suggest that the pathogenesis of SAD is different from PD. 


\section{References}

American Psychiatric Association (2000). Diagnostic and Statistical Manual of Mental Disorders. Fourth edition, text revised: Washington, DC: American Psychiatric Association.

Anderson, E. R., \& Hope, D. A. (2009). The relationship among social phobia, objective and perceived physiological reactivity, and anxiety sensitivity in an adolescent population. J Anxiety Disord, 23(1), 18-26.

Blechert, J., Wilhelm, F. H., Meuret, A. E., Wilhelm, E. M., \& Roth, W. T. (2010). Respiratory, autonomic, and experiential responses to repeated inhalations of $20 \% \mathrm{CO}(2)$ enriched air in panic disorder, social phobia, and healthy controls. Biol Psychol, 84(1), 8.

Caldirola, D., Perna, G., Arancio, C., Bertani, A., \& Bellodi, L. (1997). The $35 \% \mathrm{CO}_{2}$ challenge test in patients with social phobia. Psychiatry Res, 71(1), 41-48.

Clark, D. M., \& Wells, A. (1995). A cognitive model of social phobia. In R. G. Heimberg, M. R. Liebowitz, D. A. Hope \& F. R. Schneier (Eds.), Social phobia: Diagnosis, assessment, and treatment (pp. 41-68). New York: Guilford Press.

Colasanti, A., Salamon, E., Schruers, K., van Diest, R., van Duinen, M., \& Griez, E. J. (2008). Carbon dioxide-induced emotion and respiratory symptoms in healthy volunteers. Neuropsychopharmacology, 33(13), 3103-3110.

Craske, M. G. (1991). Phobic fear and panic attacks: the same emotional states triggered by different cues? Clinical Psychology Review 11(5), 22.

Craske, M. G., \& Sipsas, A. (1992). Animal phobias versus claustrophobias: exteroceptive versus interoceptive cues. Behav Res Ther, 30(6), 569-581.

Dillon, D. J., Gorman, J. M., Liebowitz, M. R., Fyer, A. J., \& Klein, D. F. (1987). Measurement of lactate-induced panic and anxiety. Psychiatry Res, 20(2), 97105.

Esquivel, G., Schruers, K. R., Maddock, R. J., Colasanti, A., \& Griez, E. J. (2010). Acids in the brain: a factor in panic? J Psychopharmacol, 24(5), 639-647.

Freire, R. C., Lopes, F. L., Valenca, A. M., Nascimento, I., Veras, A. B., Mezzasalma, M. A., et al. (2008). Panic disorder respiratory subtype: a comparison between responses to hyperventilation and $\mathrm{CO}_{2}$ challenge tests. Psychiatry Res, 157(1-3), 307-310.

Freire, R. C., Perna, G., \& Nardi, A. E. (2010). Panic disorder respiratory subtype: psychopathology, laboratory challenge tests, and response to treatment. Harv Rev Psychiatry, 18(4), 220-229.

Fyer, M. R., Uy, J., Martinez, J., Goetz, R., Klein, D. F., Fyer, A., et al. (1987). $\mathrm{CO}_{2}$ challenge of patients with panic disorder. Am J Psychiatry, 144(8), 1080-1082. 
Gelernter, C. S., Stein, M. B., Tancer, M. E., \& Uhde, T. W. (1992). An examination of syndromal validity and diagnostic subtypes in social phobia and panic disorder. $J$ Clin Psychiatry, 53(1), 23-27.

Gibbons, R. D., Hedeker, D. R., \& Davis, J. M. (1993). Estimation of effect size from a series of experiments involving paired comparisons. Journal of Educational Statistics, 18(3), 271-279.

Gorman, J. M., Papp, L. A., Martinez, J., Goetz, R. R., Hollander, E., Liebowitz, M. R., et al. (1990). High-dose carbon dioxide challenge test in anxiety disorder patients. Biol Psychiatry, 28(9), 743-757.

Graeff, F. G., \& Del-Ben, C. M. (2008). Neurobiology of panic disorder: from animal models to brain neuroimaging. Neurosci Biobehav Rev, 32(7), 1326-1335.

Griez, E., de Loof, C., Pols, H., Zandbergen, J., \& Lousberg, H. (1990). Specific sensitivity of patients with panic attacks to carbon dioxide inhalation. Psychiatry Res, 31(2), 193-199.

Griez, E., \& Schruers, K. (1998). Experimental pathophysiology of panic. J Psychosom Res, 45(6), 493-503.

Griez, E., \& Schruers, K. (2003). Mechanisms of $\mathrm{CO}_{2}$ challenges. J Psychopharmacol, 17(3), 260-262; discussion 267-268.

Griez, E. J., Colasanti, A., van Diest, R., Salamon, E., \& Schruers, K. (2007). Carbon dioxide inhalation induces dose-dependent and age-related negative affectivity. PLoS One, 2(10), e987.

Griez, E. J., Lousberg, H., van den Hout, M. A., \& van der Molen, G. M. (1987). $\mathrm{CO}_{2}$ vulnerability in panic disorder. Psychiatry Res, 20(2), 87-95.

Heimberg, R. G., Hope, D. A., Dodge, C. S., \& Becker, R. E. (1990). DSM-III-R subtypes of social phobia. Comparison of generalized social phobics and public speaking phobics. J Nerv Ment Dis, 178(3), 172-179.

Hodges, M. R., \& Richerson, G. B. (2010). Medullary serotonin neurons and their roles in central respiratory chemoreception. Respir Physiol Neurobiol, 173(3), 256-263.

Hofmann, S. G., Newman, M. G., Ehlers, A., \& Roth, W. T. (1995). Psychophysiological differences between subgroups of social phobia. J Abnorm Psychol, 104(1), 224231.

Holt, P. E., \& Andrews, G. (1989a). Hyperventilation and anxiety in panic disorder, social phobia, GAD and normal controls. Behav Res Ther, 27(4), 453-460.

Holt, P. E., \& Andrews, G. (1989b). Provocation of panic: three elements of the panic reaction in four anxiety disorders. Behav Res Ther, 27(3), 253-261.

LeDoux, J. E. (2000). Emotion circuits in the brain. Annu Rev Neurosci, 23, 155-184.

Maren, S. (2009). An acid-sensing channel sows fear and panic. Cell, 139(5), 867-869. 
Marks, I. M., \& Mathews, A. M. (1979). Brief standard self-rating for phobic patients. Behav Res Ther, 17(3), 263-267.

McTeague, L. M., Lang, P. J., Laplante, M. C., Cuthbert, B. N., Strauss, C. C., \& Bradley, M. M. (2009). Fearful imagery in social phobia: generalization, comorbidity, and physiological reactivity. Biol Psychiatry, 65(5), 374-382.

Papp, L. A., Klein, D. F., Martinez, J., Schneier, F., Cole, R., Liebowitz, M. R., et al. (1993). Diagnostic and substance specificity of carbon-dioxide-induced panic. Am J Psychiatry, 150(2), 250-257.

Perna, G., Bertani, A., Arancio, C., Ronchi, P., \& Bellodi, L. (1995). Laboratory response of patients with panic and obsessive-compulsive disorders to $35 \% \mathrm{CO}_{2}$ challenges. Am J Psychiatry, 152(1), 85-89.

Perna, G., Gabriele, A., Caldirola, D., \& Bellodi, L. (1995). Hypersensitivity to inhalation of carbon dioxide and panic attacks. Psychiatry Res, 57(3), 267-273.

Pols, H., Verburg, K., Hauzer, R., Meijer, J., \& Griez, E. (1996). Alprazolam premedication and $35 \%$ carbon dioxide vulnerability in panic patients. Biol Psychiatry, 40(9), 913-917.

Rapee, R. M., Brown, T. A., Antony, M. M., \& Barlow, D. H. (1992). Response to hyperventilation and inhalation of $5.5 \%$ carbon dioxide-enriched air across the DSM-III-R anxiety disorders. J Abnorm Psychol, 101(3), 538-552.

Rassovsky, Y., \& Kushner, M. G. (2003). Carbon dioxide in the study of panic disorder: issues of definition, methodology, and outcome. J Anxiety Disord, 17(1), 1-32.

Reed, V., \& Wittchen, H. U. (1998). DSM-IV panic attacks and panic disorder in a community sample of adolescents and young adults: how specific are panic attacks? J Psychiatr Res, 32(6), 335-345.

Richerson, G. B. (2004). Serotonergic neurons as carbon dioxide sensors that maintain pH homeostasis. Nat Rev Neurosci, 5(6), 449-461.

Salanti, G., Higgins, J. P., Ades, A. E., \& loannidis, J. P. (2008). Evaluation of networks of randomized trials. Stat Methods Med Res, 17(3), 279-301.

Schruers, K., Esquivel, G., van Duinen, M., Wichers, M., Kenis, G., Colasanti, A., et al. (2011). Genetic moderation of $\mathrm{CO}_{2}$-induced fear by 5-HTTLPR genotype. J Psychopharmacol, 25(1), 37-42.

Schruers, K., Klaassen, T., Pols, H., Overbeek, T., Deutz, N. E., \& Griez, E. (2000). Effects of tryptophan depletion on carbon dioxide provoked panic in panic disorder patients. Psychiatry Res, 93(3), 179-187.

Sheehan, D. V., Lecrubier, Y., Sheehan, K. H., Amorim, P., Janavs, J., Weiller, E., et al. (1998). The Mini-International Neuropsychiatric Interview (M.I.N.I.): the development and validation of a structured diagnostic psychiatric interview for DSM-IV and ICD-10. J Clin Psychiatry, 59 Suppl 20, 22-33;quiz 34-57. 
Spector, I. P., Pecknold, J. C., \& Libman, E. (2003). Selective attentional bias related to the noticeability aspect of anxiety symptoms in generalized social phobia. $J$ Anxiety Disord, 17(5), 517-531.

Spielberger, C. D. (1983). Manual for the State-Trait Anxiety Inventory. Palo Alto, CA: Consulting Psychologists Press.

van Duinen, M., Rickelt, J., \& Griez, E. (2008). Validation of the electronic Visual Analogue Scale of Anxiety. Prog Neuropsychopharmacol Biol Psychiatry, 32(4), 1045-1047.

Verburg, C., Griez, E., \& Meijer, J. (1994). A 35\% carbon dioxide challenge in simple phobias. Acta Psychiatr Scand, 90(6), 420-423.

Ziemann, A. E., Allen, J. E., Dahdaleh, N. S., Drebot, II, Coryell, M. W., Wunsch, A. M., et al. (2009). The amygdala is a chemosensor that detects carbon dioxide and acidosis to elicit fear behavior. Cell, 139(5), 1012-1021. 


\section{Chapter 4}

\section{Reduced Recognition of Anger and Disgust in Social Anxiety Disorder}

Barbara Montagne, Sara Schutters, Herman G. Westenberg, Jack van Honk, Roy P. Kessels, Edward H. de Haan (2006) 



\section{Abstract}

\section{Introduction}

The aim of this study was to investigate the recognition of facial expressions in patients with generalized social anxiety disorder. It is well documented that in different psychiatric disorders (e.g. depression, schizophrenia), patients may show an altered processing of emotions. However, in generalized social anxiety, emotion recognition has not been studied.

\section{Methods}

24 Patients with generalized social anxiety disorder and 26 healthy controls, matched on age, education and sex were included. The task entailed the emotional labelling of faces with different facial expressions (happiness, fear, disgust, sadness, surprise, anger) presented in different intensities. Subjects were asked to make a forced-choice response.

\section{Results}

Patients with generalized social anxiety disorder were less sensitive for the negative facial expressions of anger and disgust compared to the control group.

\section{Conclusion}

This deficit in emotion recognition could play a role in the development and/or the maintainance of social anxiety disorder. 


\section{Introduction}

Patients suffering from social anxiety disorder are typically afraid of negative evaluations by others, as well as of being humiliated in front of others. Social anxiety disorder was formally classified as an anxiety disorder in 1980 in the DSM-III (American Psychiatric Association, 1980). A distinction can be made between two different types of social anxiety disorder. The generalized type refers to individuals whose fears are evident in most social situations. The more restricted non-generalized type describes individuals who exhibit less fear, and the fear reactions are in specific situations such as public speaking or entering a room full of people. Both forms of social anxiety disorder have a profound impact on daily social life. In addition, patients often report high levels of depression (Schneier, Johnson, Hornig, Liebowitz, \& Weissman, 1992; Stein, Tancer, Gelernter, Vittone, \& Uhde, 1990), as well as high anxiety levels (Beidel \& Turner, 1988). Cognitive theories of emotional disorders suggest that dysfunction in information processing plays an important role in the maintenance of social anxiety disorder and possibly also in its development (Williams, Watts, MacLeod, \& Mathews, 1997). More specifically, two models have been postulated.

The first model by Rapee and Heimberg (1997) starts with saying that patients with social anxiety disorder assume that others are extremely critical, and these patients are focused on being positively appraised by others. During a social event they tend to focus on salient, mostly negative aspects of themselves and on signs of negative appraisal from the environment. The likelihood of negative evaluation by the audience depends on the discrepancy between the perceived appraisal of the audience and the standards one thinks the audience holds. The predicted negative evaluation elicits anxiety, which in turn negatively influences the mental representations one has about oneself. In contrast, Clark and Wells' model (Clark \& McManus, 2002) describes the processes that occur when patients with social anxiety disorder enter a social situation they are afraid of. Their model highlights that patients with social anxiety disorder have developed, on the basis of early experience, negative assumptions about themselves and their social environment, consequently patients appraise social situations as dangerous and they become anxious. This anxiety and negative assumptions are continued by vicious circles. For example, patients shift attention away from social situations and become highly self-focused. They then use their negative internal assumptions about themselves to evaluate how they appear to others. Furthermore, they develop safety strategies to prevent the feared situations to occur, however, those strategies maintain the negative assumptions, because the patient attributes the nonoccurrence of the situation to the strategy and not themselves. Finally, patients with social anxiety disorder are biased for detecting negative responses from others. The central characteristics 
of both theories are the focusing of patients on negative evaluations in their social environment and the enhanced attention directed towards themselves.

Research has focused on several biases in social anxiety disorder. Some studies investigating attentional biases found no bias towards threatening faces, while others found an attentional bias away from threatening faces (Asmundson, Stein, Larsen, \& Walker, 1994; Bradley, Mogg, \& Lee, 1997; Chen, Ehlers, Clark, \& Mansell, 2002; Mansell, Clark, Ehlers, \& Chen, 1999; Mogg, Philippot, \& Bradley, 2004). These results partly support the suggestion that patients with social anxiety disorder have a twofold reaction to the stimulus of their phobia (Craske, Street, Jayaraman, \& Barlow, 1991). Initially, there is a perceptual shift towards the stimulus, which is followed by a conscious attempt to avoid it.

Although, the advantage of angry face detection in a search task is not unique to social anxiety (Fox, et al., 2000; Ohman, Lundqvist, \& Esteves, 2001), patients with social anxiety tend to be more accurate at detecting negative events, even compared to nonanxious control subjects (Gilboa-Schechtman, Foa, \& Amir, 1999; Veljaca \& Rapee, 1998 ) and showed a memory bias for negative emotional events and (negative) emotional faces (Foa, Gilboa-Schechtman, Amir, \& Freshman, 2000; Lundh \& Ost, 1996). These findings are in line with findings of studies investigating an interpretation bias in patients with social anxiety disorder.

It has been demonstrated (Amin, Foa, \& Coles, 1998; Stopa \& Clark, 2000) that socially anxious patients show two clear biases. First, they tend to interpret socially ambiguous situations as negative, and second, they tend to catastrophise slightly negative situations, especially self-relevant situations. Looking at the interpretation of emotional faces, only one study by Winton, Clark, \& Edelmann (1995) has been reported. Their results showed a negative rating bias for briefly $(60 \mathrm{~ms})$ presented negative or neutral faces. Very recently Horley, Williams, Gonsalvez \& Gordon (2004) looked at perceptual scanning of facial expressions in patients with social anxiety disorder. They observed relatively fewer fixations to salient facial features (e.g. the eyes), and relatively more fixations to nonsalient features. The abnormal scan paths, in terms of number and duration of fixations, were more prominent for negative (sad) and neutral faces compared to positive (happy) faces. However, there seem to be major gaps in this field of research with respect to the way patients with social anxiety disorder interpret facial expressions. Especially given the assumption that cognitive processes play an important role in the development or maintenance of the disorder.

In addition, it is known that patients suffering from depression show a negative bias in recognising facial expressions, indicating that they perceive positively valenced faces as neutral and neutral faces as negative (Gur, et al., 1992; Mandal \& Bhattacharya, 1985). Such a bias can have profound effects on everyday-life perception of the 
external world. Furthermore, the identification of possible attentional biases using facial expressions as stimuli in patients with social anxiety disorder can aid the interpretation of the above-mentioned studies. To date, no published studies on the recognition of facial expressions of patients with social anxiety disorder exist. Hence, the aim of this study is to fill this gap and investigate the recognition of the facial expressions of anger, disgust, fear, happiness, sadness, and surprise, presented in different intensities to patients with a generalized social anxiety disorder, compared to a matched control group. We hypothesise that patients with a social anxiety disorder will show a deviated performance on the recognition of facial expressions, especially negative facial expressions, compared to a control group.

\section{Methods}

\section{Research Participants}

A total of 24 patients (10 males, 14 females) with the diagnosis of Social Anxiety Disorder, generalized type, according to the DSM-IV diagnostic criteria (American Psychiatric Association, 1994) and confirmed by the MINI-International Neuropsychiatric Interview (MINI) (Sheehan, et al., 1998), were recruited from the Anxiety Research Center at the Department of Psychiatry of the University Medical Center Utrecht, the Netherlands. Co-morbidity was excluded with the help of the MINI. Only patients with a score $<15$ on the Hamilton Depression Rating Scale (Lezak, Howieson, \& Loring, 2004) were recruited to exclude severe depressive symptoms. None of the patients was taking psychotropic medication from 4 weeks prior testing. The educational levels of all participants were recorded using 7 categories, 1 being the lowest educational level, 7 the highest (Hochstenbach, Mulder, van Limbeek, Donders, \& Schoonderwaldt, 1998). A total of 26 healthy participants (12 males, 14 females) were matched on age and educational level and included for control purposes. Control participants had no psychiatric history.

The medical ethics committee of the University Medical Center approved the study and written informed consents were obtained from all participants according to the Declaration of Helsinki. 


\section{Materials and Tests}

\section{Questionnaires}

The Beck Depression Inventory (BDI) (A. T. Beck, Ward, Mendelson, Mock, \& Erbaugh, 1961), a 21-item self-report questionnaire (scoring 0-63), was used to measure depressive symptoms. The Liebowitz Social Anxiety Scale (LSAS) (Liebowitz, 1987) consists of 24 situations in which subjects have to rate on a scale from 0 to 3 whether they find a specific situation anxious and whether they would avoid such a situation (scoring 0 144). The LSAS was administered to measure the severity of social anxiety and social avoidance. Carver and White's (1994) Behavioral Inhibition System (BIS)/ Behavioral Activation System (BAS) questionnaire is a 20-item self-report measure that corresponds to Gray's (Gray, 1987) notion of the BIS/BAS systems. The BIS scale is an index of sensitivity to threat and withdrawal-related behaviour, whereas the BAS scale assesses approach-related behaviour and sensitivity for reward.

\section{Emotion recognition task}

Stimuli for this test were based on colour pictures $(11.2 \times 11.7 \mathrm{~cm})$ from actors mimicking emotional expressions and a neutral face. There were four actors (two male, two female) who each posed six emotions (anger, disgust, fear, happiness, sadness and surprise). A computer-generated program, developed from algorithms designed by Benson \& Perrett (1991), was used to develop the stimuli. This program was devised to create intermediate morphed images between a neutral face ( $0 \%$ emotion) and a fullblown expression (100\% emotion) (Montagne, Kessels, Wester, \& de Haan, 2006). The original coloured pictures of the faces were manually delineated by 179 feature-points that define the shape of the important facial features (Rowland \& Perrett, 1995). For each expression, two photographs were available, the neutral expression and the fullblown expression. The intermediate expressions were constructed. This was done by generating 19 morphed images by calculating the difference in spatial position between two corresponding feature points in the neutral and full-blown expressions. In the morphed images, both the dimension of shape and texture underwent gradual transitions. These images were used to construct video clips that incrementally increase the degree of expression by $10 \%$ steps (see Figure 1). For each actor, nine video clips were constructed for each of the six emotions by increasing the number of morphed images presented in succession.

The presentation procedure was as follows. First, the subjects saw, in a random order, the video clips running from neutral to $20 \%$ expression of all six emotional expres- 
sions by all four actors. Subsequently, they saw video clips in which the expression changed from neutral to $30 \%$, etc., until they reached the final sequence of clips in which the neutral face changed into a full-blown expression. The duration of the animation in the video clips varied between approximately 0.5 seconds (low intensity) and 2 seconds (high intensity); after the animation the last frame remained on the screen until the subject made a response. In each trial, the subject was required to make a forced choice between one of six emotional expression labels that were displayed on the screen after the presentation of the video clip. There was no time restriction.

Figure 1. Emotion Recognition Task

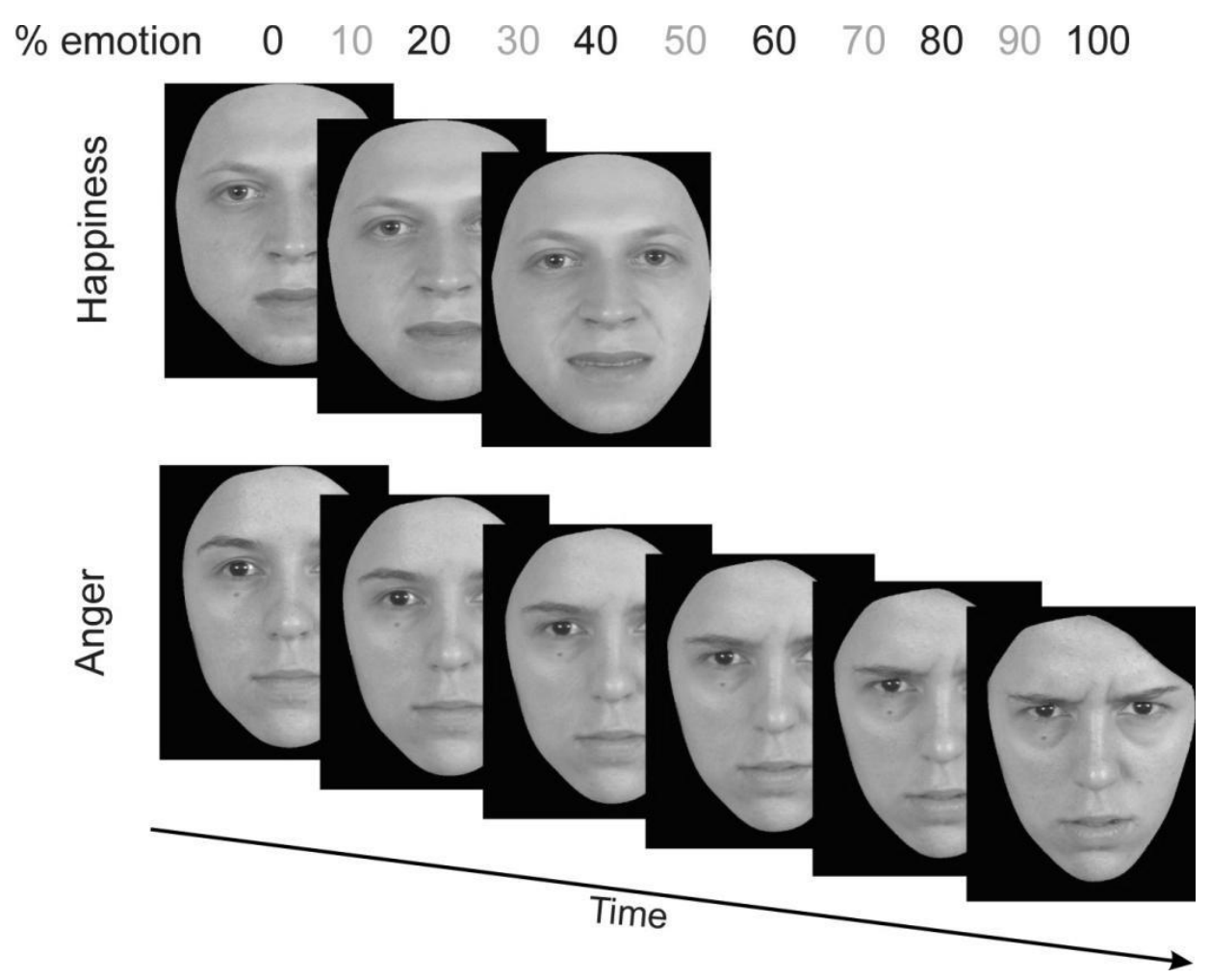


Benton Facial Recognition Test (short form)

The Benton and Van Allen (Benton, Sivan, deS Hamsher, Varney, \& Spreen, 1994) Test of Facial Recognition comprises a series of sheets containing a single photographed target face to be matched to a set of six face photographs. In the first six trials, an identical face has to be selected from among five decoys. In the remaining seven trials, three different views (changed in orientation or lighting conditions compared to the target photograph) have to be discriminated from three incorrect alternatives. The faces are physically similar, without spectacles or facial hair. Scoring ranges from 0 to 27.

\section{Procedure}

Patients were asked to participate by their treating therapist. The tests were presented to each subject in a fixed order. First, subjects were seated comfortably in front of a 17inch computer screen with a viewing distance of approximately $65 \mathrm{~cm}$ and asked to perform the emotional expression task. Participants performed four practice trials followed by the actual task. Subjects had to indicate which emotion they perceived from a set of six possible emotion labels (i.e., forced choice). There was no time restriction. Subsequently, the Benton Facial Recognition Test was administered and subjects were asked to fill out the questionnaires. The procedure was identical for the control subjects.

\section{Results}

\section{Questionnaires}

Table 1 shows the results for both groups on the questionnaires. Scores were analysed using independent samples t-tests. This revealed a significant difference between the patient group and the control group on the $\mathrm{BDI}, \mathrm{t}(46)=2.93, \mathrm{MSE}=0.81, \mathrm{p}=.005$, with the SA patients reporting more depressive symptoms than the controls. However, scores in both groups were below the clinical cut-off of 10 (Beck, Steer, \& Carbin, 1988). Furthermore, the patients scored higher than the controls on the LSAS, $t(43)=14.5, p<$ .001 , supporting the clinical diagnosis of social anxiety. Finally, the SA patients scored higher on the BIS scale than the controls, $\mathrm{t}(40)=3.8, \mathrm{p}<.001$, indicating that the patients show more behavioural inhibition. No group difference was found on the BAS scale, $\mathrm{t}(40)=1.5$. 
Table 1. Summary of patient $(n=24)$, control characteristics $(n=26)$, and performance on the Benton Face Recognition task, Beck Depression Inventory (BDI), Liebowitz Social Anxiety Scale (LSAS), and Behavioral Inhibition System (BIS)/Behavioral Activation System (BAS) scales.

\begin{tabular}{|c|c|c|c|c|}
\hline \multirow[b]{2}{*}{ Groups } & \multicolumn{2}{|c|}{ Social anxiety patients } & \multicolumn{2}{|c|}{ Control group } \\
\hline & M & SD & M & SD \\
\hline Age & 36.7 & 10.4 & 37.6 & 12.7 \\
\hline Sex (males:females) & \multicolumn{2}{|c|}{$(10: 14)$} & \multicolumn{2}{|c|}{$(12: 14)$} \\
\hline Education level & 5.8 & 0.8 & 6.2 & 0.8 \\
\hline Benton Face Recognition & 22.3 & 2.3 & 23.2 & 2.7 \\
\hline BDI & 7.0 & 6.5 & 2.6 & 3.5 \\
\hline LSAS & 69.7 & 15.6 & 13.1 & 10.4 \\
\hline BIS & 11.5 & 2.4 & 14.5 & 4.1 \\
\hline BAS & 26.8 & 6.4 & 24.0 & 5.6 \\
\hline
\end{tabular}

\section{Emotion Recognition Task}

Sensitivity score was defined as the lowest percentage of emotion expressed in the video clip from whenever the emotion was consistently recognised correctly. During the task, subjects saw all four actors making all six emotional expressions at all 9 intensity levels $(20,30,40,50,60,70,80,90,100)$. To determine the sensitivity, the nine trials of each actor were rank-ordered for each emotional expression. Subsequently, the intensity level was determined at which the first correct response was given that was followed by correct responses at all subsequent intensity levels. For example, if a subject gave a first correct response at the trial to $40 \%$, followed by a wrong response at the trial to $50 \%$, followed by correct responses at the trials to $60 \%, 70 \%, 80 \%, 90 \%$, and $100 \%$, the sensitivity level was determined at $60 \%$. This is the intensity level at which the subject gave a correct response and consistently recognised the emotional face correctly at the following trials. This procedure was selected to make sure subjects actually recognised the emotional face, making the chance of just a good guess as small as possible.

A $6 \times 2$ MANOVA was conducted with Expression (six levels: anger, disgust, fear, happiness, sadness, surprise) as within-subject factors and Group (two levels: patient, control) as between-subjects factor. This MANOVA revealed a main effect of Expression, $F(5,175)=48.6, \mathrm{MSE}=219.41, \mathrm{p}<.001)$ and interaction effects of Expression $\times$ Group, $F(5,175)=2.27, \mathrm{MSE}=219.41, \mathrm{p}<.05)$. When clustering the emotions into positive (happiness and surprise) and negative valence (anger, disgust, fear, sadness) emotions, Bonferroni-corrected post-hoc tests (alpha set at 0.025) showed a significant difference between the groups for the negative emotions, $t(48)=2,46, \mathrm{MSE}=1.7, \mathrm{p}=$ .018 , but not for the positive emotions, $\mathrm{t}(47)=0,60, \mathrm{MSE}=1.4, \mathrm{p}=.55$, with the social 
phobia patients being less sensitive to the negative emotions compared to the control subjects (see Figure 2). Independent sample t-tests showed a reduced Sensitivity in the patient group for the emotions Anger, $F(47)=2.53$, MSE $=2.7, p=.015$, and Disgust, $F(46)=2.33, \mathrm{MSE}=2.7, \mathrm{p}=.024$.

Figure 2. Sensitivity (including standard deviations) for negative emotions (anger, disgust, fear, sadness) and positive emotions (happiness, surprise) between social anxiety patients $(n=24)$ and a matched control group $(n=26)$.

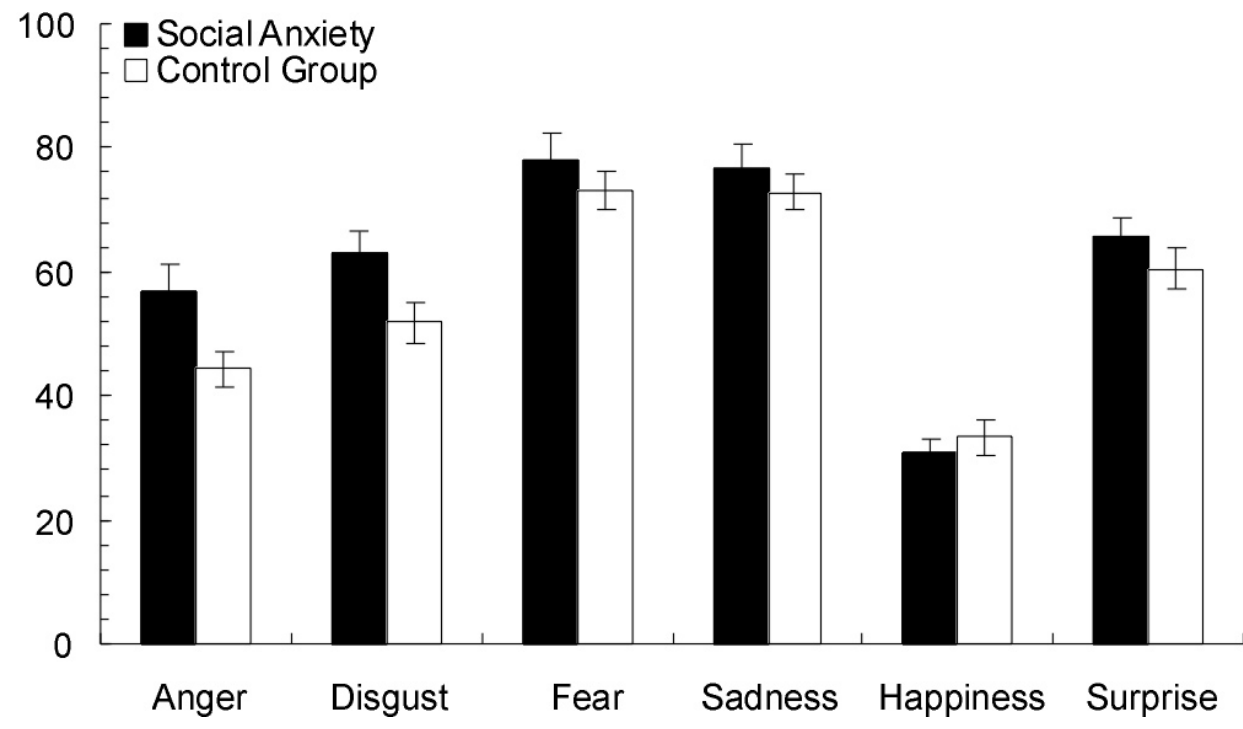

Correlations were calculated between the BDI and the overall sensitivity for negative emotions (Pearson's $r=706, p=.67$ ) and the overall sensitivity for positive emotions (Pearson's $r=.70, p=.64$ ); both were not significant. Error scores were calculated to look at the type of errors the participants made (see Table 2). Visual inspection of the error scores revealed no tendency for patients with a generalized social anxiety disorder to label happy faces as sad. In addition, no further support for a negative bias was found. 
Table 2. Percentage of error types for social anxiety patients $(n=24)$ and the control group $(n=26)$ for each emotion.

\begin{tabular}{|c|c|c|c|c|c|c|}
\hline \multirow[b]{2}{*}{$\begin{array}{l}\text { Emotional expression } \\
\text { shown on the face (\%) }\end{array}$} & \multicolumn{6}{|c|}{ Emotional expression chosen by the subject (\%) } \\
\hline & Anger & Disgust & Fear & Happiness & Sadness & Surprise \\
\hline \multicolumn{7}{|l|}{ Social anxiety patients } \\
\hline Anger & 69 & 8 & 3 & 3 & 6 & 10 \\
\hline Disgust & 25 & 58 & 2 & 3 & 7 & 5 \\
\hline Fear & 5 & 3 & 23 & 5 & 5 & 58 \\
\hline Happiness & 1 & 2 & 1 & 92 & 2 & 3 \\
\hline Sadness & 13 & 11 & 10 & 5 & 40 & 21 \\
\hline Surprise & 2 & 1 & 2 & 47 & 2 & 46 \\
\hline \multicolumn{7}{|l|}{ Controls } \\
\hline Anger & 75 & 5 & 5 & 3 & 5 & 7 \\
\hline Disgust & 25 & 60 & 3 & 4 & 5 & 3 \\
\hline Fear & 4 & 4 & 33 & 6 & 5 & 48 \\
\hline Happiness & 1 & 2 & 1 & 91 & 1 & 5 \\
\hline Sadness & 10 & 9 & 16 & 6 & 42 & 17 \\
\hline Surprise & 1 & 2 & 2 & 40 & 2 & 53 \\
\hline
\end{tabular}

Benton Facial Recognition Task

Scores were analysed using an independent sample T-test, which revealed no significant difference between the patient group and the control group $(\mathrm{t}(47)=1.24, \mathrm{MSE}=.37$, $p=0.22)$.

\section{Conclusions}

The aim of this study was to look at the explicit recognition of facial expressions in patients with generalized social anxiety disorder. Results show that patients were less sensitive in recognising negative facial expressions (anger, disgust, fear, sadness) compared to a control group, that is patients with generalized social anxiety disorder needed more information than control subjects in order to recognise facial expressions. There was no difference for the positive facial expressions (happiness, surprise) between the two groups. Since there is a specific impairment for the negative facial expressions and the patients displayed a normal performance on a test of face recognition, our main finding cannot be due to a general deficit in face perception. As the patient group did not suffer from comorbid depression and depressive symptoms in both patient and control group were minor, depressive symptoms are unlikely to have been 
a contributing factor. Furthermore, when we compare our results to the findings in depressed patients, it becomes apparent that patients with generalized social anxiety disorder show a qualitatively different pattern. Depressed patients have a negative response bias and are prone to regard happy faces as neutral and neutral faces as sad (e.g. (Gur, et al., 1992; Mandal \& Bhattacharya, 1985). This is in contrast to what we have found in patients with generalized social anxiety disorder. However, our findings partly counter the results of Sprengelmeyer et al. (1997) in patients suffering from panic disorder and generalized anxiety. They used the emotion hexagon task and found these two groups to outperform the controls in being hypersensitive for the facial expressions of anger and fear.

In trying to find out what the underlying process might be, we looked at the differences for the individual emotions between the patients with generalized social anxiety disorder compared to the control group. On two emotions, anger and disgust, the patients with generalized social anxiety disorder performed significantly worse. As the basic fear of this patient group is to be negatively evaluated by others, it is interesting that these two emotions specifically are concerned with interpersonal conflict or disapproval (Philippot, et al., 1999).

What could be the origin of our findings? On the one hand, the emotion perception deficit could be a consequence of the generalized social anxiety disorder. Ruiter \& Brosschot (1994) have suggested a twofold process in patients with social anxiety disorder in reaction to their feared stimulus. At the first stage of processing there is an attentional shift towards the stimulus, followed by a later stage in which the stimulus is avoided. Others have described the later process as cognitive avoidance (Craske, et al., 1991; Johnstone \& Page, 2004). The feared stimuli of the anxiety disorder of our patient group are faces looking disapproving, angry or disgusted, at the patients. The theory would predict an initial shift towards these faces, unconsciously, followed by a conscious shift away from these faces. The initial shift towards the stimulus was not measured, as it was not the aim of this study. However, the theory predicts patients with social anxiety disorder are very sensitive in recognising disapproving faces already in this initial unconscious stage, after recognition they disengage their attention from these faces and avoid looking at them. When asked to consciously process these faces, they will recognise these faces only when more emotional intensity is shown on the face. As a consequence, patients with social anxiety disorder will show results as if they are less sensitive for these faces, while they are probably highly sensitive.

Alternatively, social anxiety disorder can be the consequence of a deficit in recognising facial expressions. This suggests a specific deficit in recognising emotional facial expressions may underlie the social anxiety disorder itself. The inability to recognise angry and disgusted faces might result in a lack of self-confidence. This lack of self- 
confidence could play a role in the development of the social anxiety disorder. In addition, Clark and Wells's model (Clark \& McManus, 2002) suggests that patients with social anxiety disorder generally focus a lot of their attention towards themselves; this may interfere with the ability to interpret social feedback and as a consequence can have an influence on social performance. Consequently, negative beliefs about their own performance cannot be proven wrong (Spurr \& Stopa, 2002). Furthermore, subjects with social anxiety disorder believe they have poor social skills and the discrepancy between their own rating and the ratings of others concerning their performance is greater compared to the discrepancy found for a nonclinical control group (Rapee \& Lim, 1992). However, this model does not explain why patients with social anxiety disorder are not also less sensitive to other facial expressions.

The major strength of this study lies in the novelty of the results and the paradigm used. However, a few limitations have to be taken into consideration. First, the duration of the video clips took longer when the emotional intensity shown increased and it could be argued that video duration affected the results. However, this was done deliberately to make sure that subjects perceived each emotional change at the same rate. Also, the emotional face remained on the screen after the video clip until the subject made a response; there were no time restrictions. Second, the task design does not allow choosing "neutral" as the facial expression. Because we deliberately applied a forced-choice paradigm, a direct comparison with results from studies with depressive subjects is difficult. Furthermore, inclusion of patients with other anxiety disorders in future studies may give further insight into the differences and similarities in processing emotions in general or emotional faces specifically across the diagnostic boundaries of anxiety.

In conclusion, our data are the first to reveal selectively impaired recognition of negative emotional faces, specifically angry and disgusted faces, in patients with generalized social anxiety disorder in a nonanxious situation. This deficit could play a role in the development and/or the maintaining of the social anxiety. Future studies should further scrutinise this question.

\section{Acknowledgements}

Part of the data was presented at the First Congress of the European Neuropsychological Societies meeting in Modena, Italy (April 2004). This research was supported by grant 490-22-203 from the Dutch Organization of Scientific Research (NWO). Roy Kessels was supported by an NWO-VENI research grant (\#451-02-037) and Jack van Honk was supported by an Innovational Research Grant (\# 016-005-060) by NWO. 


\section{References}

American Psychiatric Association (1994). Diagnostic and Statistical Manual of Mental Disorders. Fourth edition: Washington, DC: American Psychiatric Association.

American Psychiatric Association (2000). Diagnostic and Statistical Manual of Mental Disorders. Fourth edition, text revised: Washington, DC: American Psychiatric Association.

Amin, N., Foa, E. B., \& Coles, M. E. (1998). Negative interpretation bias in social phobia. Behav Res Ther, 36(10), 945-957.

Asmundson, G. J., Stein, M. B., Larsen, D. K., \& Walker, J. R. (1994). Neurocognitive function in panic disorder and social phobia patients. Anxiety, 1(5), 201-207.

Beck, A. T., Steer, R. A., \& Carbin, M. G. (1988). Psychometric properties of the Beck Depression Inventory. Twenty-five years of evaluation. Clinical Psychological Review, 8(1), 24.

Beck, A. T., Ward, C. H., Mendelson, M., Mock, J., \& Erbaugh, J. (1961). An inventory for measuring depression. Arch Gen Psychiatry, 4, 561-571.

Beidel, D. C., \& Turner, S. M. (1988). Comorbidity of test anxiety and other anxiety disorders in children. J Abnorm Child Psychol, 16(3), 275-287.

Benson, P. J., \& Perrett, D. I. (1991). Synthesising continuous-tone caricatures. Image and Vision Computing, 9, 7.

Benton, A. L., Sivan, A. B., deS Hamsher, K., Varney, N. R., \& Spreen, O. (1994). Contributions to Neuropsychological Assessment. A Clinical Manual. (2nd ed.). New York: Oxford University Press.

Bradley, B. P., Mogg, K., \& Lee, S. C. (1997). Attentional biases for negative information in induced and naturally occurring dysphoria. Behav Res Ther, 35(10), 911-927.

Carver, C. S., \& White, T. L. (1994). Behavioral inhibition, behavioral activation, and affective responses to impending reward and punishment: The BIS/BAS scales. Journal of Personality and Social Psychology, 67, 319-333.

Chen, Y. P., Ehlers, A., Clark, D. M., \& Mansell, W. (2002). Patients with generalized social phobia direct their attention away from faces. Behav Res Ther, 40(6), 677-687.

Clark, D. M., \& McManus, F. (2002). Information processing in social phobia. Biol Psychiatry, 51(1), 92-100.

Craske, M. G., Street, L. L., Jayaraman, J., \& Barlow, D. H. (1991). Attention versus distraction during in vivo exposure: snake and spider phobias. Journal of anxiety disorders, 5(3), 13. 
de Ruiter, C., \& Brosschot, J. F. (1994). The emotional Stroop interference effect in anxiety: attentional bias or cognitive avoidance? Behav Res Ther, 32(3), 315319.

Foa, E. B., Gilboa-Schechtman, E., Amir, N., \& Freshman, M. (2000). Memory bias in generalized social phobia: remembering negative emotional expressions. J Anxiety Disord, 14(5), 501-519.

Fox, E., Lester, V., Russo, R., Bowles, R. J., Pichler, A., \& Dutton, K. (2000). Facial Expressions of Emotion: Are Angry Faces Detected More Efficiently? Cogn Emot, 14(1), 61-92.

Gilboa-Schechtman, E., Foa, E. B., \& Amir, N. (1999). Attentional biases for facial expressions in social phobia: The face-in-the-crowd paradigm. Cognition \& Emotion, 13(3), 305-318.

Gray, J. A. (1987). Problems in the behavioural sciences: Vol. 5. The psychology of fear and stress. (2nd ed.). New York: Cambridge University Press.

Gur, R. C., Erwin, R. J., Gur, R. E., Zwil, A. S., Heimberg, C., \& Kraemer, H. C. (1992). Facial emotion discrimination: II. Behavioral findings in depression. Psychiatry Res, 42(3), 241-251.

Hochstenbach, J., Mulder, T., van Limbeek, J., Donders, R., \& Schoonderwaldt, H. (1998). Cognitive decline following stroke: a comprehensive study of cognitive decline following stroke. J Clin Exp Neuropsychol, 20(4), 503-517.

Horley, K., Williams, L. M., Gonsalvez, C., \& Gordon, E. (2004). Face to face: visual scanpath evidence for abnormal processing of facial expressions in social phobia. Psychiatry Res, 127(1-2), 43-53.

Johnstone, K. A., \& Page, A. C. (2004). Attention to phobic stimuli during exposure: the effect of distraction on anxiety reduction, self-efficacy and perceived control. Behav Res Ther, 42(3), 249-275.

Lezak, M. D., Howieson, D. B., \& Loring, D. W. (2004). Neuropsychological assessment (4th ed.). New York: Oxford University Press.

Liebowitz, M. R. (1987). Social phobia. Mod Probl Pharmacopsychiatry, 22, 141-173.

Lundh, L. G., \& Ost, L. G. (1996). Recognition bias for critical faces in social phobics. Behav Res Ther, 34(10), 787-794.

Mandal, M. K., \& Bhattacharya, B. B. (1985). Recognition of facial affect in depression. Percept Mot Skills, 61(1), 13-14.

Mansell, W., Clark, D. M., Ehlers, A., \& Chen, Y. P. (1999). Social anxiety and attention away from emotional faces. Cognition \& Emotion, 13(6), 673-690.

Mogg, K., Philippot, P., \& Bradley, B. P. (2004). Selective attention to angry faces in clinical social phobia. J Abnorm Psychol, 113(1), 160-165. 
Montagne, B., Kessels, R. P., Wester, A. J., \& de Haan, E. H. (2006). Processing of emotional facial expressions in Korsakoff's syndrome. Cortex, 42(5), 705-710.

Ohman, A., Lundqvist, D., \& Esteves, F. (2001). The face in the crowd revisited: a threat advantage with schematic stimuli. J Pers Soc Psychol, 80(3), 381-396.

Philippot, P., Kornreich, C., Blairy, S., Baert, I., Den Dulk, A., Le Bon, O., et al. (1999). Alcoholics' deficits in the decoding of emotional facial expression. Alcohol Clin Exp Res, 23(6), 1031-1038.

Rapee, R. M., \& Heimberg, R. G. (1997). A cognitive-behavioral model of anxiety in social phobia. Behav Res Ther, 35(8), 741-756.

Rapee, R. M., \& Lim, L. (1992). Discrepancy between self- and observer ratings of performance in social phobics. J Abnorm Psychol, 101(4), 728-731.

Rowland, D. A., \& Perrett, D. I. (1995). Manipulating Facial Appearance through Shape and Color. leee Computer Graphics and Applications, 15(5), 70-76.

Schneier, F. R., Johnson, J., Hornig, C. D., Liebowitz, M. R., \& Weissman, M. M. (1992). Social phobia. Comorbidity and morbidity in an epidemiologic sample. Arch Gen Psychiatry, 49(4), 282-288.

Sheehan, D. V., Lecrubier, Y., Sheehan, K. H., Amorim, P., Janavs, J., Weiller, E., et al. (1998). The Mini-International Neuropsychiatric Interview (M.I.N.I.): the development and validation of a structured diagnostic psychiatric interview for DSM-IV and ICD-10. J Clin Psychiatry, 59 Suppl 20, 22-33; quiz 34-57.

Sprengelmeyer, R., Young, A. W., Pundt, I., Sprengelmeyer, A., Calder, A. J., Berrios, G., et al. (1997). Disgust implicated in obsessive-compulsive disorder. Proc Biol Sci, 264(1389), 1767-1773.

Spurr, J. M., \& Stopa, L. (2002). Self-focused attention in social phobia and social anxiety. Clin Psychol Rev, 22(7), 947-975.

Stein, M. B., Tancer, M. E., Gelernter, C. S., Vittone, B. J., \& Uhde, T. W. (1990). Major depression in patients with social phobia. Am J Psychiatry, 147(5), 637-639.

Stopa, L., \& Clark, D. M. (2000). Social phobia and interpretation of social events. Behav Res Ther, 38(3), 273-283.

Veljaca, K. A., \& Rapee, R. M. (1998). Detection of negative and positive audience behaviours by socially anxious subjects. Behav Res Ther, 36(3), 311-321.

Williams, J. M. G., Watts, F. N., MacLeod, C., \& Mathews, A. (1997). Cognitive psychology and the emotional disorders (2nd ed.). Chichester, UK: Wiley.

Winton, E. C., Clark, D. M., \& Edelmann, R. J. (1995). Social anxiety, fear of negative evaluation and the detection of negative emotion in others. Behav Res Ther, 33(2), 193-196. 


\section{Chapter 5}

\section{The association between Social Phobia, Social Anxiety Cognitions and Paranoid Symptoms}

Sara I.J. Schutters, Maria-de-Gracia Dominguez, Susanne Knappe, Roselind Lieb, Jim van Os, Koen R. J. Schruers, Hans-Ulrich Wittchen 



\begin{abstract}
Objective

Previous research suggests high levels of comorbidity between social phobia and paranoid symptoms, although the nature of this association remains unclear.

\section{Method}

Data were derived from the Early Developmental Stages of Psychopathology study, a 10-year longitudinal study in a representative German community sample of 3021 participants aged 14-24 years at baseline. The Munich-Composite International Diagnostic Interview was used to assess social phobia and paranoid symptoms, along with data on social phobia features. Cross-sectional and longitudinal analyses were conducted. Differential associations with environmental risk factors and temperamental traits were investigated.
\end{abstract}

\title{
Results
}

Lifetime social phobia and paranoid symptoms were associated with each other crosssectionally $(\mathrm{OR}=1.80,95 \% \mathrm{Cl}=1.31-2.47)$. Lifetime paranoid symptoms were associated specifically with social anxiety cognitions. Lifetime cognitions of negative evaluation predicted later onset of paranoid symptoms, whereas onset of social phobia was predicted by cognitions of loss of control and fear/avoidance of social situations. Lifetime social phobia and paranoid symptoms shared temperamental traits of behavioural inhibition, but differed in environmental risks.

\section{Conclusion}

The present study showed that paranoid symptoms and social phobia share similarities in cognitive profile and inhibited temperament. Avoidance appears to be important in the development of social phobia, whereas cannabis use and traumatic experiences may drive paranoid thinking in vulnerable individuals. 


\section{Significant outcomes}

- Social phobia and paranoid symptoms are non-randomly associated, which may be explained by shared cognitions of negative evaluation and temperamental vulnerability (behavioural inhibition).

- Environmental risks of victimization and cannabis use may increase the risk of paranoid symptoms in children with an inhibited temperament.

- Cognitions about negative evaluation may represent a suitable target for early identification of individuals at risk for paranoid symptoms.

\section{Limitations}

- The association between paranoid symptoms and social phobia was examined in the context of a large scale epidemiological study which was not explicitly designed for this purpose.

- Some key instruments used such as the Retrospective Self-Report of Inhibition are essentially self-report and may be subject to over-reporting.

- This was a population-based study combining clinical and subclinical levels of psychopathology; therefore to what degree the findings apply to clinical groups remains to be determined. 


\section{Introduction}

In the last decade, several studies have reported associations between social anxiety/phobia and paranoid symptoms (Gilbert, 2005; Huppert \& Smith, 2005; Michail \& Birchwood, 2009). In both conditions, individuals perceive threat and experience fear in relation to other people (Clark \& Wells, 1995; Freeman, Garety, Kuipers, Fowler, \& Bebbington, 2002), but their motives and thought contents appear to be different. Individuals with social phobia are afraid of negative evaluation by others. They typically worry that people would think they are dumb, weak or inadequate (American Psychiatric Association, 2000). Paranoid persons fear harm by others (Freeman \& Garety, 2000). They have ideations of being persecuted by people with bad intentions.

The cognitive model of Clark and Wells suggests that deviant processing of social threat cues plays a central role in the development and maintenance of social phobia (Clark \& Wells, 1995). The model postulates that social phobia patients have negative assumptions about themselves and their social environment, based on early experience. Consequently, social situations are appraised as dangerous resulting in anxiety. Patients shift their attention toward a detailed monitoring and observation of themselves, which reduces processing resources for monitoring external information. External monitoring is further reduced by safety behaviours such as avoidance of eye contact. Empirical evidence supports the role of biases in information processing in the development and maintenance of social phobia (Clark \& McManus, 2002; Heinrichs \& Hofmann, 2001). First, empirical studies suggest that cost and probability estimations of social events are biased (Foa, Franklin, Perry, \& Herbert, 1996; McManus, Clark, \& Hackmann, 2000). Second, studies investigating the interpretation of information demonstrated that patients interpret ambiguous social events in a negative fashion and mildly negative social events in a catastrophic fashion (Amir, Foa, \& Coles, 1998b; Stopa \& Clark, 2000). Third, empirical research has shown several attentional biases in individuals with social phobia direct their attention away from threatening faces (Amir, Elias, Klumpp, \& Przeworski, 2003; Chen, Ehlers, Clark, \& Mansell, 2002). Finally, there is evidence for safety behaviours in social phobia such as gaze aversion (Horley, Williams, Gonsalvez, \& Gordon, 2004). It is conceivable that severe avoidance behaviour and progressive distortion of information processing will drive paranoid thinking in subjects with social phobia; they may start thinking that others are really out to judge them negatively or to harm them.

In the cognitive model of Freeman and colleagues, persecutory delusions are conceptualized as threat beliefs, reflecting an interaction between psychotic processes, pre-existing beliefs and personality (particularly emotion), and the environment (Freeman, et al., 2002). It is emphasized that anxiety plays a major role in the formation 
and maintenance of paranoid thinking. Freeman and colleagues have provided empirical support for their theory in several virtual reality experiments and questionnaire studies in non-clinical samples (Freeman, Dunn, et al., 2005; Freeman \& Fowler, 2009; Freeman, Garety, Bebbington, Slater, et al., 2005; Freeman, Pugh, Vorontsova, Antley, \& Slater, 2010; Valmaggia, et al., 2007). These studies have shown that anxiety is a predictor of paranoid symptoms, which was also reported in a subsequent experience sampling study (Thewissen, et al., 2008). Furthermore, social anxiety and paranoid thoughts seem to share many of the same predictive factors such as anxiety, depression, worry and interpersonal sensitivity (Freeman, et al., 2008). Subjects with social phobia and individuals with paranoid symptoms also seem to have similar deficits in threat processing (Amir, Foa, \& Coles, 1998a; Bogels \& Mansell, 2004; Green \& Phillips, 2004). In addition, they may share temperamental vulnerability. Temperamental traits which are traditionally linked to social phobia are also seen in patients with a diagnosis of schizophrenia (Goldberg \& Schmidt, 2001; Stemberger, Turner, Beidel, \& Calhoun, 1995). Thus, "harm avoidance", a heritable tendency to respond intensely to aversive stimuli and to learn to avoid punishment, novelty, and non-reward passively (Cloninger, 1986), has repeatedly been associated with social phobia (Kennedy, Schwab, \& Hyde, 2001; Marteinsdottir, Tillfors, Furmark, Anderberg, \& Ekselius, 2003; Pelissolo, et al., 2002) and also, albeit less consistently, with psychosis (Hori, et al., 2008; Szoke, et al., 2002). "Behavioural inhibition", a temperament of reacting inhibited when confronted with novel situations or unfamiliar people, is typically associated with social phobia (Essex, Klein, Slattery, Goldsmith, \& Kalin; Hirshfeld-Becker, et al., 2008). To our knowledge, there are no published studies showing an association between behavioural inhibition and psychotic disorders or paranoid thinking.

(Proxy) environmental factors, such as trauma, cannabis use and an urban environment may cause differential expression of a certain trait. Both psychotic and anxiety disorders have been associated with trauma (Ellett, Freeman, \& Garety, 2008; Freeman \& Fowler, 2009; Gracie, et al., 2007; Hovens, et al., 2010; McCauley, et al., 1997; Scott, Chant, Andrews, Martin, \& McGrath, 2007; Shevlin, Dorahy, \& Adamson, 2007; van Os, Krabbendam, Myin-Germeys, \& Delespaul, 2005). Social phobia has been specifically associated with traumata in childhood, including separation from parents (Bandelow, et al., 2004), as well as emotional abuse and neglect (Kuo, Goldin, Werner, Heimberg, \& Gross, 2011). Psychotic symptoms have been associated with childhood trauma (Lardinois, Lataster, Mengelers, Van Os, \& Myin-Germeys, 2011; Read, van Os, Morrison, \& Ross, 2005), but also with traumatic events later in life (Gracie, et al., 2007; Shevlin, et al., 2007). It has been suggested that experience of trauma may be a predictor for onset of psychotic disorder in individuals with high levels of psychosis proneness (Bechdolf, et al., 2010). Cannabis use has often been linked with psychotic symptoms 
(Arseneault, Cannon, Witton, \& Murray, 2004; Estrada, et al., 2011; van Os, et al., 2005), as well as with anxiety disorders (van Laar, van Dorsselaer, Monshouwer, \& de Graaf, 2007; H. U. Wittchen, et al., 2007). The temporal order of the association, however, seems to differ in that anxiety disorders tend to precede cannabis use (Agosti, Nunes, \& Levin, 2002; H. U. Wittchen, et al., 2007), whereas psychosis is preceded by cannabis use (Arseneault, et al., 2004; Estrada, et al., 2011; Skinner, Conlon, Gibbons, \& McDonald, 2011). It is possible that cannabis use may induce paranoid thinking in patients with social phobia. Finally, an urban environment has been associated with paranoid symptoms (Ellett, et al., 2008; Spauwen, Krabbendam, Lieb, Wittchen, \& van Os, 2004; Sundquist, Frank, \& Sundquist, 2004; van Os, et al., 2005) and anxiety disorders (Peen, Schoevers, Beekman, \& Dekker, 2010), but, to our knowledge, not specifically with social phobia.

Based on the above psychological models (Clark \& Wells, 1995; Freeman, et al., 2002), one would hypothesize that social phobia precedes paranoid thinking, which is thought to build on emotional concerns (Freeman, Garety, Bebbington, Smith, et al., 2005). However, a recent longitudinal population study (Rietdijk, 2009) found an association between paranoid symptoms and later onset of social phobia, suggesting that paranoid thinking precedes the development of social phobia. With regard to the natural course of both conditions, this also appears counter-intuitive at first sight, given the early onset of social phobia in late childhood/early adolescence (Beesdo, et al., 2007; Knappe, Lieb, et al., 2009; H. U. Wittchen \& Fehm, 2003) and onset of psychotic disorders in late adolescence/early adulthood. However, some authors have suggested a bimodal onset of social phobia, which may account particularly for secondary social phobia in individuals with paranoid symptoms (Menezes, Fontenelle, \& Versiani, 2005). Furthermore, there is evidence for an extended psychosis phenotype in early adolescence (Verdoux, et al., 1998; Wigman, et al., 2009), suggesting that the onset of a psychotic disorder is preceded by expression of psychosis liability earlier in life, in the form of subclinical psychotic experiences. Therefore, the prospective association between paranoid symptoms and later onset of social phobia may be due to methodological issues; whereas the former is measured at the symptomatic level, the latter is assessed at "disorder" level (criteria of DSM-IV diagnosis). This procedure may have failed in detecting sub-syndromal social anxiety which precedes paranoid symptoms. Indeed, at the DSM diagnostic level, social phobia appears to be a risk factor for schizophrenia (Tien \& Eaton, 1992).

Disentangling the symptomatology of social phobia and its association with paranoid symptoms can help in clarifying the discrepancy between previous epidemiological findings and psychological models and therefore help in elucidating the nature of their comorbidity. Individuals with social phobia and paranoid symptoms both fear and avoid 
social contact. Therefore, it is conceivable that the co-occurrence of social phobia and paranoid symptoms is partly due to an overlap in emotional/behavioural symptomatology (fear and avoidance). One could expect less overlap in cognitive symptomatology because of the different focus of their thought contents (fear of negative evaluation versus fear of harm by others), although recent studies have found associations between social anxiety cognitions and delusional ideation (Kinoshita, et al.; Morrison \& Wells, 2007).

\section{Aims of the study}

Cross-sectional and longitudinal associations between social phobia and paranoid symptoms were examined at the DSM-IV diagnostic level of social phobia and at the symptomatic level of social phobia ( fear/avoidance of social situations and social anxiety cognitions). Furthermore, associations with environmental risk factors and temperamental correlates were studied, in an attempt to better understand putative pathways of either isolated or comorbid conditions.

\section{Method}

\section{Sample and Study Design}

Data were derived from the Early Developmental Stages of Psychopathology (EDSP) study, which collected data on the prevalence, incidence, risk factors, comorbidity, and course of substance use and other mental disorders in a random representative population sample of 3021 adolescents and young adults in the general population. The baseline sample, following ethics committee approval by the Ethics Committee of the Medical Faculty of the Technische Universitaet Dresden (No: EK-13811), was randomly drawn in 1994 from the respective population registry offices of Munich and its 29 counties, to mirror the distribution of individuals expected to be 14-24 years of age at the time of the baseline (TO) interview in 1995. As the primary goal of the study was to examine developmental aspects of psychopathology, the younger group (14-15 years) was sampled at twice the rate of persons aged 16-21 years, and the oldest group (22-24 years) was sampled at half this rate. After description of the study, all participants (and for those aged 18 or younger the parents) provided written informed consent.

The overall design of EDSP was observational, longitudinal and prospective, consisting of a baseline (T0: $n=3.021$; response rate $71 \%$ ) and three follow-up surveys (T1 $n=1.228$ (younger group only)); response rate=88\%, T2: $n=2.548$; response rate $=84 \%$ 
and T3: $n=2.210$; response rate $=73 \%$ ), covering a time period of on average 1.6 years (T0-T1, SD=0.2), 3.5 years (T0-T2, SD=0.3) and 8.4 years (T0-T3, range 7.3-10.5 years, $\mathrm{SD}=0.7$ ) respectively. The sample at $\mathrm{T} 1$ only included the younger members of the cohort; assessments at T0, T2 and T3 were based on the full sample. More details on the sampling, representativeness, instruments, procedures and statistical methods of the EDSP sample have previously been presented (Lieb, Isensee, von Sydow, \& Wittchen, 2000; Wittchen, Perkonigg, Lachner, \& Nelson, 1998).

\section{Instruments}

Composite International Diagnostic Interview.

Psychopathological and diagnostic assessments were based on the computer-assisted personal interview version of the Munich-Composite International Diagnostic Interview (DIA-X/M-CIDI) (Wittchen, Pfister H., 1997), a modified version of the World Health Organization (WHO) CIDI, version 1.2, supplemented by questions to cover DSM-IV criteria. The DIA-X/M-CIDI allows for the assessment of symptoms, syndromes and diagnosis of 48 mental disorders (based on DSM-IV algorithms) along with information about onset, duration, severity of symptoms and psychosocial impairment.

The instrument, designed for use by trained non-clinical interviewers, has shown high interrater (Wittchen, et al., 1991) and test-retest reliability (Reed, et al., 1998; Wittchen, 1994). However, the assessment of psychosis with CIDI by lay interviewers is not considered reliable (Wittchen, 1994). Therefore, in the EDSP Study, trained and experienced clinical interviewers at the level of psychologist conducted the interviews in the respondents' homes.

At baseline (TO for the social phobia module, T2 for the psychosis module), the MCIDI lifetime version was used. At each of the follow-up assessments, participants applied the interval version, which covers the period of assessment from the last interview until the next.

\section{Retrospective Self-Report of Inhibition}

Behavioral inhibition (BI) refers to a temperament or style of reacting that some infants and young children exhibit when confronted with novel situations or unfamiliar adults or peers. The Retrospective Self-Report of Inhibition (RSRI) (Reznick, Hegeman, Kaufman, Woods, \& Jacobs, 1992) is composed of a set of 30 questions about specific childhood behaviours reflecting $\mathrm{BI}$, defined as consistent restraint in response to both social and non-social situations (sympathetic nervous system activity, fear of things, 
etc.). Internal consistency of the total 30-item RSRI was found to be acceptable in clinical and non-clinical samples with a Cronbach coefficient $\alpha$ for the 30 questions of 0.77 or greater and median item-to-total correlations of $r \geq 0.31$. Validity was high as reflected by a strong agreement between individuals (self-report) and their parents (observer report) regarding the individual's inhibited behaviours as a child, a positive association between retrospective self-report and contemporary measures of inhibition, and explaining substantial variance in general and specific measures of mental health (Reznick, et al., 1992). Factor analysis repeatedly yielded two factors labelled 'social fears'(12 items) and 'general fearfulness and/or illness'(10 or 12 items) (Neal, Edelmann, \& Glachan, 2002; Reznick, et al., 1992; Rohrbacher, et al., 2008; Van Ameringen, Mancini, \& Oakman, 1998). These factors were not correlated significantly with each other, but were associated with the total RSRI scale $(r=.77, p<.01$ and $.65, p<$ .01 , respectively). Participants completed the German version of the RSRI at baseline (T0); higher scores indicate higher levels of BI. The psychometric properties of the German RSRI were found to be comparable to those of the English version (Rohrbacher, et al., 2008).

\section{Tridimensional Personality Questionnaire}

The Tridimensional Personality Questionnaire (TPQ) is a 100-item true-false selfquestionnaire developed by Cloninger to measure three dimensions of personality: Novelty Seeking, Harm Avoidance and Reward Dependence (Cloninger, 1987). Novelty Seeking is defined as the tendency toward the activation of behaviour such as exploratory activity in response to novelty, impulsive decision making, extravagance in approach to cues of reward, and quick loss of temper. Harm Avoidance is characterized by a tendency toward the inhibition or cessation of behaviours, such as pessimistic worry in anticipation of future problems, passive avoidant behaviours such as fear of uncertainty and shyness of strangers, and rapid fatigability. Reward Dependence is conceptualized as a tendency toward the maintenance of ongoing behaviour, and is exhibited as sentimentality, persistence, social attachment, and dependence on the approval of others. The German version of TPQ (Weyers, Krebs, \& Janke, 1995) has shown acceptable internal consistencies of the three dimensions with Cronbach coefficients of at least 0.75 . The intercorrelations of the dimensions were small, although the scales Novelty seeking and Harm avoidance were weakly negatively correlated. Factor analysis largely corroborated Cloninger's hypothesis of three independent dimensions, but the third factor represented the Reward dependence dimension only to a degree. Furthermore, Reward dependence showed only few and modest correlations with other personality traits, whereas Harm avoidance and Novelty seeking correlated strongly 
with distinct personality factors. Similar psychometric properties of TPQ have been reported by several other reliability and validity studies (Chen, Chen, Chen, Yu, \& Cheng, 2002; Clark \& Watson, 1995; Cloninger, 1987; Cloninger, Przybeck, \& Svrakic, 1991; Earleywine, Finn, Peterson, \& Pihl, 1992).

The German version of TPQ was administered at T3 with higher scores reflecting higher levels on the respective scales (Weyers, et al., 1995).

\section{Assessment of Paranoid symptoms}

CIDI data on psychotic symptoms and their clinical relevance were collected at T2 (lifetime version) and T3 (interval version). At both time points, paranoid symptoms were assessed with the four items concerning paranoid ideation in the DIA-X/M-CIDI psychosis section, as described by Rietdijk and colleagues (Rietdijk, 2009): "Have you ever been convinced that people were spying on you?" (item G1), "Has there ever been a period in which you were convinced that you were persecuted by people?" (item G2), "Have you ever been convinced that you were secretly tested on or that experiments were carried out on you?" (item G3), and "Have you ever been convinced that someone was conspiring against you, wanted to cause you harm or poison you?" (item G4). Each item was dichotomously defined as present or absent. The presence of paranoid symptoms was defined as any rating of "present" on any of the 4 items.

In order to qualify paranoid symptoms with respect to clinical relevance, items concerning dysfunction and help-seeking behaviour secondary to psychotic symptoms from the psychosis section of the DIA-X/M-CIDI were used. Two help-seeking items assessed whether participants had ever sought help because of symptoms: seeking doctors' help because of delusions (item G16), or seeking help from other mental health professionals ranging from general practitioner or school psychologist to psychiatric sheltered housing (item Q1DG). These items were rated: no (0) and yes (1). A dichotomous 'Helpseeking' variable was created indicating a positive answer to any of the 2 questions (value label: 1) versus negative answers on both (value label: 0). In addition, the dysfunction score of the psychosis $G$ section assessed the effect of psychotic experiences on (1) feeling upset, unable to work, go to places, or enjoy oneself, at the time of having these experiences (item G28), (2) being less able to work since these experiences began (item G29), (3) being less able to make friends or enjoy social relationships since these experiences began (item G29a), and (4) how much a participant's life and everyday activities were impaired when these experiences were at their worst (item G36). These 4 items were rated in a dichotomous manner (yes/no). A dichotomous variable 'Dysfunction' was constructed, representing a positive answer on any of the 4 questions (value label: 1 ) versus negative answers on all 4 questions (value label: 0 ). Subse- 
quently, a variable "Paranoid Impairment" was created (analogous to the "Psychotic Impairment' variable described by Dominguez and colleagues in an earlier report (Dominguez, Wichers, Lieb, Wittchen, \& van Os, 2009)), with rating "0" for participants with paranoid symptoms who scored " 0 " on both Help-seeking and Dysfunction, and "1" for participants scoring " 1 " on either or both.

Paranoid symptoms variables lifetime up to T2 and interval T2-T3

- Any Paranoid symptoms: A broad category of "Any Paranoid symptoms" was created, rated in a dichotomous manner: individuals with presence of paranoid symptoms (1) and individuals without paranoid symptoms (0).

- Lifetime cumulative incidence up to T2: endorsement of any lifetime paranoid symptom at T2 ("Any Paranoid symptoms up to T2")

- Interval cumulative rate T2-T3: endorsement at T3 of any paranoid symptom since T2 ("Any Paranoid symptoms T2-T3")

- Subclinical and Clinical Paranoid symptoms: "Subclinical Paranoid symptoms" was defined as the presence of paranoid symptoms without paranoid impairment whereas "Clinical Paranoid symptoms" was defined as the presence of paranoid symptoms with impairment. This differentiation was made only for the lifetime cumulative incidence up to $\mathrm{T} 2$.

\section{Assessment of Social Phobia}

CIDI data on social phobia were derived from the phobia and anxiety disorders section. At each time point, DSM-IV criteria of social phobia diagnosis were rated dichotomously as absent (0) versus present (1). To increase validity of the assessment, lists of social fear situations and cognitions were used in the EDSP Study (Wittchen, Stein, \& Kessler, 1999).

- DSM-IV criterion A (marked and persistent fear of social or performance situations in which the person is exposed to unfamiliar people or to possible scrutiny by others) was assessed with the stem question of the social phobia module (item D20): "ever having a persistent, irrational fear of, and compelling desire to avoid a situation in which the respondent attended social affairs, like going to a party or meeting". Participants were first shown a booklet to review visually seven situational clusters of situations along with more detailed examples.

- They were asked to give a concrete example for each item endorsed to allow for clarification (item D21). After at least one fear situation was elicited, a subsequent 
series of nine questions was used to elicit cognitive elements of anxiety such as fear of blushing, fear of acting in a way that might be humiliating, etc. (item D22).

- DSM-IV criterion B (exposure to the feared social situation almost invariably provokes anxiety, which may take the form of a situationally bound or situationally predisposed panic attack) was assessed by instructing participants to inspect a list of anxiety symptoms in the booklet and to indicate all symptoms of anxiety occurring in such situations (item D23). Because DSM-IV requires that cued anxiety reactions occur almost invariably, the DIA-X/M-CIDI algorithm required at least two such symptoms occurring 'almost always' when thinking about, or when being exposed to such situations.

- DSM-IV criterion C (the person recognizes that the fear is excessive or unreasonable) was assessed by asking the subject whether they considered either the anxiety or the avoidance to be excessive or unreasonable (item D25).

- DSM-IV criterion D (the feared social or performance situations are avoided or else are endured with intense anxiety or distress) was assessed by determining if the respondent frequently avoided the situations or, if not, endured the situations with distress (item D24).

- DSM-IV criterion E (the avoidance, anxious anticipation, or distress in the feared social or performance situation(s) interferes significantly with the person's normal routine, occupational (academic) functioning, or social activities or relationships, or there is marked distress about having the phobia) was assessed by determining if respondents reported that: (a) the social fears or avoidance interfered a lot with at least one of three social role areas (item D29); (b) they were persistently upset for a period of at least 1 month (item D27); or (c) they sought professional help for the fears (item Q1).

\section{Social Phobia variables lifetime up to T2 and interval T2-T3}

- Any Social Phobia: A broad category of "Any Social phobia" was defined as the presence of criteria A, B, C, D of the social phobia DIA-X/M-CIDI module. At each time point, "Any Social phobia" was rated in a dichotomous manner: individuals with presence of social phobia (1) and individuals without social phobia (0).

- Lifetime cumulative incidence up to T2: because lifetime data for the social phobia CIDI module were collected at TO whereas for the psychosis module this was done at T2, T0 and T2 variables of social phobia were pooled to produce comparable lifetime measures. Thus, the variable "Any Social phobia up to T2" was rated in a dichotomous manner: individuals with any social phobia at T0 or T2 (1) and individuals without social phobia both at T0 and T2 (0). 
- Interval cumulative rate T2-T3: the endorsement at T3 of any social phobia since T2 ("Any Social phobia T2-T3")

- Subclinical and Clinical Social Phobia: The category of "Subclinical social phobia" was used when meeting criteria for "Any Social Phobia" (criteria A, B, C, D) but not the impairment criterion E. For the category of "Clinical social phobia" all diagnostic criteria $(A-E)$ had to be met. This differentiation was made only for the lifetime measure Any Social phobia up to T2.

It should be noted that the construction of the social phobia variables is slightly different from previous publications (Knappe, Beesdo, Fehm, Lieb, \& Wittchen, 2009; Wittchen, et al., 1999). The rationale is that the focus of the present paper is the relation between two conditions which differ in reality testing; subjects with social phobia recognize their fear is excessive, whereas individuals with paranoid thinking believe their fear is justified. In this regard, it is important to ascertain that people with Any Social Phobia did meet criterion $C$ (the recognition that fear is excessive), and not just criterion $A$ and any 3 of the four other criteria ( $B, C, D, E)$, which was the definition for "subthreshold social phobia" in previous studies (Knappe, Beesdo, et al., 2009).

\section{Fear and avoidance of Social Situations}

In the DIA-X/M-CIDI module for Social Phobia, participants were shown a booklet with seven situational clusters of social situations and they were asked if they have ever had an unusually strong fear or avoidance of any of those situations (item D20): (1) eating or drinking where someone could watch you; (2) writing while someone watches; (3) going to a party or other social outing; (4) taking an important exam or interview for which you were well prepared; (5) taking part or speaking in a meeting or class; (6) talking to people because you might have nothing to say or might sound foolish; (7) any other situation where you could be the centre of attention. The seventh unspecified item was also included in analyses, in contrast to previous publications (Knappe, et al., 2010). Each item was dichotomously defined as present or absent. TO and T2 data of each item were pooled, creating a variable "Social situation lifetime up to T2", rated in a dichotomous manner: presence of the item at T0 or T2 (1) and absence of item at T0 and T2 (0).

\section{Social Anxiety Cognitions}

Whenever at least one fear situation was elicited in item D20, a subsequent series of nine questions was asked about cognitive elements of anxiety (item D22): "when you were in a situation where you could be the centre of attention or thought you would 
have to be, were you especially worried about (1) something embarrassing or shameful happening; (2) being regarded as dumb or weak; (3) being regarded as crazy; (4) experiencing an anxiety (panic) attack; (5) being confused; (6) being ashamed; (7) throwing up; (8) losing control over intestinal organs; or (9) running red in the face whenever one was in a social situation, thought about it, or was about to enter such a situation". Each item was dichotomously defined as present or absent. T0 and T2 data of each item were pooled, creating a variable "Social cognition lifetime up to T2", rated in a dichotomous manner: presence of the item at T0 or T2 (1) and absence of item at T0 and T2 (0).

\section{Assessment of Comorbidity}

In order to investigate the distribution of the syndromes and their comorbidity (lifetime measures at T2), three levels of comorbidity were distinguished:

- Group with Any Social Phobia up to T2 without Any Paranoid symptoms up to T2: "Only Social Phobia"

- Group with Any Paranoid symptoms up to T2 without Any Social Phobia up to T2: "Only Paranoid symptoms"

- Group with Any Social Phobia up to T2 and Any Paranoid symptoms up to T2: "Comorbid condition"

\section{Assessment of Temperamental traits}

For the assessment of Temperamental traits, the mean of the RSRI scale items was chosen as a general measure of Behavioral Inhibition; the three personality dimensions of the TPQ were also considered.

\section{Other Clinical Characteristics}

Environmental risk factors such as urbanicity, cannabis exposure and self-reported trauma were considered (for definitions, see Table 3), guided by previous work (Cougnard, et al., 2007; Dominguez, Can Saka, Lieb, Wittchen, \& van Os).

Other Delusions were assessed by the psychosis section of the DIA-X/M-CIDI, including 10 items: (1) conviction of being loved by a stranger (item G5) (2) can read thoughts (item G7), (3) can hear thoughts (item G8), (4) thoughts being heard by others (item G9), (5) controlled by force (item G10), (6) being given thoughts (item G11), (7) thoughts being taken (item G12), (8) messages specially directed at the person (item 
G13), (9) song or book directed specially at the person (item G13b) and (10) influenced by strange force (item G14). Each item was dichotomously coded as present or absent. T2 lifetime presence of other delusions was defined as any rating of "present" on any of the 10 delusional items.

Major depression was based on DSM-IV diagnostic algorithms of the DIA-X/M-CIDI diagnostic package. Because lifetime data for depression were collected at T0 whereas at T2 for the psychosis, T0 and T2 variables of depression were pooled to produce comparable lifetime measures (TO-T2). "Major depression up to T2" was rated in a dichotomous manner: individuals with major depression at T0 or T2 (1) and individuals without major depression at T0 and at T2 (0).

\section{Statistical Analysis}

All data were analysed using STATA statistical package, version 11 (StataCorp, College Station, Texas). No adjustment for multiple testing was applied, because the individual tests were related to individual hypotheses (see below) and adjustment would treat them as reflecting a global hypothesis which is questionable in substantive terms (Savitz \& Olshan, 1995).

First, lifetime cumulative incidence up to T2 and interval cumulative incidence estimates (T2-T3) of paranoid symptoms and social phobia constructs and their comorbidities (using lifetime measures up to T2) were calculated. The expected chance comorbidity rate was calculated as the product of their observed occurrence rates.

Second, in order to replicate the findings in the NEMESIS cohort (Rietdijk, 2009), cross-sectional and longitudinal associations between paranoid symptoms and social phobia constructs were examined using logistic regression (Odds Ratios, OR) analyses. Major depression was included as a covariate in these analyses, because depression has been linked to both social phobia (Keller, 2003; Wittchen \& Fehm, 2003) and paranoid symptoms (Ben-Zeev, Granholm, \& Cafri, 2009; Freeman, Dunn, et al., 2005).

Third, in order to further explore the links between paranoid symptoms and social phobia constructs, clinical dimensions of social phobia were obtained through principal component factor analysis of the seven D20 items (feared and/or avoided social situations) in combination with the nine D22 items (social anxiety cognitions) from the phobia and anxiety module of the CIDI. Varimax orthogonal rotation was used; resulting factors were selected on the basis of inspection of the screeplot and the criterion of value $\geq$ unity. Cross-sectional and longitudinal associations between these factors and paranoid symptoms and social phobia constructs were investigated by logistic regression. In order to investigate specificity of type of delusional ideation, it was examined to 
what degree factors that were associated with paranoid symptoms were similarly associated with other delusions.

Finally, multinomial logistic regression was applied to determine whether psychopathology groups (Only Social Phobia, Only Paranoid symptoms, Comorbid condition) differed by risk factor and correlate profile.

\section{Results}

\section{Descriptives of the Total Sample}

The sample at T2 consisted of 2548 participants with a mean age of 21.7 years (SD=3.4, range 17-28 years). Based on information obtained through German government population registries (at T0), 752 participants (29.5\%) lived in a rural environment, whereas 1796 (70.5\%) had an urban residence. Other demographic characteristics of this sample have previously been presented (Lieb, et al., 2000). In summary, there were 1297 men (50.9\%) and 1251 women (49.1\%). $12.8 \%$ of participants was attending secondary school, $25.6 \%$ attended university, while $36.2 \%$ was employed. The vast majority of participants were classified as (upper) middle class (85.8\%).

\section{Rates}

Four hundred participants (15.7\%) displayed lifetime Any Paranoid symptoms up to T2, of whom 238 (59.5\%) with Subclinical Paranoid symptoms and 162 (40.5\%) with Clinical Paranoid symptoms (i.e. presenting with impairment as defined earlier). The interval cumulative rate of Any Paranoid symptoms T2-T3 was 8.9\% (197 out of 2210); 111 (56.4\%) presented with Subclinical Paranoid symptoms and 86 (43.7\%) with Clinical Paranoid symptoms.

Lifetime cumulative incidence of Any Social Phobia up to T2 was 9.4\%; 239 participants of which 125 (52.3\%) reported Subclinical Social Phobia and 114 (47.7\%) Clinical Social Phobia. The interval cumulative rate of Any Social Phobia T2-T3 was 3.2\% (70 out of 2210 participants), of which 27 (38.6\%) presented with Subclinical Social Phobia and 43 (61.4\%) with Clinical Social Phobia.

At T2, 343 of the 2548 participants (13.5\%) met criteria for lifetime cumulative incidence of Only Paranoid symptoms and 182 (7.1\%) for Only Social Phobia, whereas 57 (2.2\%) met criteria for the Comorbid condition. The observed rate of the comorbid condition $(2.2 \%)$ was higher than the rate expected by chance $(1.5 \% ; \mathrm{N}=37$, calculated as $15.7 \% * 9.4 \%)$. 


\section{T2 Lifetime cross-sectional associations between Social Phobia and Paranoid symptoms}

Logistic regression (Odds Ratios, OR) analyses were carried out for Any Paranoid symptoms and Any Social Phobia, as well as for their separate Subclinical and Clinical constructs. Any Social Phobia up to T2 and Any Paranoid symptoms up to T2 were significantly associated with each other $(\mathrm{OR}=1.80,95 \% \mathrm{Cl}=1.31-2.47)$, which remained significant after adjustment for Major Depression $(\mathrm{OR}=1.49,95 \% \mathrm{Cl}=1.07-2.07)$. Clinical Social Phobia and Clinical Paranoid symptoms were also significantly associated with each other, $(\mathrm{OR}=2.63,95 \% \mathrm{Cl}=1.48-4.68)$, whereas Subclinical Social phobia and Paranoid symptoms were not $(\mathrm{OR}=1.25,95 \% \mathrm{Cl}=.69-2.27)$.

\section{T2-T3 Longitudinal Associations between Social Phobia and Paranoid symptoms}

Logistic regression was used to calculate (i) the association between Any Paranoid symptoms up to T2 and Any Social Phobia T2-T3, excluding participants with Any Social Phobia up to T2; and (ii) the association between Any Social Phobia up to T2 and Any Paranoid symptoms T2-T3 excluding participants with Any Paranoid symptoms up to T2.

The first prospective association between Any Paranoid symptoms and Any Social Phobia was significant $(\mathrm{OR}=2.11,95 \% \mathrm{Cl}=1.05-4.27)$; this association remained significant when controlling for Major Depression up to T2 (OR=2.10, 95\% Cl= 1.03-4.26).

The second prospective association between Any Social Phobia and Any Paranoid symptoms was not significant $(\mathrm{OR}=1.49,95 \% \mathrm{Cl}=.83-2.68)$.

\section{Factor analyses of Social Phobia Construct}

The principal component factor analysis revealed a unique factor for the seven D20 items ("Feared and/or Avoided Social Situations") from the social phobia module of the DIA-X/M-CIDI, whereas a two-factor structure was supported for the nine D22 items (social anxiety cognitions), accounting for $48 \%$ of the variance. The rotated solution revealed a number of strong loadings (Table 1). Five cognitions (items D22 (1), (2), (5), (6), and (9)), interpreted as cognitions concerning worry about negative evaluation by others, substantially loaded on factor 1, labelled "Negative Evaluation Cognitions" and accounting for $34 \%$ of variance. The remaining 4 cognitions (items D22 (3), (4), (7), and (8)) concerning worry about loss of control, loaded on factor 2, labelled "Loss of Control Cognitions", and accounted for $14 \%$ of the variance (Table 1 ). 
Table 1. Principal Component Factor analysis of Social Anxiety Cognitions and factor loading, after Varimax rotation

\begin{tabular}{|c|c|c|}
\hline Social Anxiety Cognition & $\begin{array}{c}\text { Factor } 1 \\
\text { "Negative } \\
\text { evaluation" }\end{array}$ & $\begin{array}{l}\text { Factor } 2 \\
\text { "Loss of } \\
\text { control" }\end{array}$ \\
\hline 1. Worry about something embarrassing or shameful could happen & .823 & .011 \\
\hline 2. Worry about being regarded as dumb or weak & .747 & .075 \\
\hline 3. Worry about being regarded as crazy & .258 & .351 \\
\hline 4. Afraid to experience an anxiety (panic) attack & .357 & .444 \\
\hline 5. Worry about being confused & .701 & .172 \\
\hline 6. Worry about being ashamed & .710 & .099 \\
\hline 7. Worry about having to throw up & .049 & .694 \\
\hline 8. Afraid to lose control over bladder/bowels & .006 & .660 \\
\hline 9. Afraid to blush & .762 & .038 \\
\hline
\end{tabular}

\section{Associations between Factors and Paranoid and Other Delusions}

Cross-sectional associations between the factors (lifetime up to T2) and lifetime Any Social phobia up to $\mathrm{T} 2$ and Any Paranoid symptoms up to T2 were examined (Table 2). Logistic regression analysis showed that Any Paranoid symptoms up to $\mathrm{T} 2$ was significantly associated with Negative Evaluation Cognitions ( $\mathrm{OR}=1.29,95 \% \mathrm{Cl}=1.12-1.48$ ), which remained significant after correction for possible confounding by Any Social Phobia up to $\mathrm{T} 2(\mathrm{OR}=1.31,95 \% \mathrm{Cl}=1.13-1.52)$ or Major depression up to $\mathrm{T} 2$; $\mathrm{OR}=1.22,95 \%$ $\mathrm{Cl}=1.06-1.41)$. Furthermore, the association was specific with regard to the content of the delusional ideation, as Other Delusions (Lifetime up to T2) were not associated with Negative Evaluation Cognitions, excluding participants with Any Paranoid symptoms up to $\mathrm{T} 2$ from the analysis ( $\mathrm{OR}=1.00,95 \% \mathrm{Cl}=.78-1.30$ ). 
Table 2. Associations between Factors "Feared and/or Avoided Social Situations", "Negative Evaluation Cognitions", "Loss of Control Cognitions" (Lifetime up to T2) and Lifetime/Incident Social Phobia and Paranoid symptoms

\begin{tabular}{lccc} 
& $\begin{array}{c}\text { Feared and/or } \\
\text { Avoided Social } \\
\text { Situations Lifetime } \\
\text { up to T2 }\end{array}$ & $\begin{array}{c}\text { Negative Evaluation } \\
\text { Cognitions Lifetime } \\
\text { up to T2 }\end{array}$ & $\begin{array}{c}\text { Loss of Control } \\
\text { Cognitions Lifetime } \\
\text { up to T2 }\end{array}$ \\
\hline $\begin{array}{l}\text { Cross-sectional association } \\
\text { Social Phobia lifetime up to T2 } \\
\text { (N= 239) }\end{array}$ & $1.16(.98-1.36)$ & $3.40(2.86-4.06)^{* * *}$ & $1.51(1.36-1.68)^{* * *}$ \\
$\begin{array}{l}\text { Paranoid symptoms lifetime } \\
\text { up to T2 (N= 400) }\end{array}$ & $1.14(.99-1.32)$ & $1.29(1.12-1.48)^{* * *}$ & $1.06(.96-1.16)$ \\
\hline $\begin{array}{l}\text { Longitudinal association } \\
\text { Incident Social Phobia T2-T3 }\end{array}$ & $1.62(1.16-2.26)^{* *}$ & $1.12(.75-1.66)$ & $1.26(1.02-1.55)^{*}$ \\
(N=70) \\
$\begin{array}{l}\text { Incident Paranoid symptoms } \\
\text { T2-T3 (N= 197) }\end{array}$
\end{tabular}

Odds ratio $(95 \% \mathrm{Cl}) *=p<.05, * *=p<.01, * * *=p<.001$

Longitudinal Associations between Factors and Incident Paranoid symptoms and Social Phobia

Longitudinal associations of the factors (lifetime up to T2) with Any Paranoid symptoms T2-T3 and Any Social Phobia T2-T3 were investigated by logistic regression, excluding participants with Any Paranoid symptoms up to T2 and Any Social Phobia up to T2, respectively (Table 2). Negative Evaluation Cognitions predicted Any Paranoid symptoms $\mathrm{T} 2-\mathrm{T} 3(\mathrm{OR}=1.30,95 \% \mathrm{Cl}=1.01-1.66)$, which remained significant after adjustment for Any Social Phobia T2-T3 $(\mathrm{OR}=1.29,95 \% \mathrm{Cl}=1.01-1.65)$, and was slightly reduced after adjustment for Major depression up to T2 (OR=1.27, $95 \% \mathrm{Cl}=.99-1.61)$. There was no significant association between Negative Evaluation Cognitions and incident Other Delusions T2-T3 (OR=1.21, 95\% Cl=.94-1.56).

Any Social Phobia T2-T3 was predicted by Loss of Control Cognitions (OR=1.26, $95 \% \mathrm{Cl}=1.02-1.55)$, and by Feared and/or Avoided Social situations $(\mathrm{OR}=1.62,95 \% \mathrm{Cl}=$ 1.16-2.26). 


\section{Associations with Environmental risk factors and Temperamental traits}

Multinomial logistic regression was applied to investigate the risk factor and correlate profile of the three psychopathology groups (Only Social Phobia, Only Paranoid symptoms, Comorbid condition). The reference category was the remainder of the sample, i.e. the T2 sample excluding participants reporting Only Paranoid symptoms, Only Social Phobia or Comorbid condition (Table 3). Lifetime Only Paranoid symptoms were significantly associated with traumatic experiences, cannabis use, behavioural inhibition (mean RSRI, 'social fears' and 'general fearfulness/ illness') and novelty seeking, whereas lifetime Only Social Phobia was significantly associated with behavioural inhibition and harm avoidance. The Comorbid condition was significantly associated with trauma, cannabis use, behavioural inhibition and harm avoidance. 
Table 3. Association between Environmental Risk Factors, Temperamental correlates and Social Phobia/Paranoid Syndromes, Compared to the Remainder of Sample at T2.

\begin{tabular}{|c|c|c|c|c|c|c|}
\hline & \multicolumn{2}{|c|}{$\begin{array}{l}\text { Only Paranoid symptoms } \\
\qquad(\mathrm{N}=343)\end{array}$} & \multicolumn{2}{|c|}{$\begin{array}{l}\text { Only Social Phobia } \\
\qquad(\mathrm{N}=182)\end{array}$} & \multicolumn{2}{|c|}{$\begin{array}{l}\text { Comorbid condition } \\
\qquad(\mathrm{N}=57)\end{array}$} \\
\hline & $\begin{array}{l}\text { Relative } \\
\text { Risk }\end{array}$ & $95 \% \mathrm{Cl}$ & $\begin{array}{l}\text { Relative } \\
\text { Risk }\end{array}$ & $95 \% \mathrm{Cl}$ & $\begin{array}{l}\text { Relative } \\
\text { Risk }\end{array}$ & $95 \% \mathrm{Cl}$ \\
\hline \multicolumn{7}{|l|}{ Environmental risk factors } \\
\hline Urbanicity $^{a}$ & 1.14 & $.88-1.47$ & 1.10 & $.79-1.54$ & 1.01 & $.57-1.79$ \\
\hline Trauma $^{b}$ & $1.44^{*}$ & $1.14-1.82$ & 1.07 & $.79-1.45$ & $2.27^{*}$ & $1.27-4.06$ \\
\hline Cannabis use $\mathrm{c}^{\mathrm{C}}$ & $1.68 * *$ & $1.29-2.18$ & .83 & $.55-1.25$ & $2.12^{*}$ & $1.21-3.73$ \\
\hline \multicolumn{7}{|l|}{ Temperamental correlates } \\
\hline Behavioural Inhibition $^{d}$ & $2.42 * *$ & $1.69-3.46$ & $11.74 * *$ & $7.56-18.22$ & $26.22 * *$ & $13.40-51.28$ \\
\hline Novelty Seeking ${ }^{\mathrm{e}}$ & $1.03^{*}$ & $1.00-1.06$ & .99 & $.96-1.02$ & 1.02 & $.96-1.09$ \\
\hline Harm Avoidance ${ }^{\mathrm{e}}$ & 1.01 & $.99-1.04$ & $1.09 * *$ & $1.06-1.12$ & $1.12^{* *}$ & $1.07-1.18$ \\
\hline
\end{tabular}

$*=p \leq .05, * *=p<.001$

The Remainder of the sample at $\mathrm{T} 2$ is the $\mathrm{T} 2$ sample $(\mathrm{N}=2548)$ excluding participants reporting lifetime Only Paranoia ( $N=343$ ), Only Social Phobia ( $N=182$ ) or Comorbid condition ( $N=57) ; N=1966$.

${ }^{a}$ Information obtained through German government population registries. The population density of Munich surroundings areas was 553 persons per square mile and that of the city 4061 persons per square mile.

b 'Self-reported trauma' at T2 (interval): any affirmative response of exposure to any of the 9 traumata from the Trauma module (CIDI item N1A), selected after visual presentation of a list of 9 groups of specified traumatic events such as physical threat, serious accident or sexual abuse.

${ }^{c}$ CIDI L-section cannabis use at T2 (interval): never (0), once (1), twice (2), thrice (3), four times (4), and five times or more (5). A dichotomous variable was created, defined as cannabis use of 5 times or more since the previous interview.

${ }^{\mathrm{d}}$ Behavioural inhibition assessed using Retrospective Self-Report of Inhibition

e Novelty seeking, Harm avoidance and Reward dependence assessed using Tridimensional Personality Questionnaire 
Supplemental comparisons between the Only Paranoid symptoms and the Only Social Phobia groups, using chi square tests (Table 4) showed no differences in urbanicity, self-reported trauma and reward dependence. The group with Only Social Phobia less often used cannabis, and showed a significantly higher mean 'social fears' and 'general fearfulness/illness' scores on the RSRI and a higher TPQ harm avoidance score, compared to the Only Paranoid symptoms group. TPQ novelty seeking score showed a trend for higher scores in Only Paranoid symptoms compared to Only Social Phobia $(p=.06)$.

Table 4. Comparison of Risk Factors and correlates in Only Paranoid symptoms and Only Social Phobia.

\begin{tabular}{|c|c|c|c|}
\hline & $\begin{array}{l}\text { Only Paranoid symptoms } \\
\qquad(\mathrm{N}=343)\end{array}$ & $\begin{array}{l}\text { Only Social Phobia } \\
\qquad(\mathrm{N}=182)\end{array}$ & $x^{2}$ \\
\hline \multicolumn{4}{|l|}{ Environmental risk factors } \\
\hline Urban $^{\mathrm{a}}$ & $72.6 \%$ & $72.0 \%$ & $<.1$ \\
\hline Exposure to Trauma & $60.6 \%$ & $53.3 \%$ & 2.6 \\
\hline Cannabis use $e^{c}$ & $28.9 \%$ & $16.8 \%$ & $9.0 * *$ \\
\hline \multicolumn{4}{|l|}{ Temperamental correlates } \\
\hline Behavioural Inhibition $^{d}$ & $2.1 \pm .3$ & $2.3 \pm .4$ & $36.5^{* * *}$ \\
\hline Novelty Seeking ${ }^{\mathrm{e}}$ & $17.3 \pm 5.1$ & $16.4 \pm 5.1$ & 3.6 \\
\hline Harm Avoidance ${ }^{\mathrm{e}}$ & $12.5 \pm 5.8$ & $15.1 \pm 6.8$ & $16.0 * * *$ \\
\hline Reward dependence $e^{e}$ & $18.2 \pm 4.3$ & $17.6 \pm 4.7$ & 1.56 \\
\hline
\end{tabular}

Mean \pm SD data are presented for continuous variables. Percentages are presented for categorical data.

$*=p \leq .05, * *=p<.01, * * *=p<.001$

${ }^{a}$ The German city of Munich

${ }^{\mathrm{b}}$ Any affirmative response of exposure to any of the 9 traumata from the Trauma module at T2 (DIA-X/M-CIDI item N1A), selected after visual presentation of a list of 9 groups of specified traumatic events such as physical threat, serious accident or sexual abuse.

${ }^{c}$ Cannabis use of 5 times or more since the previous interview.

${ }^{d}$ Behavioural inhibition per the Retrospective Self-Report of Inhibition

e Novelty seeking, Harm avoidance and Reward dependence assessed using Tridimensional Personality Questionnaire 


\section{Discussion}

The present general population study found a non-random co-occurrence of social phobia and paranoid symptoms, which is in accordance with the high rates of social phobia reported in patients with a diagnosis of schizophrenia (Braga, Mendlowicz, Marrocos, \& Figueira, 2005; Mazeh, et al., 2009; Pallanti, Quercioli, \& Hollander, 2004) and with associations between social anxiety and paranoid thinking previously found in clinical (Gilbert, 2005; Huppert \& Smith, 2005; Michail \& Birchwood, 2009) and epidemiological studies (Rietdijk, 2009). Moreover, the present results consistently showed that paranoid symptoms were associated with social phobia, both at the DSM-IV criterion level, and at the symptomatic level (social anxiety cognitions) whereas other delusions did not show these associations. On the one hand the association between paranoid symptoms and cognitions of negative evaluation is in line with recent findings of associations between worry about negative evaluation or social worry and delusional ideation (Kinoshita, et al.; Morrison \& Wells, 2007). Social anxiety, on the other hand, has been found to be correlated with feeling hostile toward others, and with hostile perceptions of others (DeWall, Buckner, Lambert, Cohen, \& Fincham). This indicates that paranoid symptoms and social phobia have links at the cognitive level, which may be mediated by shared alterations in the processing of threat (Amir, et al., 1998a; Bogels \& Mansell, 2004; Green \& Phillips, 2004).

Furthermore, the study confirmed the prospective association between paranoid symptoms and later onset of social phobia, as previously reported in the NEMESIS study (Rietdijk, 2009). However, this temporal association is not in line with the order proposed in psychological models (Clark \& Wells, 1995; Freeman, et al., 2002). Differences in conceptualisation and assessment may account for this counterintuitive temporal association; whereas paranoid symptoms were measured at the symptomatic level based on single experiences, social phobia was assessed at the "disorder" level (criteria for DSM-IV diagnosis). This methodological issue may also explain the higher rate of paranoid symptoms (15.7\%) compared to social phobia (9.4\%). When both syndromes were conceptualized at the symptomatic level, the temporal association was in the opposite direction: social anxiety cognitions (negative evaluation of self) predicted the onset of paranoid symptoms. This is in line with the psychological model of Freeman (Freeman, et al., 2002), in which paranoid ideations are thought to build upon common interpersonal anxieties and worries such as fears of rejection (Freeman, Garety, Bebbington, Slater, et al., 2005; Freeman, Garety, Bebbington, Smith, et al., 2005). The present findings are also in line with previous studies, suggesting that paranoid symptoms are predicted by negative beliefs about self (Fowler, et al., 2006; Gracie, et al., 2007). On the other hand, onset of social phobia was predicted by cognitions 
about loss of control. These cognitions are often observed in panic disorder, but have been linked with social phobia as well (Kristensen, Mortensen, \& Mors, 2009). The prediction of social phobia by fear and avoidance of social situations is consistent with the psychological model of Clark and Wells, which postulates a major role for safety (avoidance) behaviours in social anxiety (Clark \& Wells, 1995).

Analyses of temperamental correlates showed that paranoid symptoms and social phobia shared strong associations with behavioural inhibition compared to individuals without paranoid symptoms and/or social phobia. To our knowledge, no previous evidence has been presented of a direct association between behavioural inhibition and psychotic disorder. However, psychotic disorders have been associated with neuroticism (Lonnqvist, et al., 2009; Van Os \& Jones, 2001; Watson, 2001), an inherited tendency to experience negative emotional states, which has been associated with high levels of behavioural inhibition in children (Muris \& Dietvorst, 2006). Measurements of neuroticism (in adolescence and adulthood) and behavioural inhibition (in childhood) likely reflect the same underlying temperamental substrate. The association between neuroticism and behavioural inhibition with both anxiety (Bienvenu, et al., 2001) and psychotic disorders (Lonnqvist, et al., 2009; Van Os \& Jones, 2001) suggests that these related temperamental traits are shared vulnerability factors. However, supplemental analyses showed that the association with behavioral inhibition was strongest for only social phobia as compared to only paranoid symptoms. Furthermore, the temperamental traits of harm avoidance and novelty seeking differentially impacted on the construct of social phobia and paranoid symptoms, respectively.

With regard to environmental risk factors, only paranoid symptoms were significantly associated with self-reported trauma (Freeman \& Fowler, 2009; Gracie, et al., 2007; Scott, et al., 2007; Shevlin, et al., 2007; van Os, et al., 2005) and cannabis use (Arseneault, et al., 2004; van Os, et al., 2005). Direct comparison of the groups with only social phobia versus only paranoid symptoms showed no difference in traumatic experiences, but there was significantly more cannabis use in the latter group. Contrary to previous literature on psychotic disorder (Ellett, et al., 2008; Spauwen, et al., 2004; Sundquist, et al., 2004; van Os, et al., 2005), paranoid symptoms did not show a significant association with urban environment. However, a Swedish study examining the specific construct of paranoid symptoms also found a lower rate of paranoid symptoms in urban areas, while the opposite was found for other psychotic disorders (Widerlov, Borga, Cullberg, Stefansson, \& Lindqvist, 1989). Individuals displaying both conditions showed significant associations with both temperamental traits (associated with social phobia) and environmental risks (associated with paranoid symptoms). The quantitative differences (more risk factors and a greater strength of association compared with each syndrome separately) suggest that the combination of the two is a more severe condi- 
tion than the separate syndromes. This seems to be a general trend in comorbidity studies in psychiatry (Filho, et al.; Wittchen, Schuster, \& Lieb, 2001). An interesting finding in this regard was the strong association of the comorbid condition with cannabis use, whereas participants presenting only social phobia used significantly less cannabis than participants with only paranoid symptoms. Anxiety disorders often precede cannabis dependence (Agosti, et al., 2002) and social phobia even appears to serve as a unique risk factor for the subsequent onset of cannabis dependence. It has been suggested that individuals with social phobia start experimenting with substances later than controls, but progress more rapidly into regular, harmful use and dependence (Wittchen \& Fehm, 2003). On the other hand, it is widely known that paranoid symptoms frequently accompany cannabis intoxication (Keeler, 1967). It is conceivable that socially anxious and behaviorally inhibited persons are particularly vulnerable to develop paranoid symptoms when they use cannabis (van Os, Linscott, Myin-Germeys, Delespaul, \& Krabbendam, 2009). The putative role of behavioral inhibition as a moderator of the environmental/cannabis - association with paranoid symptoms needs to be examined in further studies.

In conclusion, the present study found evidence for both psychological models of paranoid thinking (Freeman, et al., 2002) and social phobia (Clark \& Wells, 1995) in a general population sample by investigating associations of symptomatic features of both conditions, which specifically seem to share cognitions of negative evaluation and an inhibited temperament. Avoidance behaviour appears to be important in development of social phobia, whereas environmental risks such as cannabis use and traumatic experiences may drive paranoid thinking in vulnerable individuals. Additional prospective research is essential to determine the specificity of temperamental vulnerability of behavioral inhibition with respect to development of differential states such as social phobia and paranoia. The underlying processes may be best understood in light of a dimensional perspective that considers relevant cognitive and emotional changes during development. Future studies are also needed to identify environmental factors that either enhance or suppress expression of underlying vulnerability. These studies should consider the timing of environmental influences.

\section{Limitations}

First, the association between paranoid symptoms and social phobia was examined in the context of a large-scale epidemiological study which was not designed for this purpose. It was thus constrained by the specific psychometric tools and sampling frame. Second, some assessment instruments used (RSRI, TPQ) are essentially self-report and 
therefore may be subject to over-reporting. Third, the DIA-X/M-CIDI was used to measure clinical relevance of paranoid beliefs, evaluating secondary dysfunction and helpseeking behaviour; this may have resulted in both under- and overestimation of impairment (Dominguez, et al., 2009). Fourth, there were methodological differences in the assessment of paranoid symptoms (symptoms) and social phobia (criteria of DSMIV diagnosis). In DSM-IV, paranoid symptoms is not included as a separate entity, but part of other DSM-IV 'diagnoses', such as delusional disorder. However, the categorical approach of DSM-IV would probably cause 'underdiagnosing' of paranoid symptoms (Dowbiggin, 2000). Moreover, epidemiological research in the field of psychotic disorders has found substantial evidence for an extended psychosis phenotype in the general population (van Os, et al., 2009), favouring a dimensional approach of paranoid symptoms. Because social anxiety/phobia in the general population probably fits in a continuum model as well (Fehm, Beesdo, Jacobi, \& Fiedler, 2008; Filho, et al.; Schneier, Blanco, Antia, \& Liebowitz, 2002; Tillfors, Furmark, Ekselius, \& Fredrikson, 2004), dimensional measures of social fear, avoidance and related cognitions may be more valid in investigating comorbidity with paranoid ideation. To our knowledge, the present study is the first to incorporate measures of feared/avoided social situations and related cognitions for investigating comorbidity between paranoid symptoms and social phobia in greater detail. Fifth, a single measure was used to define each variable. This may conflate attributes of single measures with those of the respective constructs they assess. Finally, the study had a longitudinal, population based epidemiological perspective, contrasting with the shorter term, selective, sample-enriching approach in highrisk and clinical populations (Gilbert, 2005; Huppert \& Smith, 2005; Michail \& Birchwood, 2009). Due to the different perspectives and their respective populations, instruments, and outcomes, comparisons should be made with caution. 


\section{Funding}

This work is further part of the EDSP Study and is supported by the German Federal Ministry of Education and Research (BMBF) project number 01EB9405/6, 01EB9910/6, EB10106200, 01EB0140, and 01EB0440. Part of the fieldwork and analyses were also additionally supported by grants of the Deutsche Forschungsgemeinschaft (DFG) LA1148/1-1, WI2246/7-1, and WI709/8-1.

\section{Acknowledgments}

Principal investigators are Dr. Hans-Ulrich Wittchen and Dr. Roselind Lieb. Core staff members of the EDSP group are: Dr. Kirsten von Sydow, Dr. Gabriele Lachner, Dr. Axel Perkonigg, Dr. Peter Schuster, Dr. Michael Höfler, Dipl.-Psych. Holger Sonntag, Dr. Tanja Brückl, Dipl.-Psych. Elzbieta Garczynski, Dr. Barbara Isensee, Dr. Agnes Nocon, Dr. Chris Nelson, Dipl.-Inf. Hildegard Pfister, Dr. Victoria Reed, Dipl.-Soz. Barbara Spiegel, Dr. Andrea Schreier, Dr. Ursula Wunderlich, Dr. Petra Zimmermann, Dr. Katja BeesdoBaum, Dr. Antje Bittner, Dr. Silke Behrendt and Dr. Susanne Knappe. Scientific advisors are Dr. Jules Angst (Zurich), Dr. Jürgen Margraf (Basel), Dr. Günther Esser (Potsdam), Dr. Kathleen Merikangas (NIMH, Bethesda), Dr. Ron Kessler (Harvard, Boston) and Dr. Jim van Os (Maastricht).

Furthermore, we would like to acknowledge Marjan Drukker and Wolfgang Viechtbauer for their help with statistics. 


\section{References}

Agosti, V., Nunes, E., \& Levin, F. (2002). Rates of psychiatric comorbidity among U.S. residents with lifetime cannabis dependence. Am J Drug Alcohol Abuse, 28(4), 643-652.

American Psychiatric Association (2000). Diagnostic and Statistical Manual of Mental Disorders. Fourth edition, text revised: Washington, DC: American Psychiatric Association.

Amir, N., Foa, E. B., \& Coles, M. E. (1998a). Automatic activation and strategic avoidance of threat-relevant information in social phobia. J Abnorm Psychol, 107(2), 285-290.

Amir, N., Foa, E. B., \& Coles, M. E. (1998b). Negative interpretation bias in social phobia. Behav Res Ther, 36(10), 945-957.

Amir, N., Elias, J., Klumpp, H., \& Przeworski, A. (2003). Attentional bias to threat in social phobia: facilitated processing of threat or difficulty disengaging attention from threat? Behav Res Ther, 41(11), 1325-1335.

Arseneault, L., Cannon, M., Witton, J., \& Murray, R. M. (2004). Causal association between cannabis and psychosis: examination of the evidence. Br J Psychiatry, 184, 110-117.

Bandelow, B., Charimo Torrente, A., Wedekind, D., Broocks, A., Hajak, G., \& Ruther, E. (2004). Early traumatic life events, parental rearing styles, family history of mental disorders, and birth risk factors in patients with social anxiety disorder. Eur Arch Psychiatry Clin Neurosci, 254(6), 397-405.

Bechdolf, A., Thompson, A., Nelson, B., Cotton, S., Simmons, M. B., Amminger, G. P., et al. (2010). Experience of trauma and conversion to psychosis in an ultra-high-risk (prodromal) group. Acta Psychiatr Scand, 121(5), 377-384.

Beesdo, K., Bittner, A., Pine, D. S., Stein, M. B., Hofler, M., Lieb, R., et al. (2007). Incidence of social anxiety disorder and the consistent risk for secondary depression in the first three decades of life. Arch Gen Psychiatry, 64(8), 903-912.

Ben-Zeev, D., Granholm, E., \& Cafri, G. (2009). Symptoms of depression and anxiety mediate the relationship between self-esteem and paranoia. Schizophr Res, 115(2-3), 377-378.

Bienvenu, O. J., Brown, C., Samuels, J. F., Liang, K. Y., Costa, P. T., Eaton, W. W., et al. (2001). Normal personality traits and comorbidity among phobic, panic and major depressive disorders. Psychiatry Res, 102(1), 73-85.

Bogels, S. M., \& Mansell, W. (2004). Attention processes in the maintenance and treatment of social phobia: hypervigilance, avoidance and self-focused attention. Clin Psychol Rev, 24(7), 827-856. 
Braga, R. J., Mendlowicz, M. V., Marrocos, R. P., \& Figueira, I. L. (2005). Anxiety disorders in outpatients with schizophrenia: prevalence and impact on the subjective quality of life. J Psychiatr Res, 39(4), 409-414.

Chen, W. J., Chen, H. M., Chen, C. C., Yu, W. Y., \& Cheng, A. T. (2002). Cloninger's Tridimensional Personality Questionnaire: psychometric properties and construct validity in Taiwanese adults. Compr Psychiatry, 43(2), 158-166.

Chen, Y. P., Ehlers, A., Clark, D. M., \& Mansell, W. (2002). Patients with generalized social phobia direct their attention away from faces. Behav Res Ther, 40(6), 677687.

Clark, D. M., \& McManus, F. (2002). Information processing in social phobia. Biol Psychiatry, 51(1), 92-100.

Clark, D. M., \& Wells, A. (1995). A cognitive model of social phobia. In R. G. Heimberg, M. R. Liebowitz, D. A. Hope \& F. R. Schneier (Eds.), Social phobia: Diagnosis, assessment, and treatment (pp. 41-68). New York: Guilford Press.

Clark, L. A., \& Watson, D. B. (1995). Constructing validity: Basic issues in objective scale development. Psychol Assessment, 7, 309-319.

Cloninger, C. R. (1986). A unified biosocial theory of personality and its role in the development of anxiety states. Psychiatr Dev, 4(3), 167-226.

Cloninger, C. R. (1987). A systematic method for clinical description and classification of personality variants. A proposal. Arch Gen Psychiatry, 44(6), 573-588.

Cloninger, C. R., Przybeck, T. R., \& Svrakic, D. M. (1991). The Tridimensional Personality Questionnaire: U.S. normative data. Psychol Rep, 69(3 Pt 1), 1047-1057.

Cougnard, A., Marcelis, M., Myin-Germeys, I., De Graaf, R., Vollebergh, W., Krabbendam, L., et al. (2007). Does normal developmental expression of psychosis combine with environmental risk to cause persistence of psychosis? A psychosis proneness-persistence model. Psychol Med, 37(4), 513-527.

DeWall, C. N., Buckner, J. D., Lambert, N. M., Cohen, A. S., \& Fincham, F. D. Bracing for the worst, but behaving the best: social anxiety, hostility, and behavioral aggression. J Anxiety Disord, 24(2), 260-268.

Dominguez, M. D., Can Saka, M., Lieb, R., Wittchen, H. U., \& van Os, J. Early Expression of Negative/Disorganized Symptoms Predicting Psychotic Experiences and Subsequent Clinical Psychosis: A 10-Year Study. Am J Psychiatry.

Dominguez, M. D., Wichers, M., Lieb, R., Wittchen, H. U., \& van Os, J. (2009). Evidence That Onset of Clinical Psychosis Is an Outcome of Progressively More Persistent Subclinical Psychotic Experiences: An 8-Year Cohort Study. Schizophr Bull.

Dowbiggin, I. (2000). Delusional diagnosis? The history of paranoia as a disease concept in the modern era. Hist Psychiatry, 11(41 Pt 1), 37-69. 
Earleywine, M., Finn, P. R., Peterson, J. B., \& Pihl, R. O. (1992). Factor structure and correlates of the Tridimensional Personality Questionnaire. J Stud Alcohol, 53(3), 233-238.

Ellett, L., Freeman, D., \& Garety, P. A. (2008). The psychological effect of an urban environment on individuals with persecutory delusions: the Camberwell walk study. Schizophr Res, 99(1-3), 77-84.

Essex, M. J., Klein, M. H., Slattery, M. J., Goldsmith, H. H., \& Kalin, N. H. Early risk factors and developmental pathways to chronic high inhibition and social anxiety disorder in adolescence. Am J Psychiatry, 167(1), 40-46.

Estrada, G., Fatjo-Vilas, M., Munoz, M. J., Pulido, G., Minano, M. J., Toledo, E., et al. (2011). Cannabis use and age at onset of psychosis: further evidence of interaction with COMT Val158Met polymorphism. Acta Psychiatr Scand, 123(6), 485-492.

Fehm, L., Beesdo, K., Jacobi, F., \& Fiedler, A. (2008). Social anxiety disorder above and below the diagnostic threshold: prevalence, comorbidity and impairment in the general population. Soc Psychiatry Psychiatr Epidemiol, 43(4), 257-265.

Filho, A. S., Hetem, L. A., Ferrari, M. C., Trzesniak, C., Martin-Santos, R., Borduqui, T., et al. Social anxiety disorder: what are we losing with the current diagnostic criteria? Acta Psychiatr Scand, 121(3), 216-226.

Foa, E. B., Franklin, M. E., Perry, K. J., \& Herbert, J. D. (1996). Cognitive biases in generalized social phobia. J Abnorm Psychol, 105(3), 433-439.

Fowler, D., Freeman, D., Smith, B., Kuipers, E., Bebbington, P., Bashforth, H., et al. (2006). The Brief Core Schema Scales (BCSS): psychometric properties and associations with paranoia and grandiosity in non-clinical and psychosis samples. Psychol Med, 36(6), 749-759.

Freeman, D., Dunn, G., Garety, P. A., Bebbington, P., Slater, M., Kuipers, E., et al. (2005). The psychology of persecutory ideation I: a questionnaire survey. J Nerv Ment Dis, 193(5), 302-308.

Freeman, D., \& Fowler, D. (2009). Routes to psychotic symptoms: trauma, anxiety and psychosis-like experiences. Psychiatry Res, 169(2), 107-112.

Freeman, D., \& Garety, P. A. (2000). Comments on the content of persecutory delusions: does the definition need clarification? Br J Clin Psychol, 39 ( Pt 4), 407414.

Freeman, D., Garety, P. A., Bebbington, P., Slater, M., Kuipers, E., Fowler, D., et al. (2005). The psychology of persecutory ideation II: a virtual reality experimental study. J Nerv Ment Dis, 193(5), 309-315. 
Freeman, D., Garety, P. A., Bebbington, P. E., Smith, B., Rollinson, R., Fowler, D., et al. (2005). Psychological investigation of the structure of paranoia in a non-clinical population. Br J Psychiatry, 186, 427-435.

Freeman, D., Garety, P. A., Kuipers, E., Fowler, D., \& Bebbington, P. E. (2002). A cognitive model of persecutory delusions. Br J Clin Psychol, 41(Pt 4), 331-347.

Freeman, D., Gittins, M., Pugh, K., Antley, A., Slater, M., \& Dunn, G. (2008). What makes one person paranoid and another person anxious? The differential prediction of social anxiety and persecutory ideation in an experimental situation. Psychol Med, 38(8), 1121-1132.

Freeman, D., Pugh, K., Vorontsova, N., Antley, A., \& Slater, M. (2010). Testing the continuum of delusional beliefs: an experimental study using virtual reality. $J$ Abnorm Psychol, 119(1), 83-92.

Gilbert, P., Boxall, M., Cheung, M., Irons, C. (2005). The relation of paranoid ideation and social anxiety in a mixed clinical population. Clinical Psychology and Psychotherapy, 12, 10.

Goldberg, J. O., \& Schmidt, L. A. (2001). Shyness, sociability, and social dysfunction in schizophrenia. Schizophr Res, 48(2-3), 343-349.

Gracie, A., Freeman, D., Green, S., Garety, P. A., Kuipers, E., Hardy, A., et al. (2007). The association between traumatic experience, paranoia and hallucinations: a test of the predictions of psychological models. Acta Psychiatr Scand, 116(4), 280-289.

Green, M. J., \& Phillips, M. L. (2004). Social threat perception and the evolution of paranoia. Neurosci Biobehav Rev, 28(3), 333-342.

Heinrichs, N., \& Hofmann, S. G. (2001). Information processing in social phobia: a critical review. Clin Psychol Rev, 21(5), 751-770.

Hirshfeld-Becker, D. R., Micco, J., Henin, A., Bloomfield, A., Biederman, J., \& Rosenbaum, J. (2008). Behavioral inhibition. Depress Anxiety, 25(4), 357-367.

Hori, H., Noguchi, H., Hashimoto, R., Nakabayashi, T., Saitoh, O., Murray, R. M., et al. (2008). Personality in schizophrenia assessed with the Temperament and Character Inventory (TCI). Psychiatry Res, 160(2), 175-183.

Horley, K., Williams, L. M., Gonsalvez, C., \& Gordon, E. (2004). Face to face: visual scanpath evidence for abnormal processing of facial expressions in social phobia. Psychiatry Res, 127(1-2), 43-53.

Hovens, J. G., Wiersma, J. E., Giltay, E. J., van Oppen, P., Spinhoven, P., Penninx, B. W., et al. (2010). Childhood life events and childhood trauma in adult patients with depressive, anxiety and comorbid disorders vs. controls. Acta Psychiatr Scand, 122(1), 66-74.

Huppert, J. D., \& Smith, T. E. (2005). Anxiety and schizophrenia: the interaction of subtypes of anxiety and psychotic symptoms. CNS Spectr, 10(9), 721-731. 
Keeler, M. H. (1967). Adverse reaction to marihuana. Am J Psychiatry, 124(5), 674-677.

Keller, M. B. (2003). The lifelong course of social anxiety disorder: a clinical perspective. Acta Psychiatr Scand Supp/(417), 85-94.

Kennedy, B. L., Schwab, J. J., \& Hyde, J. A. (2001). Defense styles and Personality dimensions of research subjects with anxiety and depressive disorders. Psychiatr $Q, 72(3), 251-262$.

Kinoshita, Y., Kingdon, D., Kinoshita, K., Saka, K., Arisue, Y., Dayson, D., et al. Fear of negative evaluation is associated with delusional ideation in non-clinical population and patients with schizophrenia. Soc Psychiatry Psychiatr Epidemiol.

Knappe, S., Beesdo-Baum, K., Fehm, L., Stein, M. B., Lieb, R., \& Wittchen, H. U. (2010). Social fear and social phobia types among community youth: Differential clinical features and vulnerability factors. J Psychiatr Res.

Knappe, S., Beesdo, K., Fehm, L., Lieb, R., \& Wittchen, H. U. (2009). Associations of familial risk factors with social fears and social phobia: evidence for the continuum hypothesis in social anxiety disorder? J Neural Transm, 116(6), 639648.

Knappe, S., Lieb, R., Beesdo, K., Fehm, L., Low, N. C., Gloster, A. T., et al. (2009). The role of parental psychopathology and family environment for social phobia in the first three decades of life. Depress Anxiety, 26(4), 363-370.

Kristensen, A. S., Mortensen, E. L., \& Mors, O. (2009). The structure of emotional and cognitive anxiety symptoms. J Anxiety Disord, 23(5), 600-608.

Kuo, J. R., Goldin, P. R., Werner, K., Heimberg, R. G., \& Gross, J. J. (2011). Childhood trauma and current psychological functioning in adults with social anxiety disorder. J Anxiety Disord, 25(4), 467-473.

Lardinois, M., Lataster, T., Mengelers, R., Van Os, J., \& Myin-Germeys, I. (2011). Childhood trauma and increased stress sensitivity in psychosis. Acta Psychiatr Scand, 123(1), 28-35.

Lieb, R., Isensee, B., von Sydow, K., \& Wittchen, H. U. (2000). The Early Developmental Stages of Psychopathology Study (EDSP): a methodological update. Eur Addict Res, 6(4), 170-182.

Lonnqvist, J. E., Verkasalo, M., Haukka, J., Nyman, K., Tiihonen, J., Laaksonen, I., et al. (2009). Premorbid personality factors in schizophrenia and bipolar disorder: results from a large cohort study of male conscripts. J Abnorm Psychol, 118(2), 418-423.

Marteinsdottir, I., Tillfors, M., Furmark, T., Anderberg, U. M., \& Ekselius, L. (2003). Personality dimensions measured by the Temperament and Character Inventory (TCI) in subjects with social phobia. Nord J Psychiatry, 57(1), 29-35. 
Mazeh, D., Bodner, E., Weizman, R., Delayahu, Y., Cholostoy, A., Martin, T., et al. (2009). Co-morbid social phobia in schizophrenia. Int J Soc Psychiatry, 55(3), 198-202.

McCauley, J., Kern, D. E., Kolodner, K., Dill, L., Schroeder, A. F., DeChant, H. K., et al. (1997). Clinical characteristics of women with a history of childhood abuse: unhealed wounds. JAMA, 277(17), 1362-1368.

McManus, F., Clark, D. M., \& Hackmann, A. (2000). Specificity of cognitive biases in social phobia and their role in recovery. Behav Cogn Psychotherapy, 28(3), 9.

Menezes, G. B., Fontenelle, L. F., \& Versiani, M. (2005). Early-onset social anxiety disorder in adults: clinical and therapeutic features. Rev Bras Psiquiatr, 27(1), 3236.

Michail, M., \& Birchwood, M. (2009). Social anxiety disorder in first-episode psychosis: incidence, phenomenology and relationship with paranoia. $\mathrm{Br} J$ Psychiatry, 195(3), 234-241.

Morrison, A. P., \& Wells, A. (2007). Relationships between worry, psychotic experiences and emotional distress in patients with schizophrenia spectrum diagnoses and comparisons with anxious and non-patient groups. Behav Res Ther, 45(7), 15931600.

Muris, P., \& Dietvorst, R. (2006). Underlying personality characteristics of behavioral inhibition in children. Child Psychiatry Hum Dev, 36(4), 437-445.

Neal, J. A., Edelmann, R. J., \& Glachan, M. (2002). Behavioural inhibition and symptoms of anxiety and depression: is there a specific relationship with social phobia? $\mathrm{Br} \mathrm{J}$ Clin Psychol, 41(Pt 4), 361-374.

Pallanti, S., Quercioli, L., \& Hollander, E. (2004). Social anxiety in outpatients with schizophrenia: a relevant cause of disability. Am J Psychiatry, 161(1), 53-58.

Peen, J., Schoevers, R. A., Beekman, A. T., \& Dekker, J. (2010). The current status of urban-rural differences in psychiatric disorders. Acta Psychiatr Scand, 121(2), 8493.

Pelissolo, A., Andre, C., Pujol, H., Yao, S. N., Servant, D., Braconnier, A., et al. (2002). Personality dimensions in social phobics with or without depression. Acta Psychiatr Scand, 105(2), 94-103.

Read, J., van Os, J., Morrison, A. P., \& Ross, C. A. (2005). Childhood trauma, psychosis and schizophrenia: a literature review with theoretical and clinical implications. Acta Psychiatr Scand, 112(5), 330-350.

Reed, V., Gander, F., Pfister, H., Steiger, A., Sonntag, H., Trenkwalder, C., et al. (1998). To what degree does the Composite International Diagnostic Interview (CIDI) correctly identify DSM-IV disorders? Testing validity issues in a clinical sample. International Journal of Methods in Psychiatric Research, 7(3), 14. 
Reznick, J. S., Hegeman, I. M., Kaufman, E. R., Woods, S. W., \& Jacobs, M. (1992). Retrospective and Concurrent Self-Report of Behavioral-Inhibition and Their Relation to Adult Mental-Health. Development and Psychopathology, 4(2), 301321.

Rietdijk, J., van Os, J., de Graaf, R., Delespaul, Ph., van der Gaag, M. (2009). Are social phobia and paranoia related, and which comes first? Psychosis, 1(1), 10.

Rohrbacher, H., Hoyer, J., Beesdo, K., Hofler, M., Bittner, A., Lieb, R., et al. (2008). Psychometric properties of the Retrospective Self Report of Inhibition (RSRI) in a representative German sample. Int J Methods Psychiatr Res, 17(2), 80-88.

Savitz, D. A., \& Olshan, A. F. (1995). Multiple comparisons and related issues in the interpretation of epidemiologic data. Am J Epidemiol, 142(9), 904-908.

Schneier, F. R., Blanco, C., Antia, S. X., \& Liebowitz, M. R. (2002). The social anxiety spectrum. Psychiatr Clin North Am, 25(4), 757-774.

Scott, J., Chant, D., Andrews, G., Martin, G., \& McGrath, J. (2007). Association between trauma exposure and delusional experiences in a large community-based sample. Br J Psychiatry, 190, 339-343.

Shevlin, M., Dorahy, M. J., \& Adamson, G. (2007). Trauma and psychosis: an analysis of the National Comorbidity Survey. Am J Psychiatry, 164(1), 166-169.

Skinner, R., Conlon, L., Gibbons, D., \& McDonald, C. (2011). Cannabis use and nonclinical dimensions of psychosis in university students presenting to primary care. Acta Psychiatr Scand, 123(1), 21-27.

Spauwen, J., Krabbendam, L., Lieb, R., Wittchen, H. U., \& van Os, J. (2004). Does urbanicity shift the population expression of psychosis? J Psychiatr Res, 38(6), 613-618.

Stemberger, R. T., Turner, S. M., Beidel, D. C., \& Calhoun, K. S. (1995). Social phobia: an analysis of possible developmental factors. J Abnorm Psychol, 104(3), 526-531.

Stopa, L., \& Clark, D. M. (2000). Social phobia and interpretation of social events. Behav Res Ther, 38(3), 273-283.

Sundquist, K., Frank, G., \& Sundquist, J. (2004). Urbanisation and incidence of psychosis and depression: follow-up study of 4.4 million women and men in Sweden. $B r J$ Psychiatry, 184, 293-298.

Szoke, A., Schurhoff, F., Ferhadian, N., Bellivier, F., Rouillon, F., \& Leboyer, M. (2002). Temperament in schizophrenia: a study of the tridimensional personality questionnaire (TPQ). Eur Psychiatry, 17(7), 379-383.

Thewissen, V., Bentall, R., Campo, J., van Lierop, T., van Os, J., \& Myin-Germeys, I. (2008). Emotional changes and paranoia: An experience sampling study. International Journal of Psychology, 43(3-4), 73-73. 
Tien, A. Y., \& Eaton, W. W. (1992). Psychopathologic precursors and sociodemographic risk factors for the schizophrenia syndrome. Arch Gen Psychiatry, 49(1), 37-46.

Tillfors, M., Furmark, T., Ekselius, L., \& Fredrikson, M. (2004). Social phobia and avoidant personality disorder: one spectrum disorder? Nord J Psychiatry, 58(2), 147-152.

Valmaggia, L. R., Freeman, D., Green, C., Garety, P., Swapp, D., Antley, A., et al. (2007). Virtual reality and paranoid ideations in people with an 'at-risk mental state' for psychosis. Br J Psychiatry Suppl, 51, s63-68.

Van Ameringen, M., Mancini, C., \& Oakman, J. M. (1998). The relationship of behavioral inhibition and shyness to anxiety disorder. J Nerv Ment Dis, 186(7), 425-431.

van Laar, M., van Dorsselaer, S., Monshouwer, K., \& de Graaf, R. (2007). Does cannabis use predict the first incidence of mood and anxiety disorders in the adult population? Addiction, 102(8), 1251-1260.

Van Os, J., \& Jones, P. B. (2001). Neuroticism as a risk factor for schizophrenia. Psychol Med, 31(6), 1129-1134.

van Os, J., Krabbendam, L., Myin-Germeys, I., \& Delespaul, P. (2005). The schizophrenia envirome. Curr Opin Psychiatry, 18(2), 141-145.

van Os, J., Linscott, R. J., Myin-Germeys, I., Delespaul, P., \& Krabbendam, L. (2009). A systematic review and meta-analysis of the psychosis continuum: evidence for a psychosis proneness-persistence-impairment model of psychotic disorder. Psychol Med, 39(2), 179-195.

Verdoux, H., van Os, J., Maurice-Tison, S., Gay, B., Salamon, R., \& Bourgeois, M. (1998). Is early adulthood a critical developmental stage for psychosis proneness? A survey of delusional ideation in normal subjects. Schizophr Res, 29(3), 247-254.

Watson, D. (2001). Dissociations of the night: individual differences in sleep-related experiences and their relation to dissociation and schizotypy. J Abnorm Psychol, 110(4), 526-535.

Weyers, P., Krebs, H., \& Janke, W. (1995). Reliability and Construct-Validity of the German Version of Cloningers Tridimensional Personality Questionnaire. Personality and Individual Differences, 19(6), 853-861.

Widerlov, B., Borga, P., Cullberg, J., Stefansson, C. G., \& Lindqvist, G. (1989). Epidemiology of long-term functional psychosis in three different areas in Stockholm County. Acta Psychiatr Scand, 80(1), 40-46.

Wigman, J. T., Vollebergh, W. A., Raaijmakers, Q. A., ledema, J., van Dorsselaer, S., Ormel, J., et al. (2009). The Structure of The Extended Psychosis Phenotype in Early Adolescence--A Cross-sample Replication. Schizophr Bull. 
Wittchen, H. U. (1994). Reliability and validity studies of the WHO--Composite International Diagnostic Interview (CIDI): a critical review. J Psychiatr Res, 28(1), 57-84.

Wittchen, H. U., \& Fehm, L. (2003). Epidemiology and natural course of social fears and social phobia. Acta Psychiatr Scand Supp/(417), 4-18.

Wittchen, H. U., Frohlich, C., Behrendt, S., Gunther, A., Rehm, J., Zimmermann, P., et al. (2007). Cannabis use and cannabis use disorders and their relationship to mental disorders: a 10-year prospective-longitudinal community study in adolescents. Drug Alcohol Depend, 88 Suppl 1, S60-70.

Wittchen, H. U., Perkonigg, A., Lachner, G., \& Nelson, C. B. (1998). Early developmental stages of psychopathology study (EDSP): objectives and design. Eur Addict Res, 4(1-2), 18-27.

Wittchen, H. U., Pfister H. (1997). DIS-X-Interviews: Manual für Screening-Verfahren und Interview; Interviewheft Längsschittuntersuchung (DIA-X-Lifetime); Ergänzungsheft (DIA-X-Lifetime); Interviewheft Querschnittsuntersuchung (DIAX-12 Monats-Version); Ergänzungsheft (DIA-X-12 Monats-Version); PCProgramm zur Durchführung der Interviews (Längsund Querschnittsuntersuchung). . Auswertungsprogramm. Frankfurt: Swets \& Zeitlinger.

Wittchen, H. U., Robins, L. N., Cottler, L. B., Sartorius, N., Burke, J. D., \& Regier, D. (1991). Cross-cultural feasibility, reliability and sources of variance of the Composite International Diagnostic Interview (CIDI). The Multicentre WHO/ADAMHA Field Trials. Br J Psychiatry, 159, 645-653, 658.

Wittchen, H. U., Schuster, P., \& Lieb, R. (2001). Comorbidity and mixed anxietydepressive disorder: clinical curiosity or pathophysiological need? Hum Psychopharmacol, 16(S1), S21-S30.

Wittchen, H. U., Stein, M. B., \& Kessler, R. C. (1999). Social fears and social phobia in a community sample of adolescents and young adults: prevalence, risk factors and co-morbidity. Psychol Med, 29(2), 309-323. 


\section{Part II}

\section{Pharmacological}

Treatment

\section{of}

Social Anxiety Disorder 



\section{Chapter 6}

\section{Mirtazapine in Generalized Social}

\section{Anxiety Disorder: A Randomised, Double- blind, Placebo-Controlled Study}

Sara I.J. Schutters, Harold J.G.M. van Megen, J. Frederieke Van Veen,

Damiaan A.J.P. Denys, Herman G.M. Westenberg (2010) International Clinical Psychopharmacology 25, 302-4 



\section{Abstract}

\section{Objectives}

This study aimed at investigating efficacy and tolerability of mirtazapine in generalized social anxiety disorder.

\section{Methods}

60 patients with generalized social anxiety disorder were randomly allocated to receive mirtazapine (30-45 mg/day) $(\mathrm{N}=30)$ or placebo $(\mathrm{N}=30)$ for 12 weeks in a double-blind study design. Primary efficacy was assessed by the Liebowitz Social Anxiety Scale (LSAS) and response to treatment was defined as a reduction of $40 \%$ on the LSAS and an improvement on the Clinical Global Impression scale of "much or very much improved".

Results

An intent-to-treat analysis showed no difference between mirtazapine and placebo on absolute LSAS scores with a mean decrease of $13.5 \pm 16.9$ and $11.2 \pm 17.8$ respectively, and on number of responders $13 \%$ and $13 \%$ respectively.

\section{Conclusion}

Mirtazapine 30-45 mg/day failed to be effective in generalized social anxiety disorder. 


\section{Introduction}

Social anxiety disorder (SAD) is a common, but still under-treated psychiatric disorder. The core feature of SAD is an excessive fear of being scrutinised or assessed by others. SAD is often associated with comorbid conditions such as depression and alcoholism. Over the past 25 years, pharmacotherapy and cognitive-behavioural therapy have been shown to be efficacious. Currently, serotonin reuptake inhibitors (SSRIs) are first-line pharmacological treatment for SAD (Baldwin, et al., 2005). Unfortunately, side effects like nausea and sexual dysfunction can complicate their long-term use and approximately $50 \%$ of the patients with SAD do not respond or still have significant residual symptoms (Van Ameringen, Mancini, Pipe, \& Bennett, 2004). Mirtazapine is an antidepressant with a different mode of action; it blocks $\alpha_{2}$-adrenergic autoreceptors, resulting in a stimulation of both noradrenergic and serotonergic pathways (de Boer, 1995). In addition, it has antagonistic properties on the $5 \mathrm{HT}_{2}$ - and $5 \mathrm{HT}_{3}$-receptors which explains its different side-effect profile. One open label study in SAD showed favourable results for mirtazapine: 5 out of 12 patients were classified as a responder, which was defined as a reduction of the Liebowitz Social Anxiety Scale (LSAS), (Liebowitz, 1987) of $40 \%$ and a Clinical Global Improvement score of 1 or 2 (Van Veen, Van Vliet, \& Westenberg, 2002). Furthermore, a placebo-controlled 10-week study with mirtazapine suggested efficacy in women with SAD (Muehlbacher, et al., 2005). The present monocenter study investigated the efficacy and tolerability of mirtazapine in men and women using a double-blind placebo-controlled design.

\section{Method}

Men and women between 18 and 65 years, with generalized SAD according to the DSM-IV and confirmed with the Mini Plus International Neuropsychiatric Interview (Sheehan, et al., 1998) were recruited through advertising in newspapers and from the outpatient population of the University Medical Centre Utrecht, The Netherlands. A subject information form was provided and written informed consent was obtained prior to entry in the study, which had been approved by the University of Utrecht Medical Ethical Review committee, the Netherlands. Patients were excluded from the study if they had a current comorbid axis I diagnosis according to the DSM-IV classification, in case of an actual risk for suicide according to the investigator, pregnancy or instable chronic physical conditions as assessed by medical history and physical examination at screening. The 17-item Hamilton Depression Rating Scale (HDRS), (Hamilton, 1960) was used to screen for comorbid depressive symptoms and patients were excluded if they 
had score of 15 or more. Psychiatric treatment in the past was assessed by asking if the patient ever received standardised treatment such as pharmacotherapy and/or cognitive-behavioural therapy for any psychiatric disorder, resulting in a dichotomous defined outcome of 'treatment-naïve' or 'received psychiatric treatment in the past'. Psychotropic medication or any psychotherapeutic interventions in the last month preceding or during the trial period were not allowed.

Subjects were randomly assigned to double-blind treatment with mirtazapine or placebo for 12 weeks. A new formulation of mirtazapine was used, an orally disintegrating tablet (ODT), which was proven to be bio-equivalent to the regular mirtazapine tablet (Van den Heuvel, Kleijn, \& Peeters, 2001). Patients received an initial dose of $30 \mathrm{mg} /$ day mirtazapine or identical looking and tasting placebo. From day 15 onwards, the dose was increased to $45 \mathrm{mg}$ mirtazapine or placebo ODT. Patients were evaluated at screening, baseline, week 2, week 4, week 8 and week 12 with the Liebowitz Social Anxiety Scale (LSAS), the Fear of Negative Evaluation Scale (FNES), (Watson \& Friend, 1969), the Sheehan Disability Scale (SDS), (Leon, Shear, Portera, \& Klerman, 1992) and the Clinical Global Impression improvement scale (CGI). Response to treatment was defined as a reduction of $40 \%$ on the LSAS and an improvement on the CGI as "much or very much improved". Sexual functioning was measured by the Arizona Sexual Experience Scale (ASEX), (McGahuey, et al., 2000). Patients were weighted at the start and at the end of the trial.

Independent-samples t-tests were conducted to compare the two treatment groups at baseline (Age, Age of onset) and at the end of the study (Weight gain, Increase in ASEX). A Chi-square test was performed for Gender. Last-observation-carriedforward (LOCF) efficacy analyses were conducted on all patients who received any double-blind medication and from whom at least 1 valid post-baseline efficacy evaluation was obtained. Mixed between-within subjects ANOVA's were performed to assess the impact of treatment (mirtazapine or placebo) on the patients' scores of LSAS, FNES and SDS over time.

\section{Results}

Sixty patients ( 26 men, 34 women; mean age=38.6, SD=10.5; mean age of onset=13.1, $\mathrm{SD}=6.1)$ were randomly allocated to receive mirtazapine $(\mathrm{N}=30)$ or placebo $(\mathrm{N}=30)$. Three patients $(0.05 \%)$ didn't complete the study; two patients from the mirtazapine group dropped out due to side-effects (mainly sedation) and one patient from the placebo group was lost for continuation, reason unknown. There were no significant differences between the two groups in age (mirtazapine: mean=37.8, SD=11.2; placebo: 
mean=39.5, SD=9.8), gender (mirtazapine: $46.7 \%$ men; placebo: $40 \%$ men) and age of onset (mirtazapine: mean=11.6, SD=5.5; placebo: mean=14.6, $\mathrm{SD}=6.5$ ). The percentage of treatment-naïve patients did not differ significantly between the groups (mirtazapine: $63.3 \%$; placebo: $43,3 \%, p=.20)$.

Furthermore, the groups did not differ in the baseline score on the ASEX (mirtazapine: mean=14.5, $S D=3.1$; placebo: mean=15.8, $S D=4.1, p=.16$ ). Mixed between-within ANOVA's revealed significant effects of time (treatment) on the LSAS $(F(1.58)=30.13$, $p<.001)$, FNES $(F(1.58)=20.60, p<.001)$ and SDS $(F(1.58)=39.94, p<.001)$, with both groups (mirtazapine and placebo) showing reductions on all these parameters. The main effects comparing the two groups were not significant (LSAS: $F(1.58)=1.85, p=.18$; FNES: $F(1.58)=.64, p=.43$; SDS: $F(1.58)=.90, p=.35)$, suggesting no difference in the effectiveness of mirtazapine and placebo. LOCF data are presented in table 1 . There was no difference in the number of responders: there were 4 responders in the mirtazapine group and 4 in the placebo group (13\%). LOCF analysis of CGI showed no significant difference between the mirtazapine (mean= 2.6, $\mathrm{SD}=.6$ ) and the placebo group (mean=2.8, SD=.6; $\mathrm{p}=.14$ ).

No unexpected or unusual side effects were reported. There was a significant difference in weight gain, with a larger increase in the mirtazapine group (mean $=2.77 \mathrm{~kg}$, $\mathrm{SD}=2.67$ ) compared to the placebo group (mean=-.59, $\mathrm{SD}=1.48 ; \mathrm{p}=.000$ ). The difference in increase in ASEX scores was not significant (mirtazapine: mean=.18, SD=2.21; placebo: mean=.03, $S D=1.30 ; p=.14)$.

Table 1. Primary and secondary efficacy variables

\begin{tabular}{lcccccc} 
& \multicolumn{2}{c}{ Baseline } & \multicolumn{2}{c}{ Endpoint } & \multicolumn{2}{c}{ Mean change } \\
& mirtazapine & placebo & mirtazapine & placebo & mirtazapine & placebo \\
LSAS & & & & & & \\
Total & $68.3 \pm 19.0$ & $73.6 \pm 16.7$ & $54.8 \pm 23.0$ & $62.4 \pm 22.1$ & $13.5 \pm 16.9$ & $11.2 \pm 17.8$ \\
Fear & $37.1 \pm 7.9$ & $38.6 \pm 7.9$ & $29.8 \pm 11.3$ & $33.5 \pm 11.3$ & $7.2 \pm 8.8$ & $5.1 \pm 9.9$ \\
Avoidance & $31.2 \pm 11.7$ & $35.0 \pm 9.4$ & $25.0 \pm 12.3$ & $28.9 \pm 11.4$ & $6.3 \pm 8.9$ & $6.0 \pm 8.5$ \\
FNES & $34.4 \pm 7.9$ & $34.4 \pm 9.2$ & $27.7 \pm 9.6$ & $31.1 \pm 10.5$ & $6.7 \pm 9.2$ & $3.3 \pm 7.7$ \\
SDS & $18.3 \pm 4.2$ & $18.5 \pm 4.4$ & $12.5 \pm 6.3$ & $14.5 \pm 6.2$ & $5.8 \pm 5.9$ & $4.0 \pm 6.1$
\end{tabular}

Mean \pm SD values of the last-observation-carried-forward data set are presented. Abbreviations: LSAS= Liebowitz social anxiety scale, FNES= fear of negative evaluation scale, SDS= Sheehan disability scale. 


\section{Discussion}

The present study failed to find superior efficacy of mirtazapine compared to placebo in the treatment of generalized SAD. This finding contrasts with a recent 10-week study with mirtazapine in women with SAD (Muehlbacher, et al., 2005). Reanalysis of our data with women only did not show a significant effect on the LSAS in the mirtazapine group either $(t(32)=-.367, p=.716)$. Methodological differences might explain these contradicting results. First, patients in our study had 'pure SAD'. Patients with any other primary axis I or II diagnosis and patients with depressive symptoms as assessed with the HDRS had been excluded. In the study of Muehlbacher, Nickel et al. (2005), there was a high rate of comorbidity and though they had excluded patients with a major depressive episode, depressive symptoms were not assessed. It is conceivable that improvement in depressive or other psychiatric symptoms might have blurred the effects on social anxiety efficacy measures. Second, although we have used a higher dose of mirtazapine ( $45 \mathrm{mg}$ compared to $30 \mathrm{mg}$ ), it is unlikely that this can explain the difference in results because mirtazapine was well tolerated in our study and discontinuation due to side effects was very low $(0.03 \%)$. Third, we used an orally disintegrating tablet of mirtazapine, which differs from the mirtazapine tablets used by Muehlbacher, Nickel et al. (2005). Previous studies have shown however the bio-equivalence of this formulation to the regular mirtazapine tablet (Van den Heuvel, et al., 2001). On the other hand, our study was not without limitations. A disadvantage of excluding comorbidity is the selection of a less severe subgroup of patients with SAD. In addition, initial severity was lower in the mirtazapine group. Albeit not significant, this difference might have produced a bias, because response to effective medication is mostly seen in the more severe patient. Furthermore, the sample size of our study is small. The failure to detect a significant difference in the present study might be due to a type 2 error of having insufficient power.

Despite these limitations, this is the first randomized placebo-controlled study with mirtazapine in male and female patients with 'pure' SAD, which failed to show superior effectivity of mirtazapine. However, future studies in larger patient groups are warranted.

\section{Acknowledgements}

This study was funded by an unrestricted grant by Organon. 


\section{References}

Baldwin, D. S., Anderson, I. M., Nutt, D. J., Bandelow, B., Bond, A., Davidson, J. R., et al. (2005). Evidence-based guidelines for the pharmacological treatment of anxiety disorders: recommendations from the British Association for Psychopharmacology. J Psychopharmacol, 19(6), 567-596.

de Boer, T. (1995). The effects of mirtazapine on central noradrenergic and serotonergic neurotransmission. Int Clin Psychopharmacol, 10 Suppl 4, 19-23.

Hamilton, M. (1960). A rating scale for depression. J Neurol Neurosurg Psychiatry, 23, 56-62.

Leon, A. C., Shear, M. K., Portera, L., \& Klerman, G. L. (1992). Assessing impairment in patients with panic disorder: the Sheehan Disability Scale. Soc Psychiatry Psychiatr Epidemiol, 27(2), 78-82.

Liebowitz, M. R. (1987). Social phobia. Mod Probl Pharmacopsychiatry, 22, 141-173.

McGahuey, C. A., Gelenberg, A. J., Laukes, C. A., Moreno, F. A., Delgado, P. L., McKnight, K. M., et al. (2000). The Arizona Sexual Experience Scale (ASEX): reliability and validity. J Sex Marital Ther, 26(1), 25-40.

Muehlbacher, M., Nickel, M. K., Nickel, C., Kettler, C., Lahmann, C., Pedrosa Gil, F., et al. (2005). Mirtazapine treatment of social phobia in women: a randomized, double-blind, placebo-controlled study. J Clin Psychopharmacol, 25(6), 580583.

Sheehan, D. V., Lecrubier, Y., Sheehan, K. H., Amorim, P., Janavs, J., Weiller, E., et al. (1998). The Mini-International Neuropsychiatric Interview (M.I.N.I.): the development and validation of a structured diagnostic psychiatric interview for DSM-IV and ICD-10. J Clin Psychiatry, 59 Suppl 20, 22-33; quiz 34-57.

Van Ameringen, M., Mancini, C., Pipe, B., \& Bennett, M. (2004). Optimizing treatment in social phobia: a review of treatment resistance. CNS Spectr, 9(10), 753-762.

Van den Heuvel, M. W., Kleijn, H. J., \& Peeters, P. A. M. (2001). Bioequivalence Trial of Orally Disintegrating Mirtazapine Tablets and Conventional Oral Mirtazapine Tablets in Healthy Volunteers. Clinical Drug Investigation, 21(6), 437-442.

Van Veen, J. F., Van Vliet, I. M., \& Westenberg, H. G. (2002). Mirtazapine in social anxiety disorder: a pilot study. Int Clin Psychopharmacol, 17(6), 315-317.

Watson, D., \& Friend, R. (1969). Measurement of social-evaluative anxiety. J Consult Clin Psychol, 33(4), 448-457. 


\section{Chapter 7}

\section{Paroxetine augmentation in patients with Generalized Social Anxiety Disorder, non-responsive to mirtazapine or placebo}

Sara I.J. Schutters, Harold J.G.M. van Megen, J. Frederieke Van Veen, Koen R.J. Schruers, Herman G.M. Westenberg (2011) Human Psychopharmacology, 26 (1), 72-76 



\begin{abstract}
Objectives

The aim of the study was to investigate if combination of mirtazapine with paroxetine causes a greater therapeutic effect and less sexual side effects than paroxetine monotherapy in social anxiety disorder (SAD).
\end{abstract}

\title{
Methods
}

Twenty one patients with generalized SAD, non-responsive to a 12 week trial with mirtazapine and 22 patients, non-responsive to placebo received paroxetine (20-40mg) in addition to their double-blind treatment with mirtazapine or placebo for another 12 weeks. The Liebowitz Social Anxiety Scale (LSAS) and the Clinical Global ImpressionImprovement (CGI-I) scale were used to measure efficacy. Sexual functioning was assessed by the Arizona Sexual Experiences Scale (ASEX).

\section{Results}

Both treatments showed a significant LSAS reduction and their response rates (based on LSAS reduction $\geq 40 \%$ and CGI-I $\leq 2$ ) were similar (paroxetine and mirtazapine: $52.4 \%$, paroxetine and placebo: 59.1\%). Sexual dysfunction (based on ASEX $\geq 19$ ) was found in half of patients treated with paroxetine and placebo, and in $38 \%$ of patients treated with paroxetine and mirtazapine.

\section{Conclusion}

The present study did not find support for a greater efficacy of combination pharmacotherapy in SAD, however results suggest that combination of paroxetine with mirtazapine might cause less sexual dysfunction than treatment with paroxetine alone. 


\section{Introduction}

Currently, selective serotonin reuptake inhibitors (SSRI's) and the serotonin noradrenalin reuptake inhibitor, venlafaxine are pharmacologically the first-line treatment of social anxiety disorder (SAD) (Stein, et al., 2010). Unfortunately, approximately $50 \%$ of the patients with SAD do not respond or still have significant residual symptoms after pharmacological treatment (Van Ameringen, Mancini, Pipe, \& Bennett, 2004). Little is known about the effect of co-administration of serotonergic drugs in the treatment of SAD.

Mirtazapine is an antidepressant with a different mode of action; it blocks $\alpha_{2}$ adrenergic autoreceptors, resulting in a stimulation of both noradrenergic and serotonergic pathways while directly blocking the $5 \mathrm{HT}_{2}$ - and $5 \mathrm{HT}_{3}$-receptors (de Boer, 1995). Basic research suggests that the combination of paroxetine with mirtazapine produces a greater activation of the postsynaptic $5-\mathrm{HT}_{1 \mathrm{~A}}$ receptors than either drug given alone (Besson, Haddjeri, Blier, \& de Montigny, 2000). This enhancement of serotonergic activation by addition of mirtazapine to a SSRI's might improve the therapeutic response. A greater response has been found in a placebo-controlled mirtazapine augmentation study in patients with major depression (Carpenter, Yasmin, \& Price, 2002), but this has not been investigated in SAD yet.

Furthermore, mirtazapine has a different side-effect profile compared to the SSRI's, such as paroxetine, in which long-term use is often complicated by sexual dysfunction. Mirtazapine appears to have a lower propensity for sexual side effects (Montejo, Llorca, Izquierdo, \& Rico-Villademoros, 2001; Serretti \& Chiesa, 2009), presumably through blockade of the $5 \mathrm{HT}_{2}$-receptor. It has been suggested that mirtazapine reduces sexual dysfunction induced by SSRI treatment (Gelenberg, et al., 2000; Ozmenler, et al., 2008).

The first aim of this study was to investigate if the combination of mirtazapine and paroxetine enhances the efficacy of pharmacological treatment of SAD. A second goal was to assess if there are less sexual side effects in the combination treatment.

\section{Method}

Participants were recruited from a study with 60 patients with generalized SAD. In this previous study (Schutters, Van Megen, Van Veen, Denys, \& Westenberg, 2010), patients were recruited through advertising in newspapers and from the outpatient population of the University Medical Centre Utrecht, The Netherlands. Written informed consent was obtained prior to entry in the study, which had been approved by the University of Utrecht Medical Ethical Review committee, the Netherlands. Generalized SAD was 
diagnosed according to DSM-IV and confirmed with the Mini Plus International Neuropsychiatric Interview (Sheehan, et al., 1998). Assessments were conducted by the primary investigator (medical doctor) who previously received special training in psychiatric interviewing. All participants were interviewed by a qualified psychiatrist before entry into the study. Patients were excluded from the study if they had a current comorbid axis I diagnosis according to the DSM-IV classification, in case of an actual risk for suicide according to the investigator, pregnancy or instable chronic physical conditions as assessed by medical history and physical examination at screening. The 17-item Hamilton Depression Rating Scale (HDRS), (Hamilton, 1960) was used to screen for comorbid depressive symptoms and patients were excluded if they had score of 15 or more. Psychiatric treatment in the past was assessed by asking if the patient ever received standardised treatment such as pharmacotherapy and/or cognitive-behavioural therapy for any psychiatric disorder, resulting in a dichotomous defined outcome of 'treatment-naïve' or 'received psychiatric treatment in the past'. A 12 week randomized controlled trial (Schutters, et al., 2010) was conducted in which patients received double-blind treatment with placebo or mirtazapine, in the formulation of orally disintegrating tablets, which was proven to be bio-equivalent to the regular mirtazapine tablet (Van den Heuvel, Kleijn, \& Peeters, 2001). The percentage of treatment-naïve patients did not differ significantly between the groups (mirtazapine: 61.9\%; placebo: 45,5\%, $\mathrm{p}=.36)$. After 12 weeks, response to treatment was determined by an a priori defined double criterion: a reduction of at least $40 \%$ on the Liebowitz Social Anxiety Scale (LSAS) (Liebowitz, 1987) and a Clinical Global Impression-Improvement (CGI-I) rating of "much improved" (2) or "very much improved" (1) (Bandelow, Baldwin, Dolberg, Andersen, \& Stein, 2006; Montgomery, et al., 2004). The responders ( $N=8)$ continued their double-blind treatment. These patients are not included in analyses, because it does not contribute to the aim of the present study.

The present study concerns the non-responders $(N=43)$ of the randomized controlled trial. Double-blind treatment with mirtazapine or placebo (dose: $45 \mathrm{mg}$ ) was continued. Patients received immediate-release paroxetine in addition to their doubleblind treatment for another 12 weeks. The dosage of paroxetine was $20 \mathrm{mg}$ at start. After 4 weeks, patients on placebo received a fixed dose titration to $40 \mathrm{mg}$ paroxetine. The patients on mirtazapine did not receive a dose titration, but in order to ensure the blindness, a placebo capsule was added using a double dummy technique. During the last week of the trial period, the dose of paroxetine was decreased to $20 \mathrm{mg}$ in a fixed way in the patients on placebo. Other psychotropic medication or any psychotherapeutic interventions were not allowed during the trial.

Patients were evaluated at baseline, week 4, week 8 and week 12 with the LSAS and at week 4, 8 and 12 with the CGI. Patients were weighted at baseline and at week 
12. Sexual functioning was assessed by the Arizona Sexual Experiences Scale (ASEX) (McGahuey, et al., 2000) at baseline, week 4 and week 12. Sexual dysfunction was defined as a score of at least 19 on the ASEX (Baldwin, Cooper, Huusom, \& Hindmarch, 2006).

Last-observation-carried-forward (LOCF) efficacy analyses were conducted on all patients from whom at least 1 valid post-baseline efficacy evaluation was obtained. Response to treatment was determined by two definitions: 1 ) CGI-I 2 and LSAS reduction $\geq 40 \%$., 2) CGI-I $\leq 2$. Paired samples t-tests were conducted to investigate effects of each treatment on LSAS, Weight and ASEX. Percentages of sexual dysfunction were computed.

Efficacy data were compared with three large randomized controlled studies with immediate-release paroxetine in SAD (Baldwin, Bobes, Stein, Scharwachter, \& Faure, 1999; Liebowitz, et al., 2002; Stein, et al., 1998).

\section{Results}

Twenty two patients received paroxetine and placebo (paroxetine group) and 21 patients received paroxetine and mirtazapine (combination group). The two treatment groups were similar with respect to Age, Gender and Age of onset (data are depicted in Table 1). Furthermore, mean baseline scores on LSAS (paroxetine group: $67.8 \pm 19.7$; combination group: $62.3 \pm 21.3$ ) and ASEX (paroxetine group $16.1 \pm 4.6$; combination group: $15.3 \pm 3.4$ ) did not show large differences. One patient from the combination group didn't complete the study due to balance problems.

At endpoint, there were 13 responders in the paroxetine group (59.1\%) and 11 in the combination group (52.4\%), based on the double criterion of CGI-I $\leq 2$ and LSAS reduction $\geq 40 \%$. Response rates based on the less stringent criterion of response (CGI$I \leq 2)$, revealed larger numbers: 17 responders $(77.3 \%)$ in the paroxetine group versus $14(66.7 \%)$ in the combination group. These response rates are similar to those found by previous randomized controlled studies with paroxetine in SAD (Baldwin, et al., 1999; Liebowitz, et al., 2002; Stein, et al., 1998) (data are depicted in table 1). 
Table 1. Dosing, demographics and efficacy data of the present trials with paroxetine and placebo (paroxetine) and with paroxetine and mirtazapine (combination), and three previous clinical trials with Paroxetine in SAD

\begin{tabular}{|c|c|c|c|c|c|c|c|}
\hline & \multicolumn{2}{|c|}{ Present study } & \multicolumn{5}{|c|}{ Previous trials } \\
\hline & Paroxetine & Combination & Stein et al & Baldwin et & Lie & owitz $e$ & 2002 \\
\hline Dose & $20-40$ & 20 & $20-50$ & $20-50$ & 20 & 40 & 60 \\
\hline $\mathbf{N}$ & 22 & 21 & 94 & 139 & 97 & 95 & 97 \\
\hline $\begin{array}{l}\text { Age, mean (SD), } \\
\text { years }\end{array}$ & $39.5(10.0)$ & 39.1 (11.7) & 35.9 & 34.7 & 36.2 & 37.9 & 36.0 \\
\hline Gender, $\%$ men & 50.0 & 57.1 & 46.8 & 46.0 & 52.6 & 66.3 & 57.7 \\
\hline $\begin{array}{l}\text { Age of onset, } \\
\text { mean (SD), years }\end{array}$ & $15.1(7.1)$ & $11.4(5.9)$ & 14.7 & 20.0 & & Jot rep & \\
\hline $\begin{array}{l}\text { Response rate, } \\
\% \text { responders }\end{array}$ & 77.3 & 66.7 & 55.0 & 65.7 & 57.6 & 63.6 & 63.0 \\
\hline $\begin{array}{l}\text { Reduction LSAS, } \\
\text { mean (SD) }\end{array}$ & $26.3(21.3)$ & $17.6(16.0)$ & 30.5 & 29.4 & 31.4 & 24.5 & 25.2 \\
\hline
\end{tabular}

LSAS, Liebowitz Social Anxiety Scale.

LOCF analyses showed significant decreases in LSAS scores in both groups (paroxetine group: $t(21)=5.8, p<.001$; combination group: $t(20)=5.0 ; p<.001)$. The numeric decrease in LSAS in the combination group $(17.6 \pm 16.0)$ was rather small in comparison with LSAS reductions found in the present paroxetine group $(26.3 \pm 21.3)$ and in previous studies with paroxetine in SAD (Baldwin, et al., 1999; Liebowitz, et al., 2002; Stein, et al., 1998) (data are depicted in table 1).

Weight gain was significant in the combination group (mean=1.6 $\pm 1.5 \mathrm{~kg}, \mathrm{t}(20)=-$ $4.9, p<.001$ ), not in the paroxetine group (mean $=0.4 \pm 1.8 \mathrm{~kg}, \mathrm{t}(21)=-1.0, \mathrm{p}=.34$ ). There was a significant increase in ASEX in the two groups (paroxetine group: mean $=3.2 \pm 4.8$, $\mathrm{t}(21)=-3.1, \mathrm{p}=.005$; combination group: mean $=1.7 \pm 2.7, \mathrm{t}(20)=-2.8, \mathrm{p}=.01)$. The number of patients with sexual dysfunction (ASEX $\geq 19$ ) doubled in the combination group (baseline: 19\%, endpoint: 38\%), but the percentage of sexual dysfunction was higher after treatment with paroxetine alone (baseline: $9 \%$, endpoint: $50 \%$ ). 


\section{Discussion}

Both treatments with paroxetine, with or without mirtazapine, substantially improved social anxiety scores and showed similar response rates in SAD patients, which were conform previous data from three large randomized controlled studies with paroxetine in SAD (Baldwin, et al., 1999; Liebowitz, et al., 2002; Stein, et al., 1998). This suggests that paroxetine in addition to mirtazapine does not cause a greater clinical improvement in generalized SAD than paroxetine alone. This is in contrast with our hypothesis, expecting a greater response of the combination treatment based on the preclinical finding of a greater serotonergic activation by the combination of paroxetine with mirtazapine than either drug given alone (Besson, et al., 2000) and on the greater response of mirtazapine augmentation found in major depression (Carpenter, et al., 2002). However, a mirtazapine augmentation study in obsessive-compulsive disorder also failed to show a greater therapeutic response (Pallanti, Quercioli, \& Bruscoli, 2004). Moreover, the efficacy of mirtazapine in SAD is still a matter of debate: one randomized placebo-controlled trial in woman with SAD found evidence for a superior efficacy of mirtazapine (Muehlbacher, et al., 2005), whereas this was not confirmed in our previous study (Schutters, et al., 2010). A possible explanation might be the lack of mirtazapine to induce serotonergic effects, which has previously been suggested, because sufficient evidence from human research is lacking (Gillman, 2006). It is noteworthy that the numeric decrease in LSAS was more in the paroxetine (26.3) than in the combination group (17.6). This might be due to the higher dosage of paroxetine in the former group. However, previous data comparing paroxetine $20 \mathrm{mg}, 40 \mathrm{mg}$ and 60 $\mathrm{mg} /$ day demonstrated that there was no further significant benefit from the higher doses (Liebowitz, et al., 2002).

Furthermore, the present study showed that both treatments with paroxetine (with or without mirtazapine) induced substantial sexual side effects, although the numerical increase in ASEX was greatest in the treatment with paroxetine alone. Half of the patients treated with paroxetine experienced sexual dysfunction, which is in line with the prevalence of antidepressant-induced sexual dysfunction found in a recent cross-sectional survey in the Netherlands (53.4\%) (Williams, Edin, Hogue, Fehnel, \& Baldwin, 2010). In the treatment with paroxetine in combination with mirtazapine, the presence of sexual dysfunction was lower, although still substantial (38\%). This rate of sexual dysfunction is higher than expected, because previous studies found a higher reduction in SSRI-induced sexual dysfunction after switching to or augmentation with mirtazapine (58\%, approximately $50 \%$ respectively) in patients with remitted depressive disorder (Gelenberg, et al., 2000; Ozmenler, et al., 2008). However, in this latter study, the improvement of sexual function might have been caused by the mood en- 
hancing effect of mirtazapine (Nutt, 2002). It is conceivable that mirtazapine might be less potent in reducing sexual dysfunction in the present study population, in which SAD patients with substantial depressive symptoms were excluded. Another explanation might be the use of an assessment scale which is possibly a less sensitive measure of sexual function than some other scales (Haberfellner, 2007).

This study has several methodological limitations. Sample sizes were small and direct comparison of the two treatment groups is not straightforward, because one group of patients was previously treated with placebo whereas the other with a potentially active drug, mirtazapine. Therefore, the present results could only be compared with results from previous studies with these drugs. Another potential limitation of the study is that higher response rates may have been found in the combination group when a higher dose of paroxetine had been used.

In conclusion, the present study did not find support for the hypothesis of a greater efficacy of pharmacological treatment in SAD when paroxetine is combined with mirtazapine. The results suggest that combination treatment with mirtazapine might cause less sexual dysfunction. Randomized, double-blind, placebo-controlled trials are needed to fully evaluate the benefit for mirtazapine augmentation in enhancing response and diminishing sexual side effects of SSRI treatment in these patients.

\section{Acknowledgements}

This study was funded by an unrestricted grant by Organon. 


\section{References}

Baldwin, D., Bobes, J., Stein, D. J., Scharwachter, I., \& Faure, M. (1999). Paroxetine in social phobia/social anxiety disorder. Randomised, double-blind, placebocontrolled study. Paroxetine Study Group. Br J Psychiatry, 175, 120-126.

Baldwin, D. S., Cooper, J. A., Huusom, A. K., \& Hindmarch, I. (2006). A double-blind, randomized, parallel-group, flexible-dose study to evaluate the tolerability, efficacy and effects of treatment discontinuation with escitalopram and paroxetine in patients with major depressive disorder. Int Clin Psychopharmacol, 21(3), 159-169.

Bandelow, B., Baldwin, D. S., Dolberg, O. T., Andersen, H. F., \& Stein, D. J. (2006). What is the threshold for symptomatic response and remission for major depressive disorder, panic disorder, social anxiety disorder, and generalized anxiety disorder? J Clin Psychiatry, 67(9), 1428-1434.

Besson, A., Haddjeri, N., Blier, P., \& de Montigny, C. (2000). Effects of the coadministration of mirtazapine and paroxetine on serotonergic neurotransmission in the rat brain. Eur Neuropsychopharmacol, 10(3), 177188.

Carpenter, L. L., Yasmin, S., \& Price, L. H. (2002). A double-blind, placebo-controlled study of antidepressant augmentation with mirtazapine. Biol Psychiatry, 51(2), 183-188.

de Boer, T. (1995). The effects of mirtazapine on central noradrenergic and serotonergic neurotransmission. Int Clin Psychopharmacol, 10 Suppl 4, 19-23.

Gelenberg, A. J., McGahuey, C., Laukes, C., Okayli, G., Moreno, F., Zentner, L., et al. (2000). Mirtazapine substitution in SSRI-induced sexual dysfunction. J Clin Psychiatry, 61(5), 356-360.

Gillman, P. K. (2006). A systematic review of the serotonergic effects of mirtazapine in humans: implications for its dual action status. Hum Psychopharmacol, 21(2), 117-125.

Haberfellner, E. M. (2007). A review of the assessment of antidepressant-induced sexual dysfunction used in randomized, controlled clinical trials. Pharmacopsychiatry, 40(5), 173-182.

Hamilton, M. (1960). A rating scale for depression. J Neurol Neurosurg Psychiatry, 23, 56-62.

Liebowitz, M. R. (1987). Social phobia. Mod Probl Pharmacopsychiatry, 22, 141-173.

Liebowitz, M. R., Stein, M. B., Tancer, M., Carpenter, D., Oakes, R., \& Pitts, C. D. (2002). A randomized, double-blind, fixed-dose comparison of paroxetine and placebo 
in the treatment of generalized social anxiety disorder. J Clin Psychiatry, 63(1), 66-74.

McGahuey, C. A., Gelenberg, A. J., Laukes, C. A., Moreno, F. A., Delgado, P. L., McKnight, K. M., et al. (2000). The Arizona Sexual Experience Scale (ASEX): reliability and validity. J Sex Marital Ther, 26(1), 25-40.

Montejo, A. L., Llorca, G., Izquierdo, J. A., \& Rico-Villademoros, F. (2001). Incidence of sexual dysfunction associated with antidepressant agents: a prospective multicenter study of 1022 outpatients. Spanish Working Group for the Study of Psychotropic-Related Sexual Dysfunction. J Clin Psychiatry, 62 Suppl 3, 10-21.

Montgomery, S. A., Lecrubier, Y., Baldwin, D. S., Kasper, S., Lader, M., Nil, R., et al. (2004). ECNP Consensus Meeting, March 2003. Guidelines for the investigation of efficacy in social anxiety disorder. Eur Neuropsychopharmacol, 14(5), 425433.

Muehlbacher, M., Nickel, M. K., Nickel, C., Kettler, C., Lahmann, C., Pedrosa Gil, F., et al. (2005). Mirtazapine treatment of social phobia in women: a randomized, double-blind, placebo-controlled study. J Clin Psychopharmacol, 25(6), 580583.

Nutt, D. J. (2002). Tolerability and safety aspects of mirtazapine. Hum Psychopharmacol, 17 Suppl 1, S37-41.

Ozmenler, N. K., Karlidere, T., Bozkurt, A., Yetkin, S., Doruk, A., Sutcigil, L., et al. (2008). Mirtazapine augmentation in depressed patients with sexual dysfunction due to selective serotonin reuptake inhibitors. Hum Psychopharmacol, 23(4), 321326.

Pallanti, S., Quercioli, L., \& Bruscoli, M. (2004). Response acceleration with mirtazapine augmentation of citalopram in obsessive-compulsive disorder patients without comorbid depression: a pilot study. J Clin Psychiatry, 65(10), 1394-1399.

Schutters, S. I., Van Megen, H. J., Van Veen, J. F., Denys, D. A., \& Westenberg, H. G. (2010). Mirtazapine in generalized social anxiety disorder: a randomized, double-blind, placebo-controlled study. Int Clin Psychopharmacol, 25(5), 302304.

Serretti, A., \& Chiesa, A. (2009). Treatment-emergent sexual dysfunction related to antidepressants: a meta-analysis. J Clin Psychopharmacol, 29(3), 259-266.

Sheehan, D. V., Lecrubier, Y., Sheehan, K. H., Amorim, P., Janavs, J., Weiller, E., et al. (1998). The Mini-International Neuropsychiatric Interview (M.I.N.I.): the development and validation of a structured diagnostic psychiatric interview for DSM-IV and ICD-10. J Clin Psychiatry, 59 Suppl 20, 22-33; quiz 34-57. 
Stein, D. J., Baldwin, D. S., Bandelow, B., Blanco, C., Fontenelle, L. F., Lee, S., et al. (2010). A 2010 evidence-based algorithm for the pharmacotherapy of social anxiety disorder. Curr Psychiatry Rep, 12(5), 471-477.

Stein, M. B., Liebowitz, M. R., Lydiard, R. B., Pitts, C. D., Bushnell, W., \& Gergel, I. (1998). Paroxetine treatment of generalized social phobia (social anxiety disorder): a randomized controlled trial. JAMA, 280(8), 708-713.

Van Ameringen, M., Mancini, C., Pipe, B., \& Bennett, M. (2004). Optimizing treatment in social phobia: a review of treatment resistance. CNS Spectr, 9(10), 753-762.

Van den Heuvel, M. W., Kleijn, H. J., \& Peeters, P. A. M. (2001). Bioequivalence Trial of Orally Disintegrating Mirtazapine Tablets and Conventional Oral Mirtazapine Tablets in Healthy Volunteers. Clinical Drug Investigation, 21(6), 437-442.

Williams, V. S., Edin, H. M., Hogue, S. L., Fehnel, S. E., \& Baldwin, D. S. (2010). Prevalence and impact of antidepressant-associated sexual dysfunction in three European countries: replication in a cross-sectional patient survey. J Psychopharmacol, 24(4), 489-496. 


\section{Chapter 8}

\section{Efficacy of Quetiapine in Generalized Social Anxiety Disorder:}

Results from an open-label study 



\section{Introduction}

The generalized form of social anxiety disorder is a highly prevalent psychiatric condition that causes persistent functional impairment (Westenberg, 1998). Although selective serotonin reuptake inhibitors (SSRIs) have become the first-line treatment for social anxiety disorder (Blanco, Raza, Schneier, \& Liebowitz, 2003) these drugs do not always give adequate symptom relief, and side effects like initial increase of anxiety, gastrointestinal complaints, and sexual dysfunction can complicate their long-term use.

Animal models have shown that atypical antipsychotics also possess anxiolytic properties (Manzaneque, Brain, \& Navarro, 2002; Moore, Rees, Sanger, \& Tye, 1994; Nowakowska, Chodera, Kus, \& Rybakowski, 1999). Recently, clinical reports have confirmed this anxiolytic profile (Carson, Kitagawa, \& Nemeroff, 2004; Denys, van Megen, \& Westenberg, 2002; Francobandiera, 2002; Hamner, Deitsch, Brodrick, Ulmer, \& Lorberbaum, 2003; Petty, et al., 2001; Tollefson, Sanger, Beasley, \& Tran, 1998). The atypical antipsychotic olanzapine has shown favourable results in a small placebocontrolled trial in social anxiety disorder patients (Barnett, Kramer, Casat, Connor, \& Davidson, 2002).

Quetiapine is an atypical antipsychotic registered for use in schizophrenia with a low propensity for extrapyramidal and endocrine side effects (Nemeroff, Kinkead, \& Goldstein, 2002). The objective of this study was to investigate the efficacy and tolerability of quetiapine, as monotherapy, in generalized social anxiety disorder patients.

\section{Method}

Thirteen patients with primary social anxiety disorder, generalized type (according to the DSM-IV and confirmed by the Mini-International Neuropsychiatric Interview; (Sheehan, et al., 1998), who presented at the anxiety clinic at University Medical Center Utrecht, the Netherlands, were included in a 12-week open-label study. None of the patients had another current primary Axis I disorder or a primary personality disorder, with the exception of avoidant personality disorder. Eleven patients were drugnaive, and 2 were nonresponders to an adequate treatment with paroxetine. The Medical Ethical Review Committee of the University Medical Center (Utrecht, the Netherlands) approved the study. Data were collected from January to July 2004. Written informed consent was obtained from patients prior to inclusion. Quetiapine was orally administered at flexible doses (150-300 mg/day). No other psychotropic medication was allowed during the study. Subjects were assessed at baseline and weeks 1, 3, 5, 8, and 12 . 
The primary outcome parameters were the Liebowitz Social Anxiety Scale (LSAS) (Liebowitz, 1987) and the number of responders. Responders were defined as those who had a score of $\leq 2$ (much or very much improved) on the Clinical Global Impressions-Improvement scale (Guy, 1976). Other outcome scales were the Brief Social Phobia Scale (Davidson, et al., 1991), the Social Phobia Inventory (Connor, et al., 2000), the Fear of Negative Evaluation Scale (Watson \& Friend, 1969), the Hamilton Anxiety Rating Scale for Anxiety (Hamilton, 1959) and the Sheehan Disability Scale (Sheehan, 1983). Vital signs (blood pressure, heart rate, and body weight) were measured at each visit, and plasma drug levels were assayed in weeks 8 and 12 .

Table 1. Primary and secondary outcome variables: Mean (SD) values and LOCF analysis

\begin{tabular}{|c|c|c|c|c|}
\hline & Baseline & Endpoint & $\mathbf{t}$ & $P^{*}$ \\
\hline \multicolumn{5}{|l|}{ LSAS } \\
\hline Total & $76.77 \pm 10.25$ & $48.61 \pm 21.07$ & 4.79 & 0.0001 \\
\hline Fear & $42.62 \pm 5.08$ & $28.08 \pm 11.86$ & 4.56 & 0.001 \\
\hline Avoidance & $34.15 \pm 7.56$ & $20.54 \pm 9.61$ & 4.40 & 0.001 \\
\hline \multicolumn{5}{|l|}{ BSPS } \\
\hline Total & $42.69 \pm 7.17$ & $23.77 \pm 14.20$ & 5.02 & 0.0001 \\
\hline Fear & $18.46 \pm 3.41$ & $11.15 \pm 6.36$ & 3.96 & 0.002 \\
\hline Avoidance & $17.00 \pm 3.42$ & $9.62 \pm 6.27$ & 4.48 & 0.001 \\
\hline Physical & $7.23 \pm 2.77$ & $3.00 \pm 2.55$ & 5.69 & 0.0001 \\
\hline SPIN & $42.23 \pm 5.59$ & $22.85 \pm 13.18$ & 5.22 & 0.0001 \\
\hline \multicolumn{5}{|l|}{ SDS } \\
\hline Work & $7.46 \pm 1.71$ & $3.69 \pm 2.56$ & 4.95 & 0.0001 \\
\hline Social & $8.23 \pm 1.17$ & $4.54 \pm 2.60$ & 5.13 & 0.0001 \\
\hline Family & $4.77 \pm 3.11$ & $2.54 \pm 2.63$ & 2.34 & 0.038 \\
\hline HAS & $12.90 \pm 4.07$ & $2.20 \pm 1.93$ & 10.53 & 0.0001 \\
\hline CGI-I & - & $2.15 \pm 1.07$ & - & - \\
\hline Dose, mg/day & - & $250.00 \pm 54.01$ & - & - \\
\hline Weight, kg & $82.40 \pm 14.70$ & $84.30 \pm 15.00$ & 2.51 & 0.028 \\
\hline Plasma drug level, $\mathrm{ng} / \mathrm{ml}$ & - & $104.46 \pm 136.8$ & - & - \\
\hline
\end{tabular}

* Student t-test (paired) using LOCF data. Analysis of HAS was based on completer data set. 


\section{Results}

The mean \pm SD age of the patients ( 8 women and 5 men) was $33.2 \pm 8.6$ years. Ten patients $(77 \%)$ completed the trial. Three patients discontinued prematurely due to adverse events (mainly sedation); 1 patient discontinued at week 8 , and 2 patients dropped out after 1 week of treatment. Nine patients (69\% of the last-observationcarried-forward sample) were considered responders. The only nonresponder who completed the trial appeared to be noncompliant (based on plasma drug level assays). This patient had previously also failed to respond to paroxetine. The baseline-toendpoint scores dropped significantly for all outcome measures (Table 1). The total LSAS score decreased with by $36.7 \%$. The difference from baseline was significant as of week 3. The mean \pm SD dose of quetiapine at endpoint was $250 \pm 54 \mathrm{mg}$. Quetiapine was generally well tolerated. The most common adverse events were sedation, dry mouth, and dizziness. The mean plasma drug level at endpoint was $104 \pm 137 \mathrm{ng} / \mathrm{mL}$.

\section{Conclusion}

The response rate in this open-label study compares favourably with the results reported previously for SSRIs (Stein, Fyer, Davidson, Pollack, \& Wiita, 1999; Stein, et al., 1998; Van Ameringen, et al., 2001) and olanzapine (Barnett, et al., 2002).

In conclusion, this study provides preliminary evidence for the efficacy of quetiapine in generalized social anxiety disorder. Currently, SSRIs are first-line treatment for patients with social anxiety disorder, but quetiapine might have a prospective role in social anxiety disorder patients who fail to respond to an adequate SSRI treatment. Larger controlled studies are warranted to better define the potential role of atypical antipsychotics in the treatment of generalized social anxiety disorder. 


\section{References}

Barnett, S. D., Kramer, M. L., Casat, C. D., Connor, K. M., \& Davidson, J. R. (2002). Efficacy of olanzapine in social anxiety disorder: a pilot study. J Psychopharmacol, 16(4), 365-368.

Blanco, C., Raza, M. S., Schneier, F. R., \& Liebowitz, M. R. (2003). The evidence-based pharmacological treatment of social anxiety disorder. Int J Neuropsychopharmacol, 6(4), 427-442.

Carson, W. H., Kitagawa, H., \& Nemeroff, C. B. (2004). Drug development for anxiety disorders: new roles for atypical antipsychotics. Psychopharmacol Bull, 38 Suppl 1, 38-45.

Connor, K. M., Davidson, J. R., Churchill, L. E., Sherwood, A., Foa, E., \& Weisler, R. H. (2000). Psychometric properties of the Social Phobia Inventory (SPIN). New self-rating scale. Br J Psychiatry, 176, 379-386.

Davidson, J. R., Potts, N. L., Richichi, E. A., Ford, S. M., Krishnan, K. R., Smith, R. D., et al. (1991). The Brief Social Phobia Scale. J Clin Psychiatry, 52 Suppl, 48-51.

Denys, D., van Megen, H., \& Westenberg, H. (2002). Quetiapine addition to serotonin reuptake inhibitor treatment in patients with treatment-refractory obsessivecompulsive disorder: an open-label study. J Clin Psychiatry, 63(8), 700-703.

Francobandiera, G. (2002). Quetiapine augmentation of sertraline in obsessivecompulsive disorder. J Clin Psychiatry, 63(11), 1046-1047.

Guy, W. (1976). ECDEU Assessment Manual for Psychopharmacology: Publication ADM 76-338. Rockville, MD: US department of Health, Education and Welfare., 6.

Hamilton, M. (1959). The assessment of anxiety states by rating. Br J Med Psychol, 32(1), 50-55.

Hamner, M. B., Deitsch, S. E., Brodrick, P. S., Ulmer, H. G., \& Lorberbaum, J. P. (2003). Quetiapine treatment in patients with posttraumatic stress disorder: an open trial of adjunctive therapy. J Clin Psychopharmacol, 23(1), 15-20.

Liebowitz, M. R. (1987). Social phobia. Mod Probl Pharmacopsychiatry, 22, 141-173.

Manzaneque, J. M., Brain, P. F., \& Navarro, J. F. (2002). Effect of low doses of clozapine on behaviour of isolated and group-housed male mice in the elevated plusmaze test. Prog Neuropsychopharmacol Biol Psychiatry, 26(2), 349-355.

Moore, N. A., Rees, G., Sanger, G., \& Tye, N. C. (1994). Effects of olanzapine and other antipsychotic agents on responding maintained by a conflict schedule. Behav Pharmacol, 5(2), 196-202.

Nemeroff, C. B., Kinkead, B., \& Goldstein, J. (2002). Quetiapine: preclinical studies, pharmacokinetics, drug interactions, and dosing. J Clin Psychiatry, 63 Suppl 13, 5-11. 
Nowakowska, E., Chodera, A., Kus, K., \& Rybakowski, J. (1999). Some behavioural effects of risperidone in rats: comparison with haloperidol. Eur Neuropsychopharmacol, 9(5), 421-426.

Petty, F., Brannan, S., Casada, J., Davis, L. L., Gajewski, V., Kramer, G. L., et al. (2001). Olanzapine treatment for post-traumatic stress disorder: an open-label study. Int Clin Psychopharmacol, 16(6), 331-337.

Sheehan, D. V. (1983). The Anxiety Disease.

Sheehan, D. V., Lecrubier, Y., Sheehan, K. H., Amorim, P., Janavs, J., Weiller, E., et al. (1998). The Mini-International Neuropsychiatric Interview (M.I.N.I.): the development and validation of a structured diagnostic psychiatric interview for DSM-IV and ICD-10. J Clin Psychiatry, 59 Suppl 20, 22-33;quiz 34-57.

Stein, M. B., Fyer, A. J., Davidson, J. R., Pollack, M. H., \& Wiita, B. (1999). Fluvoxamine treatment of social phobia (social anxiety disorder): a double-blind, placebocontrolled study. Am J Psychiatry, 156(5), 756-760.

Stein, M. B., Liebowitz, M. R., Lydiard, R. B., Pitts, C. D., Bushnell, W., \& Gergel, I. (1998). Paroxetine treatment of generalized social phobia (social anxiety disorder): a randomized controlled trial. JAMA, 280(8), 708-713.

Tollefson, G. D., Sanger, T. M., Beasley, C. M., \& Tran, P. V. (1998). A double-blind, controlled comparison of the novel antipsychotic olanzapine versus haloperidol or placebo on anxious and depressive symptoms accompanying schizophrenia. Biol Psychiatry, 43(11), 803-810.

Van Ameringen, M. A., Lane, R. M., Walker, J. R., Bowen, R. C., Chokka, P. R., Goldner, E. M., et al. (2001). Sertraline treatment of generalized social phobia: a 20-week, double-blind, placebo-controlled study. Am J Psychiatry, 158(2), 275-281.

Watson, D., \& Friend, R. (1969). Measurement of social-evaluative anxiety. J Consult Clin Psychol, 33(4), 448-457.

Westenberg, H. G. (1998). The nature of social anxiety disorder. J Clin Psychiatry, 59 Suppl 17, 20-26. 


\section{Summary}

\section{and}

\section{Discussion}



The research reported in the present thesis examined SAD from different perspectives with two main aims. Part I aimed at enhancing our understanding of SAD by exploring threat processing in this condition by means of different methodological tools, such as a $\mathrm{CO}_{2}$-challenge, an emotion recognition task and epidemiological research. The aim of Part II was to investigate new drug treatments to improve the pharmacological treatment of SAD.

\section{Part I. Threat processing in Social Anxiety Disorder}

In chapter three, we investigated $35 \% \mathrm{CO}_{2}$-sensitivity in SAD patients to evaluate if hypersensitivity to physiological threatening stimuli is involved. $35 \% \mathrm{CO}_{2}$ challenges have repeatedly shown to induce panic attacks in patients with panic disorder. SAD patients often experience panic-like symptoms, such as sweating, palpitations or even panic attacks and therefore, they also may be hypersensitive to $\mathrm{CO}_{2}$. First, a $35 \% \mathrm{CO}_{2}-$ experiment including 16 SAD patients, 16 normal controls and 16 patients with panic disorder was performed. Second, a meta-analysis of the results of our experiment and previous $35 \% \mathrm{CO}_{2}$-response data was conducted. Our results showed that SAD patients do not share an exaggerated $35 \% \mathrm{CO}_{2}$-sensitivity with panic disorder patients, although they may be more sensitive than normal controls. These data imply that the pathophysiology of SAD differs from panic disorder and suggest that hypersensitivity to threatening psychological cues is not specifically linked to SAD.

Chapter four aimed at examining sensitivity to psychologically threatening cues, using a facial recognition task in which 24 SAD patients and 26 normal controls were asked to label the emotion depicted by the faces. We found a reduced recognition of threatening faces in SAD, which may be explained by avoidance of processing of threat. This study suggests that SAD patients display a deviant processing of threatening information.

Chapter five represents a large general population study, exploring pathways of comorbidity of SAD and paranoid symptoms, which are both characterized by fear of social threat. The study revealed that the high co-occurrence of these syndromes is not merely an overlap in symptomatology and that social anxiety cognitions predict onset of paranoid symptoms. Behavioural inhibition is a shared temperamental vulnerability, while trauma and cannabis use appear to be more specifically linked to the pathogenesis of paranoid symptoms. The data suggest that in a natural environment, an inhibited temperament is an important risk factor for development of symptoms related to fear of social threat, such as social anxiety symptoms or even paranoia in case of victimization and cannabis use. 
The studies of part I all suggest that processing of threat may be deviant in SAD. Nevertheless, integration of the results is difficult since the studies used different methodologies. Therefore, each study will be discussed particularly.

Our study of physiological threat processing in $\mathrm{SAD}$, using $\mathrm{CO}_{2}$-inhalation as a possible sign of suffocation, is in line with other chemical challenges such as pentagastrin and caffeine, suggesting that SAD patients generally are less sensitive than panic disorder patients and slightly more than healthy controls (Coupland, 2001). Chemical challenges predominantly seem to mimic panic attacks, and some studies in SAD patients even reported that the sensations provoked by the challenge were different from their naturally occurring social anxiety (Caldirola, Perna, Arancio, Bertani, \& Bellodi, 1997; Liebowitz, et al., 1985). Accordingly, the $35 \% \mathrm{CO}_{2}$ challenge appears to be a valid model for panic (Esquivel, Schruers, \& Griez, 2008), but not for SAD. We suggest that future chemical challenges assess social anxiety symptoms specifically and may include a psychological provocation of social fear, such as a speech task or an autobiographic script.

Our emotion recognition study adds to the concept of deviant processing of social threat in SAD. The deviant processing of threatening facial cues seems to have a neurobiological basis, since neuroimaging studies have repeatedly shown increased neural responses to threatening faces in SAD (Amir, et al., 2005; Phan, Fitzgerald, Nathan, \& Tancer, 2006; Stein, Goldin, Sareen, Zorrilla, \& Brown, 2002). Future projects are warranted to further explore neurobiological underpinnings of deviant processing of social/psychological threat in SAD patients. Pharmacological challenges in combination with exposure to threat may help in elucidating underlying biological abnormalities. Research into effects of treatment on biases in threat processing in SAD patients may clarify if these biases are state or trait phenomena, and in addition may clarify if psychological and pharmacological treatments have similar effects on processing of threatening information. With regard to the emotion recognition task specifically, we suggest that future studies use a time restriction in their task, as there is now growing evidence for a bimodal pattern in attentional processes in SAD, in which hypervigilance for social cues at the start of exposure (Gamble \& Rapee, 2010; Heuer, Lange, Isaac, Rinck, \& Becker, 2010; Streit, et al., 2003), is followed by active avoidance of this information (Garner, Mogg, \& Bradley, 2006).

Whereas the first two studies examined threat processing of SAD patients in an experimental setting, the third study investigated occurrence of symptoms related to processing of social threat in a natural environment. In this perspective, the strong association between social anxiety and paranoid symptoms, which in turn were both associated with inhibited temperament, might indicate that problems in dealing with social threat may have an inborn basis. Environmental influences such as traumatic experiences and cannabis use rather seem to predispose the development of the para- 
noid phenotype. Since SAD may be related to more subtle environmental factors, research on the impact of daily social experiences on social anxiety and SAD may help in understanding the role of environment in the development and maintenance of the condition. Social defeat, a concept which is currently investigated in the field of psychosis research, may play a mediating role in the association between social anxiety and paranoia; this warrants further investigation. Apart from its theoretical significance, the epidemiological study may have clinical implications, as the results, if confirmed in clinical populations, call for development of adapted psycho-education and treatment strategies for individuals with social anxiety cognitions, who are at risk for later paranoia.

\section{Part II. Pharmacological treatment of Social Anxiety Disorder}

Chapter six describes a randomised, double-blind, placebo-controlled trial with mirtazapine in generalized SAD. There were no significant differences between mirtazapine and placebo with regard to response or responder rates. We found a mean decrease on the Liebowitz Social Anxiety Scale (LSAS) of $13.5 \pm 16.9$ in the mirtazapine group and $11.2 \pm 17.8$ in the placebo group. The responder rate (based on LSAS reduction $\geq 40 \%$ and Clinical Global Impression of Improvement of 'much' or 'very much' improved) was $13 \%$ in both groups. The results of this study suggest that mirtazapine is well tolerated, but not effective for treatment of SAD.

The aim of Chapter seven was to investigate if combination of mirtazapine with paroxetine causes a greater therapeutic effect and less sexual side effects than paroxetine monotherapy in SAD. Both treatments showed a significant LSAS reduction and their response rates were similar (paroxetine and mirtazapine: $52.4 \%$, paroxetine and placebo: 59.1\%). Sexual dysfunction (based on Arizona Sexual Experience Scale $\geq 19$ ) was found in half of patients treated with paroxetine and placebo, and in $38 \%$ of patients treated with paroxetine and mirtazapine. These results indicate that mirtazapine does not enhance therapeutic efficacy of paroxetine in SAD, but may have beneficial effects on sexual dysfunction.

Chapter eight represents a pilot study with quetiapine in generalized SAD. There was a substantial decrease in LSAS, and $69 \%$ of the last-observation-carried-forward sample was considered responders with a mean dose of $250 \mathrm{mg}$ quetiapine. This open pilot study suggests that quetiapine may be effective in SAD and warrants further placebo-controlled studies with this agent. 
The studies presented in part II suggest that mirtazapine is not a potent drug in the treatment of SAD, neither as monotherapy, nor as enhancer of SSRI treatment, whereas a low dosage of quetiapine seems to improve SAD symptoms substantially. These studies have added knowledge about pharmacological treatment of SAD. In clinical practice, mirtazapine should not be considered as treatment of choice for SAD without comorbidity. On the other hand, mirtazapine seems to diminish sexual dysfunction, therefore it may be used as an add-on for SSRI-treatment with disturbing sexual side effects. Quetiapine and other atypical antipsychotics may be an effective alternative for treatment of SAD and merit further investigation as monotherapy, but also as augmentation therapy in addition to SSRI's. In a theoretical sense, responses to pharmacological agents may help in clarifying which neurotransmitter systems are involved in SAD. With regard to mirtazapine, it was hypothesized that this agent would be effective in SAD, due to its antagonistic effects on the $5 \mathrm{HT}_{2}$-receptor and/or indirect stimulation of serotonergic neurotransmission. However, mirtazapine was not effective in our study and nefazodone, a $5 \mathrm{HT}_{2}$-receptor antagonist also failed to show efficacy in SAD (Van Ameringen, et al., 2007). Therefore, we postulate that not $5 \mathrm{HT}_{2}$-antagonism, but increase in serotonergic neurotransmission is most important for the treatment of SAD. Furthermore, the dual acting potency of mirtazapine has been argued recently due to the absence of demonstrable serotonergic effects in humans (Gillman, 2006). Quetiapine works on serotonergic, dopaminergic, noradrenergic, and histaminergic receptors, thus all of these systems and their interactions may be involved in the treatment of SAD as well.

A number of unanswered questions regarding pharmacological treatment of SAD merit further consideration and research. It is not known which symptoms improve with pharmacotherapy, what is the optimal duration of treatment to prevent relapse and what is the best management strategy in case of comorbidity. Long-term studies with SAD patients with and without comorbid disorders are definitely needed. The neurobiological underpinnings of the efficacy of current drug treatments are not clear. We suggest that future pharmacological treatment and challenge studies investigate the relation between the agent's mechanism of action and the three symptom domains in SAD specifically, namely physiological, cognitive and behavioural symptoms. For instance, it is possible that noradrenergic dysfunction is involved in physiological symptoms of social anxiety, whereas dopaminergic disturbances may mainly underlie cognitive symptoms (Remy \& Samson, 2003; Savitz, Solms, \& Ramesar, 2006). Further elucidation of the neurobiological underpinnings of different social anxiety symptoms may guide the development of better drug treatments for SAD. 


\section{References}

Amir, N., Klumpp, H., Elias, J., Bedwell, J. S., Yanasak, N., \& Miller, L. S. (2005). Increased activation of the anterior cingulate cortex during processing of disgust faces in individuals with social phobia. Biol Psychiatry, 57(9), 975-981.

Caldirola, D., Perna, G., Arancio, C., Bertani, A., \& Bellodi, L. (1997). The $35 \% \mathrm{CO}_{2}$ challenge test in patients with social phobia. Psychiatry Res, 71(1), 41-48.

Coupland, N. J. (2001). Social phobia: etiology, neurobiology, and treatment. J Clin Psychiatry, 62 Suppl 1, 25-35.

de Boer, T. (1996). The pharmacologic profile of mirtazapine. J Clin Psychiatry, 57 Suppl 4, 19-25.

Esquivel, G., Schruers, K., \& Griez, E. (2008). Experimental models: panic and fear. In R. J. Blanchard, D. C. Blanchard, G. Griebel \& D. J. Nutt (Eds.), Handbook of Anxiety and Fear. Amsterdam: Elsevier B.V.

Gamble, A. L., \& Rapee, R. M. (2010). The time-course of attention to emotional faces in social phobia. J Behav Ther Exp Psychiatry, 41(1), 39-44.

Garner, M., Mogg, K., \& Bradley, B. P. (2006). Orienting and maintenance of gaze to facial expressions in social anxiety. J Abnorm Psychol, 115(4), 760-770.

Gillman, P. K. (2006). A systematic review of the serotonergic effects of mirtazapine in humans: implications for its dual action status. Hum Psychopharmacol, 21(2), 117-125.

Heuer, K., Lange, W. G., Isaac, L., Rinck, M., \& Becker, E. S. (2010). Morphed emotional faces: emotion detection and misinterpretation in social anxiety. J Behav Ther Exp Psychiatry, 41(4), 418-425.

Liebowitz, M. R., Fyer, A. J., Gorman, J. M., Dillon, D., Davies, S., Stein, J. M., et al. (1985). Specificity of lactate infusions in social phobia versus panic disorders. Am J Psychiatry, 142(8), 947-950.

Phan, K. L., Fitzgerald, D. A., Nathan, P. J., \& Tancer, M. E. (2006). Association between amygdala hyperactivity to harsh faces and severity of social anxiety in generalized social phobia. Biol Psychiatry, 59(5), 424-429.

Remy, P., \& Samson, Y. (2003). The role of dopamine in cognition: evidence from functional imaging studies. Curr Opin Neurol, 16 Suppl 2, S37-41.

Savitz, J., Solms, M., \& Ramesar, R. (2006). The molecular genetics of cognition: dopamine, COMT and BDNF. Genes Brain Behav, 5(4), 311-328.

Stein, M. B., Goldin, P. R., Sareen, J., Zorrilla, L. T., \& Brown, G. G. (2002). Increased amygdala activation to angry and contemptuous faces in generalized social phobia. Arch Gen Psychiatry, 59(11), 1027-1034. 
Streit, M., Dammers, J., Simsek-Kraues, S., Brinkmeyer, J., Wolwer, W., \& Ioannides, A. (2003). Time course of regional brain activations during facial emotion recognition in humans. Neurosci Lett, 342(1-2), 101-104.

Van Ameringen, M., Mancini, C., Oakman, J., Walker, J., Kjernisted, K., Chokka, P., et al. (2007). Nefazodone in the treatment of generalized social phobia: a randomized, placebo-controlled trial. J Clin Psychiatry, 68(2), 288-295. 


\title{
Samenvatting
}

en

\author{
Discussie
}



De Sociale Angststoornis (SAD) is een vaak voorkomende, invaliderende psychiatrische aandoening die gekenmerkt wordt door een extreme angst voor een negatieve beoordeling door anderen. SAD gaat vaak gepaard met andere aandoeningen zoals depressies en alcoholisme. Het is aangetoond dat verscheidene neurobiologische, psychologische en sociale factoren een rol spelen bij SAD, maar de precieze etiologie en pathogenese van deze aandoening zijn nog niet bekend. SAD kan behandeld worden met farmacotherapie en/of psychotherapie, maar wordt nog vaak onderbehandeld (hoofdstuk één).

In deze thesis wordt SAD onderzocht vanuit verschillende perspectieven. In hoofdstuk twee wordt een algemeen overzicht van de studies gepresenteerd. Deel I van deze thesis doelt op het verrijken van ons begrip van SAD door de verwerking van bedreiging te onderzoeken in deze stoornis met behulp van verschillende methodes, zoals een $\mathrm{CO}_{2}$-experiment, een emotie herkenningstaak en een epidemiologisch onderzoek. Het doel van Deel II is om nieuwe medicatie te testen om de farmacologische behandeling van SAD te verbeteren.

\section{Deel I. Verwerking van Bedreiging in de Sociale Angststoornis}

Angst voor bepaalde potentieel gevaarlijke stimuli, zoals pijn is normaal en kan bijdragen aan de overlevingskans van de mens en/of aan het succes van een persoon. Als er echter sprake is van een extreme gevoeligheid voor potentieel bedreigende, maar alledaags voorkomende stimuli kan dit problematisch zijn in iemands leven en kan er een angststoornis ontstaan. Bij experimenteel onderzoek naar de verwerking van bedreiging kunnen zowel fysiologische als psychologische stimuli gebruikt worden.

In hoofdstuk drie hebben we de $35 \% \mathrm{CO}_{2}$-gevoeligheid van SAD patiënten onderzocht om na te gaan of er sprake is van een overgevoeligheid voor fysiologisch bedreigende stimuli. De inhalatie van een hoge concentratie $\mathrm{CO}_{2}$ triggert waarschijnlijk een alarm centrum in de hersenen, omdat het een mogelijk teken van verstikking kan zijn. $35 \% \mathrm{CO}_{2}$ experimenten hebben herhaaldelijk getoond dat patiënten met een paniekstoornis overgevoelig zijn en paniekaanvallen krijgen bij het inhaleren van $35 \% \mathrm{CO}_{2}$. SAD patiënten hebben vaak ook paniekachtige symptomen, zoals zweten, hartkloppingen of zelfs paniekaanvallen en daarom zou het kunnen dat zij ook overgevoelig zijn voor $\mathrm{CO}_{2}$. Ten eerste werd er een $35 \% \mathrm{CO}_{2}$-experiment uitgevoerd, waaraan 16 patiënten met SAD, 16 gezonde controles en 16 patiënten met een paniekstoornis deelnamen. Ten tweede werd er een meta-analyse gedaan met de resultaten van ons experiment in combinatie met data van andere $35 \% \mathrm{CO}_{2}$-experimenten waaraan SAD patiënten deelnamen. Onze resultaten tonen dat SAD patiënten niet dezelfde overgevoelig- 
heid voor $35 \% \mathrm{CO}_{2}$ hebben als patiënten met een paniekstoornis, maar ze zijn mogelijk wel sensitiever dan gezonde controles. Deze data veronderstellen dat de pathofysiologie van SAD verschilt met die van de paniekstoornis en dat een overgevoeligheid voor bedreigende fysiologische prikkels mogelijk niet op de voorgrond staat bij SAD.

Hoofdstuk vier doelde op het onderzoeken van de gevoeligheid voor bedreigende psychologische stimuli. 24 SAD patiënten en 26 gezonde controles voerden een emotie herkenningstaak uit, waarbij ze de emotie moesten noemen die uitgebeeld werd door het gepresenteerde gezicht. De patiënten met SAD hadden meer moeite met het herkennen van bedreigende (boos en walgend kijkende) gezichten. Dit kan mogelijk verklaard worden door vermijding van het verwerken van bedreigende informatie.

Hoofdstuk vijf beschrijft een grote epidemiologische studie in de algemene populatie. Zowel personen met SAD als die met paranoïde symptomen zijn bang voor sociale bedreigingen, maar de inhoud van hun angst is verschillend: terwijl degenen met SAD bang zijn voor een negatieve beoordeling, zijn paranoïde personen bang voor beschadiging door anderen. Onze epidemiologische studie toont dat typische sociale angstgedachten (zoals denken dat anderen je beoordelen) het ontstaan van paranoïde gedachten vooraf gaan. Beide syndromen zijn geassocieerd met gedragsmatige geremdheid, terwijl traumatische ervaringen en cannabis gebruik enkel gelinkt zijn met paranoïde symptomen. Deze data suggereren dat een geremd temperament een risico factor is voor de ontwikkeling van symptomen gerelateerd aan angst voor sociale bedreiging, zoals sociale angst symptomen en zelfs paranoia in geval van traumatisering en cannabis gebruik.

De studies van deel I suggereren allen dat er sprake is van een afwijkende verwerking van bedreiging in SAD. Integratie van de resultaten is echter lastig aangezien er verschillende methodes werden gebruikt. Daarom zal iedere studie apart besproken worden.

Onze studie over de verwerking van fysiologische bedreiging $\left(\mathrm{CO}_{2}\right.$-inhalatie $)$ in SAD is in overeenstemming met andere chemische experimenten, zoals pentagastrine en cafeïne infusie, waarbij over het algemeen gevonden wordt dat SAD patiënten minder gevoelig zijn dan patiënten met een paniekstoornis maar enigszins meer dan gezonde controles (Coupland, 2001). Bij deze chemische experimenten worden echter voornamelijk paniekaanvallen opgewekt, en sommige studies met SAD patiënten hebben gerapporteerd dat de ervaringen uitgelokt door het experiment anders waren dan hun natuurlijk voorkomende sociale angst (Caldirola, Perna, Arancio, Bertani, \& Bellodi, 1997; Liebowitz, et al., 1985). Daarom lijkt het erop dat de $35 \% \mathrm{CO}_{2}$ challenge voornamelijk een goed model is voor paniek (Esquivel, Schruers, \& Griez, 2008). Tot nu toe is er nog geen valide fysiologisch experimenteel model voor sociale angst of SAD. We stellen voor dat toekomstige chemische studies specifieke meetinstrumenten voor 
sociale angst gebruiken en een psychologische provocatie toepassen door bijvoorbeeld een spreektaak of een autobiografisch script.

Onze emotie herkennings studie draagt bij aan het concept van een afwijkende verwerking van sociale bedreiging in SAD. Deze afwijkende informatie verwerking lijkt bovendien een neurobiologische basis te hebben, want hersenscans hebben herhaaldelijk aangetoond dat patiënten met SAD een verhoogde neurale respons hebben bij het bekijken van bedreigende gezichten (Amir, et al., 2005; Phan, Fitzgerald, Nathan, \& Tancer, 2006; Stein, Goldin, Sareen, Zorrilla, \& Brown, 2002). Toekomstige studies zijn nodig om de neurobiologische basis van de afwijkende verwerking van sociale/psychologische bedreiging in SAD verder te onderzoeken. Farmacologische experimenten in combinatie met exposure aan bedreiging kunnen bijdragen aan het verhelderen van de onderliggende biologische abnormaliteiten. Onderzoek naar het effect van behandeling op afwijkingen in informatie verwerking in SAD patiënten kan verduidelijken of deze afwijkingen veranderlijke fenomenen zijn. Bovendien dient onderzocht te worden of psychologische en farmacologische behandelingen hetzelfde effect hebben op de verwerking van bedreigende informatie. Wat betreft de emotie herkenningstaak, stellen we voor dat toekomstige studies een tijdsrestrictie gebruiken, want er zijn nu steeds meer studies die aantonen dat er een bimodaal patroon is in aandachtsprocessen bij SAD, waarbij een initiële verhoogde alertheid voor sociale prikkels (Gamble \& Rapee, 2010; Heuer, Lange, Isaac, Rinck, \& Becker, 2010; Streit, et al., 2003), gevolgd wordt door vermijding van deze stimuli (Garner, Mogg, \& Bradley, 2006).

Terwijl de eerste twee studies de verwerking van bedreiging bij SAD onderzochten in een experimentele setting, exploreert de derde studie symptomen gerelateerd aan het verwerken van sociale bedreiging in een natuurlijke omgeving. De sterke associatie tussen sociale angst en paranoïde symptomen en hun sterke link met een geremd temperament zou eventueel kunnen duiden op een aangeboren basis van problemen met het omgaan met sociale bedreiging. Omgevingsfactoren zoals traumatische ervaringen en cannabis lijken bovendien bij te dragen aan de ontwikkeling van paranoïde symptomen. Omdat SAD mogelijk gerelateerd is aan meer subtiele omgevingsfactoren, kan onderzoek naar de invloed van dagelijkse sociale ervaringen op sociale angst en SAD bijdragen aan het beter begrijpen van de rol van de omgeving op de ontwikkeling en de instandhouding van deze aandoening. Het concept "social defeat", gedefinieerd als de chronische ervaring van een onderdanige positie of een 'outsider' status, wordt hedendaags uitgebreid onderzocht in het kader van psychose, en speelt mogelijk een medierende rol in the associatie tussen sociale angst en paranoia; deze hypothese vraagt om verder onderzoek. Naast dit theoretisch belang heeft de epidemiologische studie mogelijk ook klinische implicaties, omdat de resultaten als ze bevestigd worden in klinische studies, pleiten voor het ontwikkelen van aangepaste psycho-educatie en behandel- 
strategieën voor personen met sociale angstgedachten in verband met een verhoogd risico op paranoïde symptomen.

\section{Deel II. Farmacologische behandeling van de Sociale Angststoornis}

SAD kan farmacologisch behandeld worden met 'selective serotonin reuptake inhibitors' (SSRI's) zoals paroxetine, maar deze medicijnen zijn niet altijd effectief en ze kunnen vervelende bijwerkingen veroorzaken. Mirtazapine en quetiapine zijn medicijnen met een ander werkingsmechanisme, waardoor ze minder kans geven op bepaalde bijwerkingen zoals seksuele dysfunctie en mogelijk ook werkzaam zijn bij SAD.

Hoofdstuk zes beschrijft een gerandomiseerde, dubbel-blinde, placebogecontroleerde studie met mirtazapine bij 60 patiënten met de gegeneraliseerde vorm van SAD. Er waren geen significante verschillen tussen mirtazapine en placebo wat betreft de effectiviteit. We vonden een gemiddelde daling op de Liebowitz Sociale Angst Schaal (LSAS) van $13.5 \pm 16.9$ in de mirtazapine groep en $11.2 \pm 17.8$ in de placebo groep. Het percentage responders (gebaseerd op een LSAS afname $\geq 40 \%$ en een goede of zeer goede globale klinische verbetering) was $13 \%$ in beide groepen. De resultaten van deze studie suggereren dat mirtazapine goed getolereerd wordt, maar niet effectief is voor behandeling van SAD.

Het doel van Hoofdstuk zeven was om te onderzoeken of de combinatie van mirtazapine en paroxetine een groter therapeutisch effect en minder seksuele bijwerkingen veroorzaakt dan paroxetine monotherapie in de gegeneraliseerde SAD. Beide behandelingen tonen een significante LSAS afname en een vergelijkbaar aantal responders (paroxetine and mirtazapine: 52.4\%, paroxetine and placebo: 59.1\%). Seksuele dysfunctie (gebaseerd op een score $\geq 19$ op de Arizona Seksuele Ervaringen Schaal) was aanwezig bij $50 \%$ van de patiënten behandeld met paroxetine en placebo, en bij $38 \%$ van de patiënten behandeld met paroxetine en mirtazapine. Deze resultaten tonen aan dat mirtazapine de therapeutische effectiviteit van paroxetine in SAD waarschijnlijk niet vergroot, maar mogelijk wel gunstige effecten heeft op seksuele dysfunctie.

In Hoofdstuk acht wordt een open pilot studie met quetiapine bij 13 patiënten met de gegeneraliseerde vorm van SAD gepresenteerd. Er was een substantiële afname van de LSAS, en $69 \%$ van de totale groep kan beschouwd worden als responders (gemiddelde dosis van quetiapine: $250 \mathrm{mg}$ ). Deze pilot studie suggereert dat quetiapine mogelijk effectief is voor SAD en vraagt om verder placebo-gecontroleerd onderzoek met dit medicijn. 
De studies gepresenteerd in deel II tonen aan dat mirtazapine geen krachtig medicijn is voor de behandeling van SAD, noch als monotherapie, noch als versterker van een SSRI behandeling, terwijl een lage dosering van quetiapine SAD symptomen substantieel lijkt te verbeteren. In de praktijk zou mirtazapine daarom niet beschouwd moeten worden als eerste keuze behandeling voor SAD zonder comorbiditeit. Van de andere kant lijkt mirtazapine wel seksuele dysfunctie te verminderen en kan daarom mogelijk toegepast worden als een toevoeging bij SSRI-behandeling wanneer er sprake is van verstorende seksuele bijwerkingen. Quetiapine en andere atypische antipsychotica vormen mogelijk een alternatief voor SSRI's in de behandeling van SAD en verdienen verder onderzoek als monotherapie, maar ook als bijkomende behandeling bij SSRI's.

Theoretisch gezien kan de respons op farmacologische middelen aanwijzingen geven over welke neurotransmitter systemen betrokken zijn bij SAD. Wat betreft mirtazapine hadden we de hypothese dat dit middel effectief zou zijn in SAD door de antagonerende effecten op de $5 \mathrm{HT}_{2}$-receptor en/of door indirecte stimulatie van de serotonerge neurotransmissie. Echter, mirtazapine was niet effectief in onze studie en ook nefazodone, een $5 \mathrm{HT}_{2}$-receptor antagonist faalde in een effectiviteitsstudie in SAD (Van Ameringen, et al., 2007). Daarom veronderstellen we dat niet $5 \mathrm{HT}_{2}$-antagonisme, maar een toename van serotonerge neurotransmissie het belangrijkst is in de farmacologische behandeling van SAD. Bovendien werd het duale werkingsmechanisme van mirtazapine recentelijk bekritiseerd omdat humane studies nooit evidente serotonerge effecten van mirtazapine hebben aangetoond (Gillman, 2006). Quetiapine bindt op serotonerge, dopaminerge, noradrenerge, en histaminerge receptoren, en al deze systemen en hun interacties zouden theoretisch een rol kunnen spelen bij de behandeling van SAD.

Een aantal onbeantwoorde vragen betreffende de farmacologische behandeling van SAD verdienen verder onderzoek. Zo is het niet bekend welke symptomen verbeteren bij farmacotherapie, wat de optimale duur van behandeling is om een terugval te voorkomen en wat de beste behandelstrategie is in geval van comorbiditeit. Gecontroleerde lange-termijn studies met SAD patiënten met en zonder comorbide stoornissen zijn zeker nodig. Bovendien zijn de neurobiologische mechanismen van farmacologische effectiviteit in SAD niet duidelijk. Daarom stellen we voor dat toekomstige farmacologische behandel en experimentele studies de relatie onderzoeken tussen het werkingsmechanisme van een middel en de drie symptoom domeinen van SAD, namelijk fysiologische, cognitieve en gedragsmatige symptomen. Het is bijvoorbeeld mogelijk dat noradrenerge dysfunctie meer betrokken is bij fysiologische symptomen van sociale angst, terwijl dopaminerge afwijkingen voornamelijk een rol spelen bij cognitieve symptomen (Remy \& Samson, 2003; Savitz, Solms, \& Ramesar, 2006). Verdere verheldering 
van de neurobiologische basis van verschillende sociale angstsymptomen kan bijdragen aan de ontwikkeling van betere medicijnen voor de behandeling van SAD. 


\section{Referenties}

Amir, N., Klumpp, H., Elias, J., Bedwell, J. S., Yanasak, N., \& Miller, L. S. (2005). Increased activation of the anterior cingulate cortex during processing of disgust faces in individuals with social phobia. Biol Psychiatry, 57(9), 975-981.

Caldirola, D., Perna, G., Arancio, C., Bertani, A., \& Bellodi, L. (1997). The 35\% CO2 challenge test in patients with social phobia. Psychiatry Res, 71(1), 41-48.

Coupland, N. J. (2001). Social phobia: etiology, neurobiology, and treatment. J Clin Psychiatry, 62 Suppl 1, 25-35.

Esquivel, G., Schruers, K., \& Griez, E. (2008). Experimental models: panic and fear. In R. J. Blanchard, D. C. Blanchard, G. Griebel \& D. J. Nutt (Eds.), Handbook of Anxiety and Fear. Amsterdam: Elsevier B.V.

Gamble, A. L., \& Rapee, R. M. (2010). The time-course of attention to emotional faces in social phobia. J Behav Ther Exp Psychiatry, 41(1), 39-44.

Garner, M., Mogg, K., \& Bradley, B. P. (2006). Orienting and maintenance of gaze to facial expressions in social anxiety. J Abnorm Psychol, 115(4), 760-770.

Gillman, P. K. (2006). A systematic review of the serotonergic effects of mirtazapine in humans: implications for its dual action status. Hum Psychopharmacol, 21(2), 117-125.

Heuer, K., Lange, W. G., Isaac, L., Rinck, M., \& Becker, E. S. (2010). Morphed emotional faces: emotion detection and misinterpretation in social anxiety. J Behav Ther Exp Psychiatry, 41(4), 418-425.

Liebowitz, M. R., Fyer, A. J., Gorman, J. M., Dillon, D., Davies, S., Stein, J. M., et al. (1985). Specificity of lactate infusions in social phobia versus panic disorders. Am J Psychiatry, 142(8), 947-950.

Phan, K. L., Fitzgerald, D. A., Nathan, P. J., \& Tancer, M. E. (2006). Association between amygdala hyperactivity to harsh faces and severity of social anxiety in generalized social phobia. Biol Psychiatry, 59(5), 424-429.

Remy, P., \& Samson, Y. (2003). The role of dopamine in cognition: evidence from functional imaging studies. Curr Opin Neurol, 16 Suppl 2, S37-41.

Savitz, J., Solms, M., \& Ramesar, R. (2006). The molecular genetics of cognition: dopamine, COMT and BDNF. Genes Brain Behav, 5(4), 311-328.

Stein, M. B., Goldin, P. R., Sareen, J., Zorrilla, L. T., \& Brown, G. G. (2002). Increased amygdala activation to angry and contemptuous faces in generalized social phobia. Arch Gen Psychiatry, 59(11), 1027-1034.

Streit, M., Dammers, J., Simsek-Kraues, S., Brinkmeyer, J., Wolwer, W., \& loannides, A. (2003). Time course of regional brain activations during facial emotion recognition in humans. Neurosci Lett, 342(1-2), 101-104. 
Van Ameringen, M., Mancini, C., Oakman, J., Walker, J., Kjernisted, K., Chokka, P., et al. (2007). Nefazodone in the treatment of generalized social phobia: a randomized, placebo-controlled trial. J Clin Psychiatry, 68(2), 288-295. 